\title{
DEVELOPING, EVALUATING, AND DEMONSTRATING AN OPEN SOURCE GATEWAY AND MOBILE APPLICATION FOR THE SMARTFARM DECISION SUPPORT SYSTEM
}

\author{
A Thesis \\ presented to \\ the Faculty of California Polytechnic State University, \\ San Luis Obispo
}

In Partial Fulfillment

of the Requirements for the Degree

Master of Science in Agriculture, Specialization in BioResource and Ag Systems

by

Caleb D. Fink

June 2018 
(C) 2018

Caleb D. Fink

ALL RIGHTS RESERVED 


\title{
COMMITTEE MEMBERSHIP
}

TITLE: Developing, evaluating, and demonstrating an open source gateway and mobile application for the SmartFarm decision support system

\author{
AUTHOR: Caleb D. Fink \\ DATE SUBMITTED: June 2018
}

COMMITTEE CHAIR: Dr. Bo Liu, Ph. D.

Assistant Professor of BRAE

COMMITTEE MEMBER: Dr. Ben Swan, Ph. D.

Associate Professor of AGED

COMMITTEE MEMBER: John Penvenne, P.E. Lecturer of BRAE 


\section{ABSTRACT}

Developing, evaluating, and demonstrating an open source gateway and mobile application for the SmartFarm decision support system

\section{Caleb D. Fink}

The purpose of this research is to design, develop, evaluate, and demonstrate an open source gateway and mobile application for the SmartFarm open source decision support system to improve agricultural stewardship, environmental conservation, and provide farmers with a system that they own. There are very limited options for an open source gateway for collecting data on the farm. The options available are: expensive, require professional maintenance, are not portable between systems, improvements are made only by the manufacturer, limited in customization options, difficult to operate, and data is owned by the company rather than the farmer. The gateway is designed to send data to the cloud from remote SmartFarm Data Acquisition (DAQ) nodes, collect measurement data from remote SmartFarm DAQ nodes, provide a means of wirelessly programming remote SmartFarm DAQ nodes, and a tool that provides data analysis and insight from remote SmartFarm DAQ nodes. It is evaluated to work with $900 \mathrm{MHz}$ radios, SmartFarm DAQ nodes, and costs $\$ 35$. Its setup takes 4 steps and $\sim 20$ minutes installation time, does not require maintenance, can utilize $\mathrm{Wi}-\mathrm{Fi}$, Bluetooth, and other wireless protocols, and software can port to other systems. The gateway measured data rate of $93.4 \mathrm{Mbit} / \mathrm{s}$ internet upload speed, passing a range of 252 to 1592 bytes of data from a remote node to the cloud, consumes 2.8 Watts, with a software efficiency of $25 \%$ CPU usage, a measurement efficiency of 1 message every 15 seconds, can provide data analysis with the cloud service tool, and it can wirelessly program remote DAQ nodes. The goal of the mobile app is educating farmers, academia, and community members, of farming sustainably today, and for the future. The app is used as a tool to aid people in farming sustainably, teaching agricultural stewardship, and teaching environmental conservation. The app is evaluated with adaptation of $85.1 \%$, frequency of use at 0.12 respondents/minute, and 22 respondents said they find the SmartFarm DSS as beneficial. By developing, evaluating, and demonstrating the gateway and mobile app, the SmartFarm decision support system is a viable option for improving agricultural stewardship and retaining farmers' ownership of their data.

Keywords: Base Station, Decision Support Tool, Decision Support System, DSS, Gateway, Mobile Application, Open Source, Precision Agriculture 


\section{ACKNOWLEDGMENTS}

I acknowledge my Lord and Savior Jesus Christ, for His grace, mercy, love, and providence, my family for their support, care and providence, my advisor Dr. Bo Liu for guidance and providence of all materials, my committee members Dr. Ben Swan and John Penvenne for project advice and direction, and Fletcher Easton for his feedback, and the many students, faculty, friends, and family for their support. SmartFarm is a collaborative project with Chandra Krintz, Rich Wolski, and Nevena Golubovic of University of California Santa Barbara, and Balaji Sethuramasamyraja and Senal Deva of California State University Fresno. I'd also like to acknowledge National Science Foundation, on awarding funding, NSF SmartFarm CyberSEES Award \# 1539570. 


\section{TABLE OF CONTENTS}

List of Tables

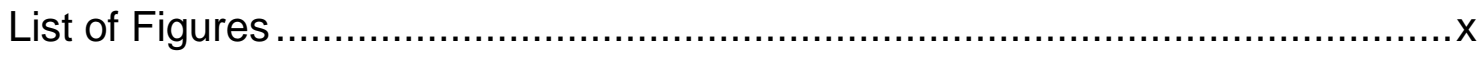

CHAPTER 1.Executive Summary and Literature Review..............................1

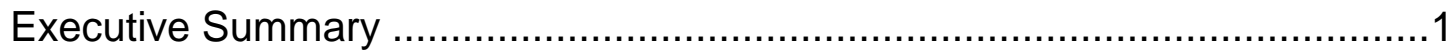

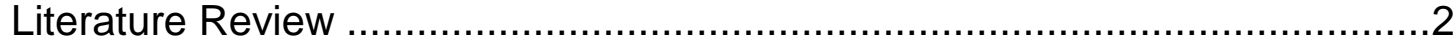

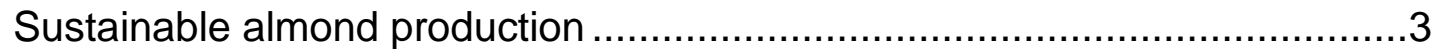

Crop production monitoring with open source wireless sensor network

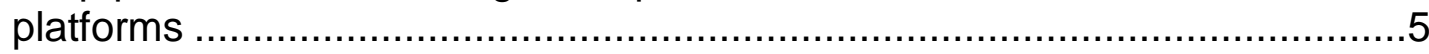

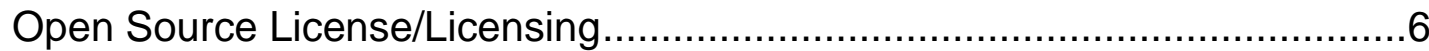

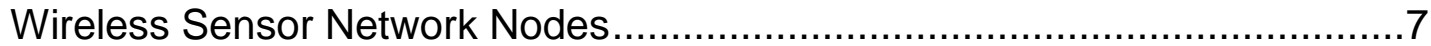

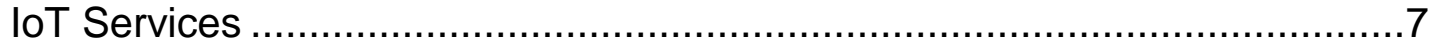

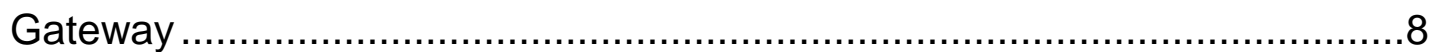

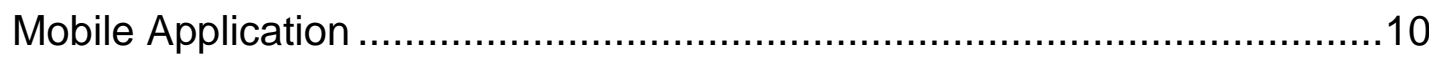

CHAPTER 2.Design, Development and Evaluation of an Open Source Gateway for the SmartFarm Decision Support System ................................11

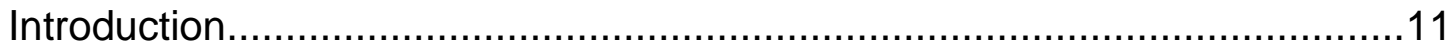

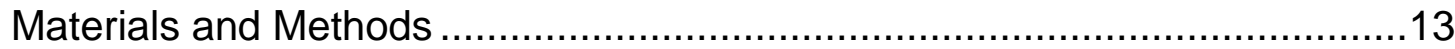

SmartFarm Decision Support System ................................................13

Design Objective 1 - Cloud data for remote SmartFarm DAQ nodes ..........14

Design Objective 2 - Local storage from remote SmartFarm DAQ nodes ...16

Design Objective 3 - Capability of wirelessly programming remote

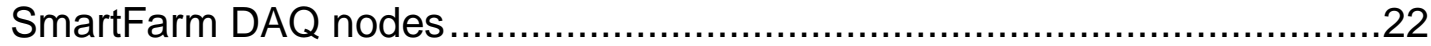

Design Objective 4 - Capability of providing data analysis and insight from remote SmartFarm DAQ nodes....................................................22

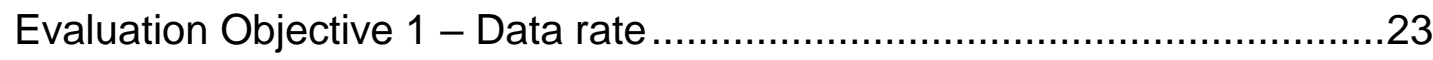

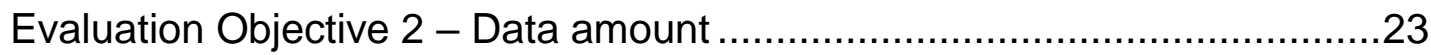

Evaluation Objective 3 - Power consumption .......................................24

Evaluation Objective 4 - Software efficiency...........................................24

Evaluation Objective 5 - Measurement efficiency ....................................24

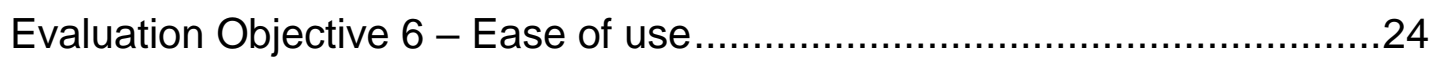

Evaluation Objective 7 - Availability of resources and support ...................25 
Evaluation Objective 8 - Maintenance required ......................................25

Evaluation Objective 9 - Installation time .............................................25

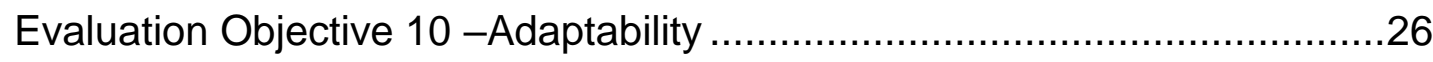

Evaluation Objective 11 - Software portability .........................................26

Evaluation Objective 12 - Comparison of gateways ..................................26

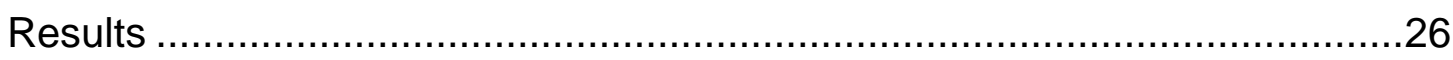

Design Objective 1 - Cloud data for remote SmartFarm DAQ nodes ..........26

Design Objective 2 - Local storage from remote SmartFarm DAQ nodes ...29

Design Objective 3 - Capability of wirelessly programming remote

SmartFarm DAQ nodes

Design Objective 4 - Capability of providing data analysis and insight from remote SmartFarm DAQ nodes

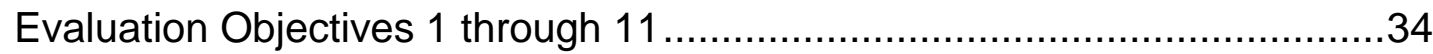

Evaluation Objective 12 - Comparison of Gateways..................................35

Gateway Conclusion

CHAPTER 3.Development and evaluation of using a mobile application as a demonstration tool for outreach to inform and educate farmers, academia, and the community of agricultural stewardship using the SmartFarm

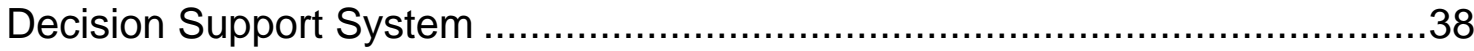

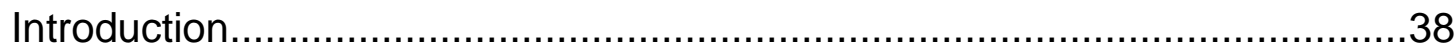

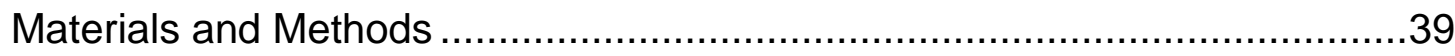

Design Objective - Used to teach academia, farmers, and community members on sustainable farming and stewardship practices ......................40

Evaluation Objective 1 - Adaptation ....................................................... 40

Evaluation Objective 2 - Frequency of use ............................................ 41

Evaluation Objective 3 - Usage .......................................................... 41

Evaluation Objective 4 - Assessment of ag stewardship ............................41

Evaluation Objective 5 -Teaching effectiveness ......................................41

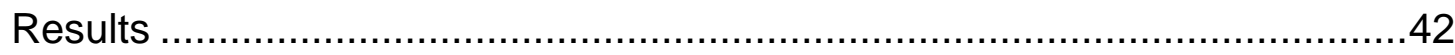

Design Objective 1 - Used to teach academia, farmers, and community members on sustainable farming and stewardship practices such as using

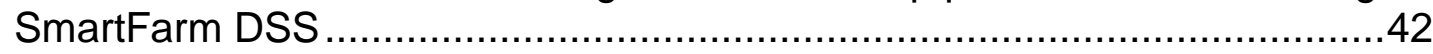

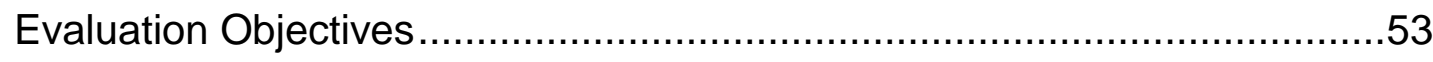

Demonstration Mobile App Tool Conclusion.................................................54

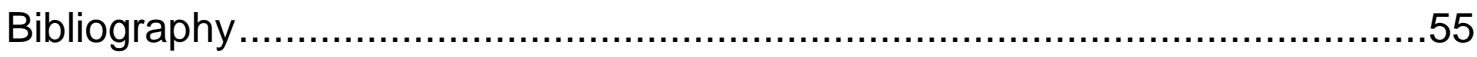




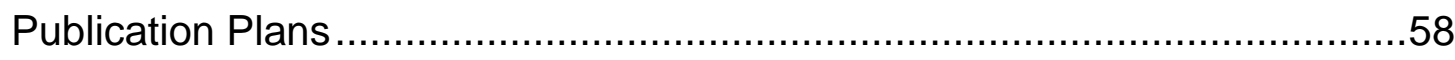

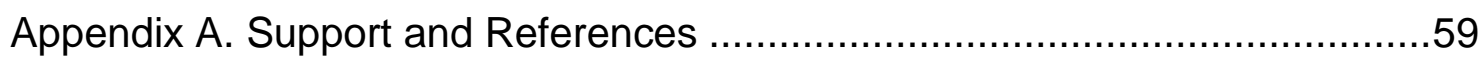

Appendix B. ThingSpeakCode.py posts data to ThingSpeak.com...................60

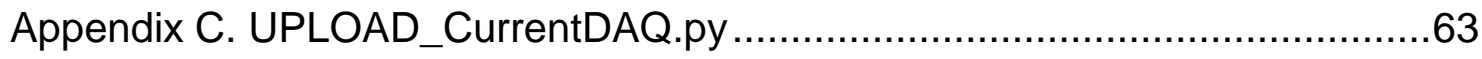




\section{LIST OF TABLES}

Page

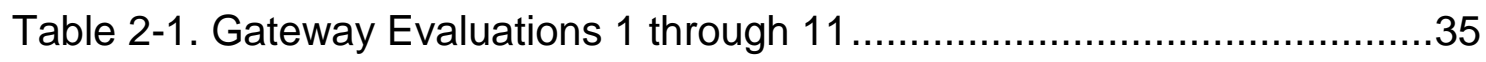

Table 2-3. Comparison of Open Source Gateways. XBee radios tested successfully to 1.2 miles point to point. SmartFarm Gateway is planned for release as open source. Others may be used but have not been tested.

Range is dependent on which wireless technology is used.

Table 3-1. Frequency of use was determined by total responses/length of demonstration period outing. Assessment of Ag stewardship is a count of 'yes' responses for beneficial DSS. App effectiveness calculated as percentage of correct answers. $\mathrm{N}=37$. 


\section{LIST OF FIGURES}

Page

Figure 1-1. Yield and Irrigation Water Productivity (adapted from Goldhamer, Viveros, \& Salinas, 2006, Table 2)

Figure 1-2. Mean 5-year yield and average water productivity (yield/AW expressed as kg/m3). (excerpted from Goldhamer \& Fereres, 2017 Figure 10).5

Figure 1-3. Comparison between the professional weather station and the OSH-WS: (a) air temperature, (b) air humidity. ((Mesas-Carrascosa, Santano, Merono, de la Orden, \& Garcia-Ferrer, 2015), Fig. 7).

Figure 2-1. SmartFarm Decision Support Wireless Sensor Network

Architecture .13

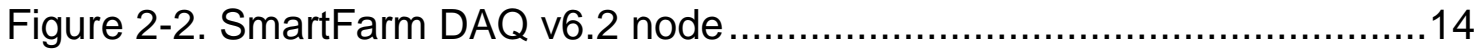

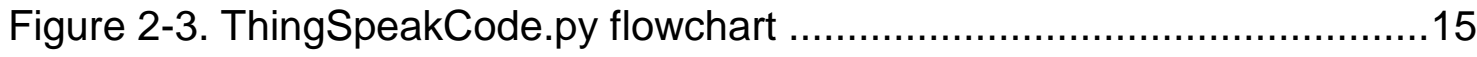

Figure 2-4. SmartFarm Field Test Fresno Almond Orchard, (36 $49^{\prime} 32.5^{\prime \prime} \mathrm{N}$ $\left.119^{\circ} 44^{\prime} 59.5 " W\right)$ Image credit: Google Maps .............................................17

Figure 2-5. SmartFarm Fresno Initial Field Deployment side view .................17

Figure 2-6. SmartFarm Fresno Initial Field Deployment sensor view ...............18

Figure 2-7. SmartFarm Fresno Initial Field Deployment solar panel view ........18

Figure 2-8. SmartFarm Fresno Initial Field Deployment side view 2 ...............19

Figure 2-9. Flow chart for daq2rpi.py local storage script .............................19

Figure 2-10. Greenhouse Student Experiment Farm, Cal Poly, San Luis Obispo, CA, (35¹8'36.6"N 12040'24.7"W). Image credit: Google Maps ........20

Figure 2-11. SEF Gateway Install with serial wires and coordinator radio ........21

Figure 2-12. SEF field deployment diagram for a single DAQ node with 6

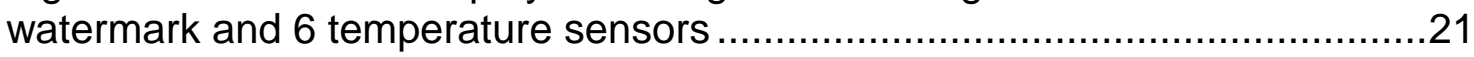

Figure 2-13. Flowchart for uploading on next wake cycle with PlatformIO .......22

Figure 2-14. Speed testing the SmartFarm Gateway internet connection ........23

Figure 2-15. Sample SmartFarm DAQ v6.2 data posted to ThingSpeak ${ }^{\mathrm{TM}}$.

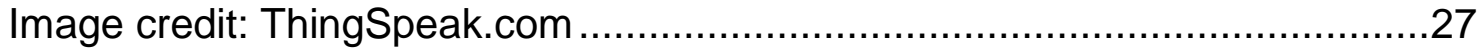

Figure 2-16. Gateway CPU temperature and usage from ThingSpeak ${ }^{\mathrm{TM}}$ MATLAB® Visualization App,

Figure 2-17. An 'NA' value from the DAQ is not shown in ThingSpeak ${ }^{\mathrm{TM}}$ using MATLAB® visualization, sample rate 80 seconds, continuous posting 26 days 28

Figure 2-18. An 'NA' value from the DAQ is shown as ' 0 ' in Microsoft Excel, sample rate 80 seconds, continuous posting 26 days 
Figure 2-19. 1 -foot depth sensors (A) Watermark and Soil Temperature West, (B) Watermark and Soil Temperature East.

Figure 2-20. 2-foot depth sensors (A) Watermark and Soil Temperature West, (B) Watermark and Soil Temperature East.

Figure 2-21. 3-foot depth sensors (A) Watermark and Soil Temperature West, (B) Watermark and Soil Temperature East.......................................... 32

Figure 2-22. Node Battery and Solar Panel Voltage ......................................33

Figure 2-23. ThingSpeak ${ }^{\mathrm{TM}}$ MATLAB $®$ Analysis, Image Credit ThingSpeak.com.

Figure 2-24. Open source gateways. (A) The Things Network Gateway image credit: The Things Network, (B) Libelium ${ }^{\mathrm{TM}}$ MeshLium $^{\mathrm{TM}}$ image credit: Libelium $^{\mathrm{TM}}$ Comunicaciones Distribuidas S.L, (C) Vinduino PCB Gateway

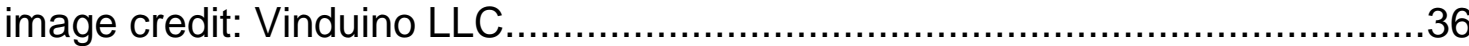

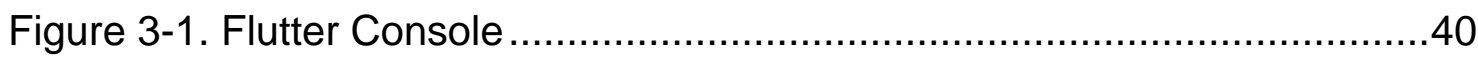

Figure 3-2. The Mobile app homepage Titled SmartFarm Demonstration Tool. Image credit: https://pixabay.com/, Quote credit: BrainyQuote.com ........43

Figure 3-3. Mobile app screen 2, thesis project goal ...................................44

Figure 3-4. Mobile app screen 3 description of the mobile app ......................44

Figure 3-5. Mobile app screen 4 Definition for ag stewardship and

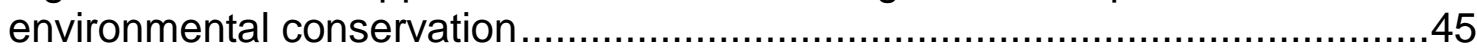

Figure 3-6. Mobile app screen 5 How SmartFarm DSS works .......................45

Figure 3-7. Mobile app screen 7, Describing a DSS .....................................46

Figure 3-8. Mobile app screen 8, Describing a DSS part 2...........................46

Figure 3-9. Mobile app screen 9, Describing a DSS part 3 ...........................47

Figure 3-10. Mobile app screen 10, Describing a DSS part $4 \ldots \ldots \ldots \ldots \ldots \ldots \ldots \ldots \ldots . . .47$

Figure 3-11. Mobile app screen 11, Describing a DSS part 5......................47

Figure 3-12. Mobile app screen 12, Describing a DSS part 6........................48

Figure 3-13. Mobile app screen 13, Describing a DSS part 7 ........................48

Figure 3-14. Mobile app screen 14, sample irrigation trend data field 1 ...........49

Figure 3-15. Mobile app screen 15, sample irrigation trend data field 2 ...........49

Figure 3-16. Mobile app screen 16, sample Irrigation trend data field $3 . . \ldots \ldots \ldots . .50$

Figure 3-17. Mobile app screen 17, sample Irrigation trend field results ..........50

Figure 3-18. Using the Mobile app at Downtown San Luis Obispo Farmers Market

Figure 3-19. Survey question: Would using a DSS like SmartFarm be beneficial? $\mathrm{N}=35$. 
Figure 3-20. Percentage of respondents that answered questions correctly. Example: Question 1 What does DSS stand for? $85.29 \%$ of respondents answered correctly. Questions above Threshold of Effective Teaching percentage are well presented and taught. Questions below the threshold need more development to teach effectively with the app. 


\section{EXECUTIVE SUMMARY AND LITERATURE REVIEW}

\section{Executive Summary}

Growing hunger, food security and production, and increasing population are issues that Liu, Pan, \& Li, 2015; \& Foley et al., 2011; Zaks \& Kucharik, 2011 have acknowledged and have recommendations to improve food production with least effort and cost, increased resiliency of foods, better technological decision support tools (DSTs) and technology use cannot be constrained.

Wireless sensor network (WSN) technologies serve as DSTs for agriculture from research by Anisi, Abdul-Salaam, \& Abdullah, 2015; Aqeel ur, Abbasi, Islam, \& Shaikh, 2014. These WSNs as DST have many components such as sensors, nodes, wireless protocols and network topologies, data collection schemes, actuation methods, and power consumption methods. Many WSN are mainly utilized for irrigation scheduling, as stated by from research by Anisi, Abdul-Salaam, \& Abdullah, 2015. One study by Clarke et al., 2017 on subsistence farming evaluated a DST and its economic benefits. WSN as precision ag technologies need long battery life and the best power management possible for long lasting operation research (Dargie, 2012). WSN mainly makes use of single hop radio technologies from research by Anisi, Abdul-Salaam, \& Abdullah, 2015. DST presentation of data must be immediate, simple, and accessible and the system must perform its duties well from a study by Rose et al., 2016.

Smartphone technology can be used to collect data and employ many citizens, including farmers, to contribute agricultural science from a study by 
Dehnen-Schmutz, Foster, Owen, \& Persello, 2016 who measured participation in farming citizen science using smartphones. A smartphone app was developed that can measure Nitrogen, which results in using sustainable amounts in research done by Delgado, Kowalski, \& Tebbe, 2013.

SmartFarm is one such DST that aims to provide the farmer with a solution to sustainable agriculture encompassing smart technologies with data analytics and ownership that the farmer can leverage. The smart technologies are open source, inexpensive devices and services that are adaptable, portable, and customizable, allowing the farmer to remain in charge and not having to rely on corporate or commercial products that bind the farmer into contracts that stifle their ability to produce sustainably. The SmartFarm DST architecture gives the farmer the control of data on the farm, utilizing sensors and information technologies that incorporate all facets of farm management.

\section{Literature Review}

Technological advances in agriculture are making it possible for farmers to collect and analyze data to make informed decisions on their farming operations in real time. These technologies which range from monitoring crop irrigation trends and plant stress to managing autonomous tractors and equipment, provide the benefits of sustainably managing agriculture resources and improving crop production (Fisher, Ledwaba, Hancke, \& Kruger, 2015). However, these technological advances are usually costly, which can diminish the value of their efficacy. Important emerging agricultural technologies are open source hardware and software technologies. Open source hardware makes the design of 
electronic devices and components generally free and open to the public. The public can alter, adapt, change, replicate, and use open source hardware as they see fit, with licenses specifying the permissions of the hardware. The same goes for open source software; programs are made available to the public to use, alter, and share, guided by the permissions of the licenses that bound them (Fisher et al., 2015). With the availability of open source hardware and software technologies, collection and analysis of agriculture data is at hand, which can be utilized to improve agricultural operations.

The main objective of this study is to understand current almond management practices, understand how they can be made sustainable to improve yields, and understand open source technologies to monitor sustainable practices. I will focus my attention and investigation in almond irrigation practices, and open source wireless sensor networks for monitoring agricultural practices for the purposes of this assignment.

\section{Sustainable almond production}

Sustainable management practices are required for improving almond production in a sustainable manner. Almonds are the third largest export in California(CDFA, 2017). Yield production of almonds is affected by climate (Lobell, Field, Cahill, \& Bonfils, 2006), and irrigation management (Goldhamer \& Fereres, 2017), among other factors like pollination management (Brittain, Williams, Kremen, \& Klein, 2013). It is important to understand these effects on yields to determine sustainable practices for managing almonds, and the most important of these factors is water conservation when considering sustainability. 
Several studies have been conducted in reducing the amount of water usage in almond production. Pulsed drip irrigation reduces water usage significantly but also reduces yield (Phogat, Skewes, Mahadevan, \& Cox, 2013). By using regulated deficit irrigation $(\mathrm{RDI})$, stressing the trees pre harvest can "increase fruiting density and reduce canopy size," which reduces the amount of pruning needed, which reduces the amount of labor required (Goldhamer, Viveros, \& Salinas, 2006). Utilizing RDI increases irrigation water productivity, (Figure 0-1).

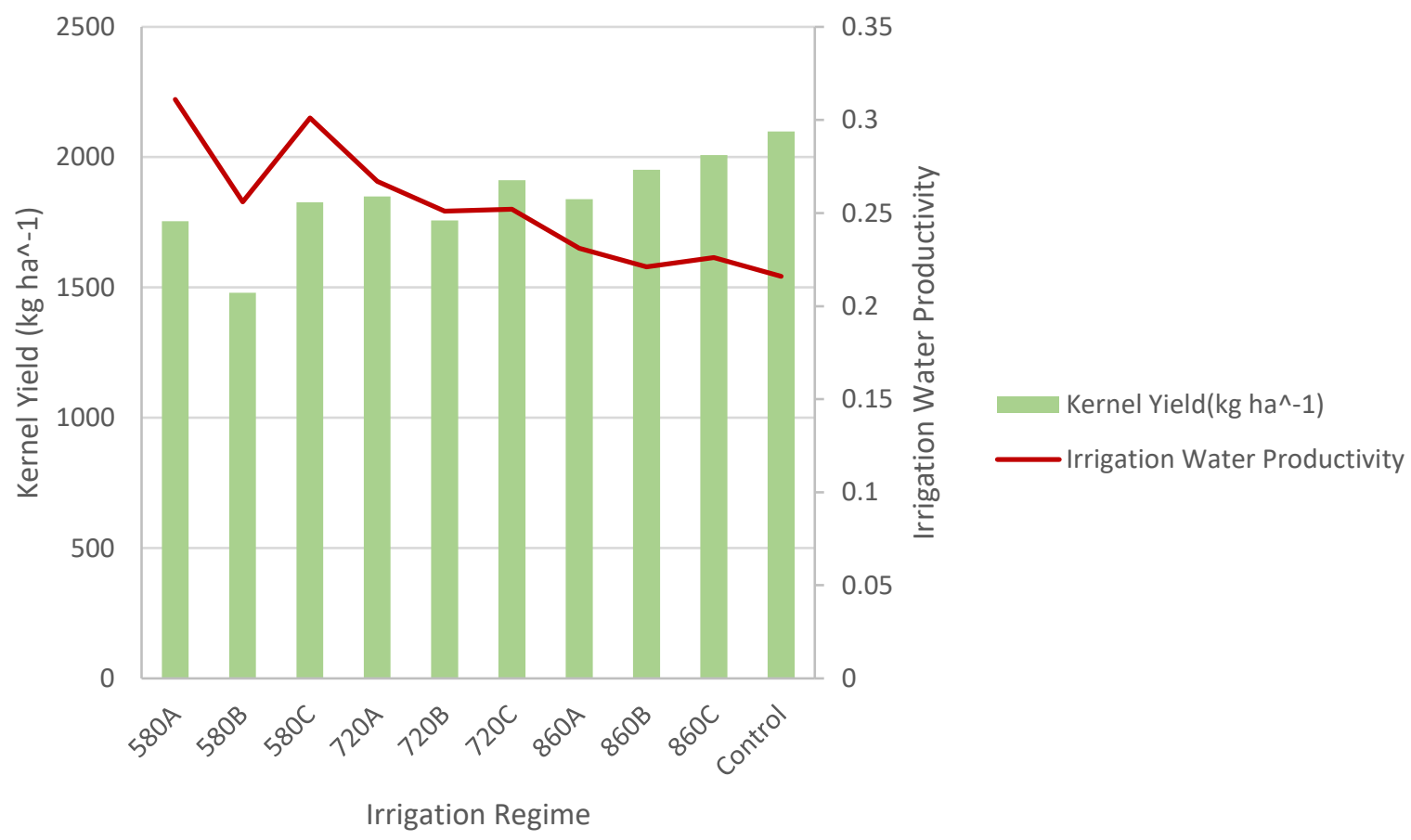

Figure 0-1. Yield and Irrigation Water Productivity (adapted from Goldhamer, Viveros, \& Salinas, 2006, Table 2)

Almond production remains suitable with $10 \%$ lower irrigation requirements (Goldhamer \& Fereres, 2017). Water is more productive with less amounts of water applied in irrigation, though almond yield is lower (Figure 0-2). Irrigating with 1170mm is the break-even point of almond yield to water use. By maintaining water applied to almonds at the break-even point, it may be possible 
to sustainably irrigate almonds. Management practices can be sustainably improved by monitoring irrigation trends with wireless sensor networks.

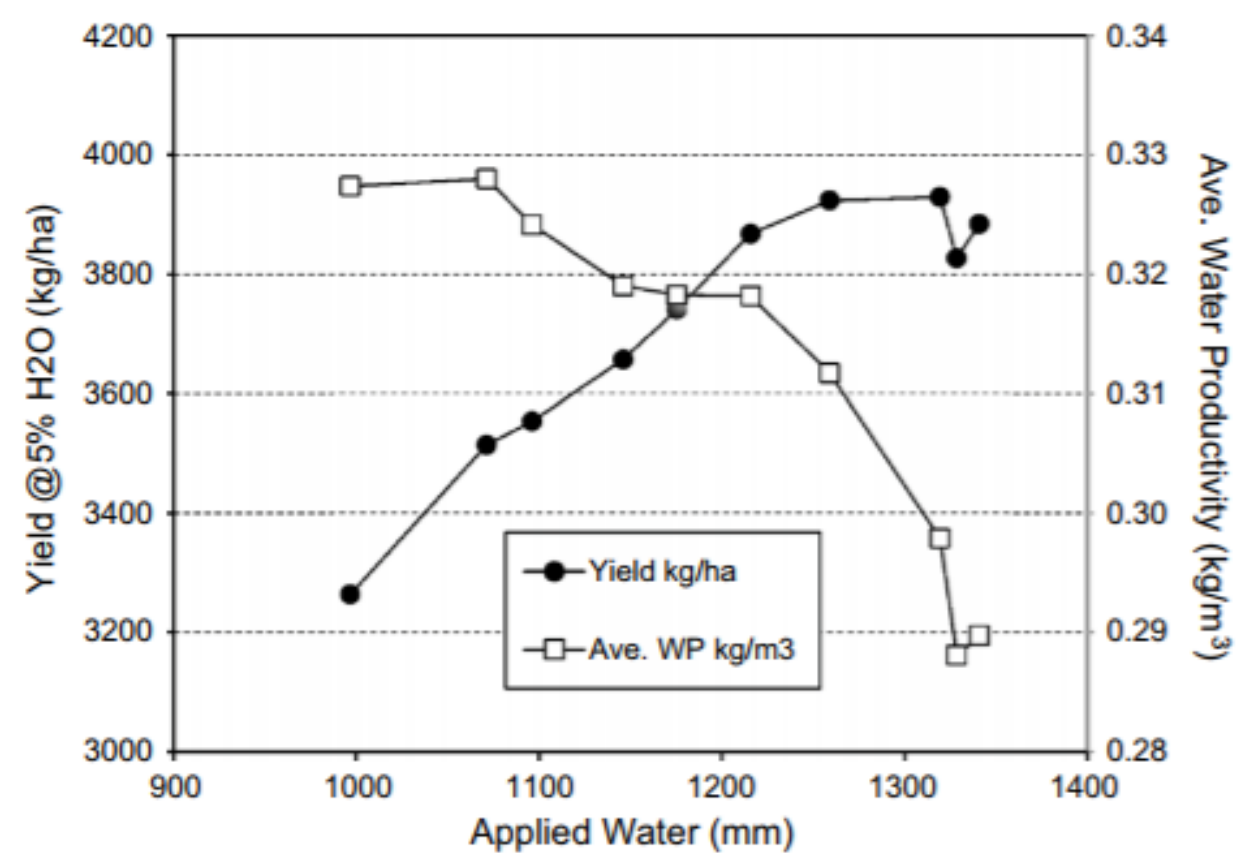

Figure 0-2. Mean 5-year yield and average water productivity (yield/AW expressed as kg/m3). (excerpted from Goldhamer \& Fereres, 2017 Figure 10)

Crop production monitoring with open source wireless sensor network platforms

Wireless sensor networks (WSNs) are gaining traction and are helpful in monitoring agricultural applications (Aqeel ur, Abbasi, Islam, \& Shaikh, 2014). Sensors can collect data to monitor irrigation and water usage, fertilization, and even weather. Open source WSNs utilize open source hardware OSH and range with these parameters: system cost, scalability, sensor types and capabilities, adaptability, power management, reliability, and user friendliness, among others. Open source WSNs must utilize effective power management that is important for long lasting WSNs. (Dargie, 2012). An OSH weather station is compared to a 
professional instrument and indicates that open source technology is suitable to perform just as professional instruments do, Figure 0-3. The comparison between systems was performed by a one-way analysis of variance test. The $\mathrm{OSH}$ system was not significantly different than the reference professional system. This gives strong support that $\mathrm{OSH}$ is a viable option for implementing WSNs and monitoring agricultural practices data.

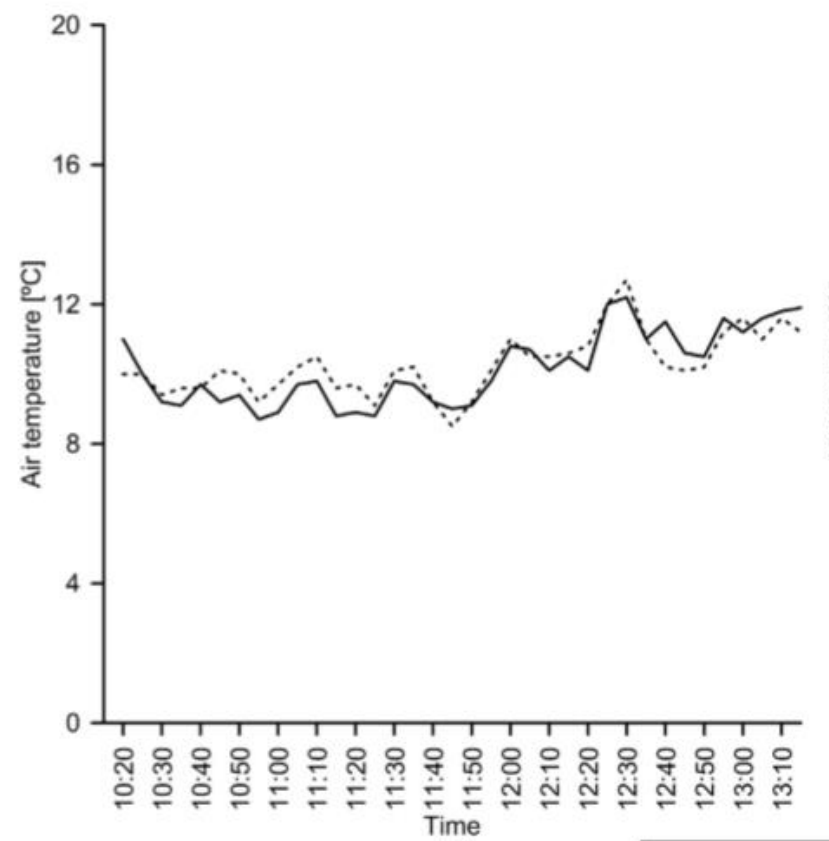

(a)

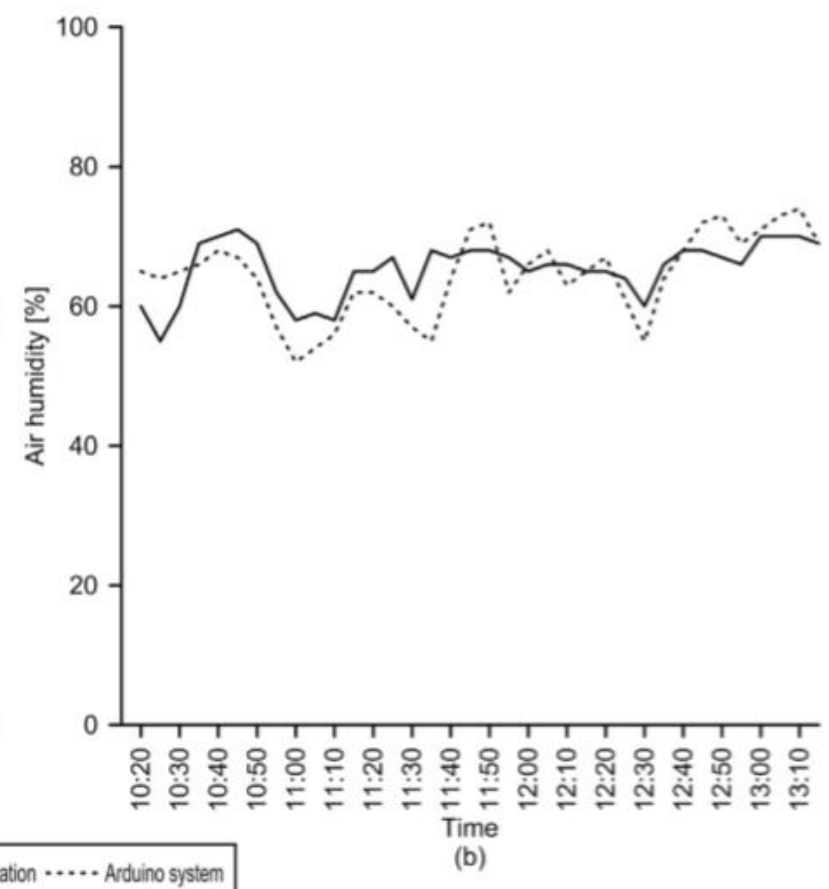

Reference station ...... Arduino system

Figure 0-3. Comparison between the professional weather station and the $\mathrm{OSH}$ WS: (a) air temperature, (b) air humidity. ((Mesas-Carrascosa, Santano, Merono, de la Orden, \& Garcia-Ferrer, 2015), Fig. 7)

\section{Open Source License/Licensing}

The MIT license allows commercial use, distribution, modification, and private use. The license and copyright notice must be included with the software. 
The Apache License 2.0 includes patent use, requires documented changes, and does not allow trademark rights. Other licenses include more conditions.

\section{Wireless Sensor Network Nodes}

There are many node designs available that can be used as wireless sensor networks. The nodes are features vary in battery life, radio protocol, cost, sensors, range, open source software and hardware, and system architecture. A few are named for reference. Crossbow Technologies makes a remote $2.4 \mathrm{GHz}$ node called MicaZ, which uses MoteWorks wireless sensor network platform. The TelosB remote nodes are 802.15.4. Samsung developed an loT line of products called Artik. There are many more available, and this is not an exhausted list.

\section{$\underline{\text { loT Services }}$}

Services for connecting and utilizing cloud data and device management ThingSpeak is and an "open loT platform with MATLAB analytics" (https://thingspeak.com/). It is a trademark of MathWorks and provides access to using MATLAB style code for analyzing data. The free service allows approximately 8,200 messages per day, less than 3 million messages per year

and allows posting data every 15 seconds. An account must be created to use ThingSpeak. myDevices is an "IoT solutions company" https://mydevices.com/about/ which created Cayenne loT Project builder. The project builder is a drag-and-drop builder for loT devices. It works with Arduino, 
Raspberry $\mathrm{Pi}$, and many other devices. It also works with LoRaWAN, and wifi. An loT Ready Program enables hardware integration with Cayenne. myDevices offers an implementation for agriculture called Greenhouses and Ag Services. The service provides temperature and humidity data, a gateway, a dashboard and a mobile app for $\$ 395$. ThingsBoard is an open source customizable dashboard covered under the Apache License version 2.0.

\section{Gateway}

The Definition of a gateway is a device that passes data from local devices to the internet and allows data to be available on the web. The gateway consists of hardware and software. There are many options for both gateway hardware and software. Hardware options include boards and board makers such as Arduino, Raspberry Pi, Intel NUC, BeagleBoard, Libelium, Marvell WiFi Microcontroller 88MW300/302 among many others. The gateways may utilize many wireless protocols for connecting to the internet and to remote nodes. The Vinduino project, (http://www.vinduino.com/ and

http://vanderleevineyard.com/index.html), is very similar to SmartFarm in that remote sensor data is collected with sensor boards, reported to a gateway, and sent to the cloud. Made by Reinier Van Der Lee, the Vinduino LoRaLAN gateway communicates with the Vinduino R3 sensor station by LoRa radio modules and WiFi to post data to ThingSpeak cloud. Vinduino also employs a LoRaWAN Network Server with The Things Gateway. The Things Gateway is based on open source. It works with LoRa $868 \mathrm{MHz}$ (EU), and $915 \mathrm{MHz}$ (US) radios for a 
cost of $\$ 325$. It can reach a range of 6 miles, requires about 5 minutes setup time, includes website activation. The device can be opened via the lid and has a diamond shape, which may make it non-ideal for agricultural solutions where a gateway may need to be installed in a weatherproof enclosure. The Things Network is open source and found at (https://github.com/TheThingsNetwork). More info for The Things Network can be found at (https://www.thethingsnetwork.org/). Digi, the manufacturer of the XBee radios makes a gateway called the ConnectPort X2 for the XBee PRO 900HP for $\$ 160$ and found at Mouser.com. Samsungs Artik 5/7 modules can be used as gateways, and support WLAN, Bluetooth, ZigBee. They come with a secure element, and cost $\$ 46.50$. Advanticsys makes an ethernet gateway, AS-SG1100, for $\$ 455.64$. It uses $802.15 .4,2.4 \mathrm{GHz}$ radio communication protocol. Mozilla's Things Gateway was made using a raspberry pi. The software is open source under Mozilla Public License 2.0, supports Digi XStick, and Z-Wave home automation protocol. Just as there are lots of hardware options, there are many options for software as well. An loT gateway can be made with Android Things but with limitations on commercialization (if developers want to commercialize further down the road it would be very difficult). Ubuntu Core uses its snaps software package updates for loT apps. Microsofts Azure loT Edge is a framework between devices and loT Hub, which is used to manage and monitor devices. To develop the software, different languages can be utilized, such as C, Java, Python, JavaSCript, HTML, Swift, php, and C++. Libelium is a communications company that has a range of loT applications, 
(http://www.libelium.com/). The Meshlium gateway utilizes a multitude of wireless protocols to collect sensor data and post to cloud services.

\section{Mobile Application}

Blynk, https://www.blynk.cc/, is a drag and drop digital dashboard to control devices using an iOS or Android app over an internet connection. Flutter is an open source mobile app SDK made by Google (https://flutter.io/). Flutter allows the app to be written in one language and deployed on Android or iOS devices. The language used is Dart. React Native is a framework for building mobile apps using JavaScript and React made by Facebook. 


\title{
DESIGN, DEVELOPMENT AND EVALUATION OF AN OPEN SOURCE GATEWAY FOR THE SMARTFARM DECISION SUPPORT SYSTEM
}

\author{
Introduction \\ Food production relies on agricultural practices. These practices can be \\ monitored and adjusted according to incoming data from devices, such as \\ decision support tools and systems. These systems and tools aid farmers to \\ make informed decisions based on collected data from their farm, which may be \\ able to improve crop yield and environmental stewardship. The systems, \\ however, are underutilized and do not provide adequate benefits to farmers from
} research by (Foley et al., 2011; Zaks \& Kucharik, 2011). (Krintz, et al., 2016) found that these decision support tools and systems are often expensive, limited in functionality, complicated, geographically unavailable, and private. However, a decision support system can be developed with open source hardware and software to provide the user with inexpensive, customizable, uncomplicated, and commonly available components. The system could be tailored to the users' specifications, as opposed to being constrained. Therefore, the overall research goal is to develop, evaluate, and demonstrate open source platforms to improve sustainable agricultural production, environmental stewardship, and to provide a way for farmers to control and own their farm data.

Improving sustainable agricultural production may require current management practices to be overhauled if they are not sustainable. Sustainable agricultural production requires understanding current farming practices, monitoring those practices, adjusting resources used to sustainable levels, and improving 
production. This will likely be accomplished by iterative cycles of monitoring and improving agricultural management practices in the pursuit of sustainability. Environmental factors can be monitored with dataloggers. Once logged, the data can be analyzed, allowing for users to make informed decisions. Data logging and analysis can be performed with commercially available products; however, these are usually functionally limited and costly. The limitations of these systems are that they only work with specific sensors, they keep ownership of the data and the system, and they require the companies' technical support. Therefore, open source platforms can be designed to monitor inputs and resources in agricultural production, without the burdens that commercial systems may impose. The benefits of open source platforms include being inexpensive, adaptable, geographically available, and open in design. These benefits can be employed to develop a tool and system for data collecting and analyzing, to improve agricultural production, to motivate environmental stewardship, and to give farmers the option of owning their own system and data.

The objectives of this research are to develop, evaluate, and demonstrate a gateway for the SmartFarm decision support system. The gateway design objectives are 1) cloud data for remote SmartFarm DAQ nodes, 2) local storage from remote SmartFarm DAQ nodes, 3) capability of wirelessly programming remote SmartFarm DAQ nodes, and 4) capability of providing data analysis and insight from remote SmartFarm DAQ. The gateway evaluation objectives are to compare it to other gateways, and determining its 1) data rate, 2) data amount, 3) power consumption, 4) software efficiency, 5) measurement efficiency, 6) ease of 
use, 7) availability of resources and support, 8) required maintenance, 9)

installation time, 10) adaptability, 11) software portability, and 12) to compare it to other gateways.

\section{Materials and Methods}

\section{SmartFarm Decision Support System}

The overall decision system architecture involves sensors, the SmartFarm DAQ node(s), and gateway, Figure $0-1$. The SmartFarm DAQ nodes form a wireless sensor network with the Digi XBee PRO S3B $900 \mathrm{MHz}$ radios (Digi International, Minnetonka, MN). The wireless sensor network transmits sensor data to the gateway, which transmits it to the cloud service ThingSpeak ${ }^{\mathrm{TM}}$.

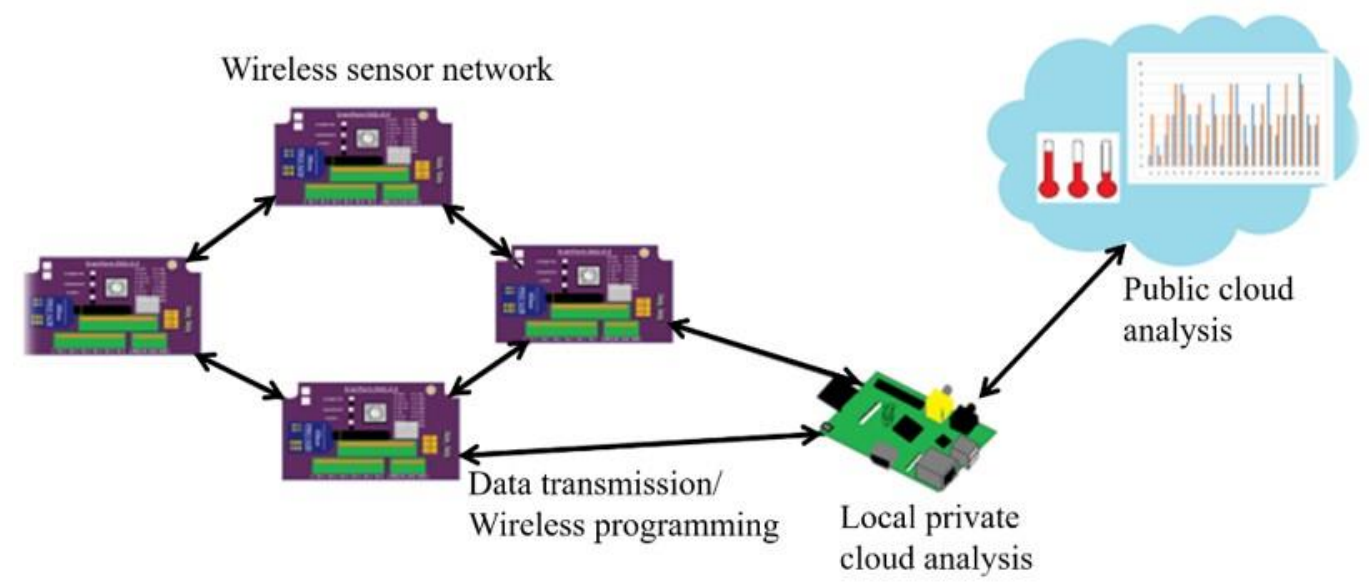

Figure 0-1. SmartFarm Decision Support Wireless Sensor Network Architecture

The SmartFarm DAQ v6.2 node, Figure $0-2$, is the remote circuit board that collects sensor data and sends it to the gateway. The node is adaptable to many sensor types, battery and solar powered with a 3.3 volt LiPo battery and 5 volt 
solar panel, includes a wireless module port for adapting different wireless protocols, and microSD card slot for onboard storage. The node has three modes, measurement mode for collecting sensor data, wireless programming mode for remotely programming the node, and sleep mode for low power consumption. The node sleep mode can be controlled onboard by the timer or by the radio.

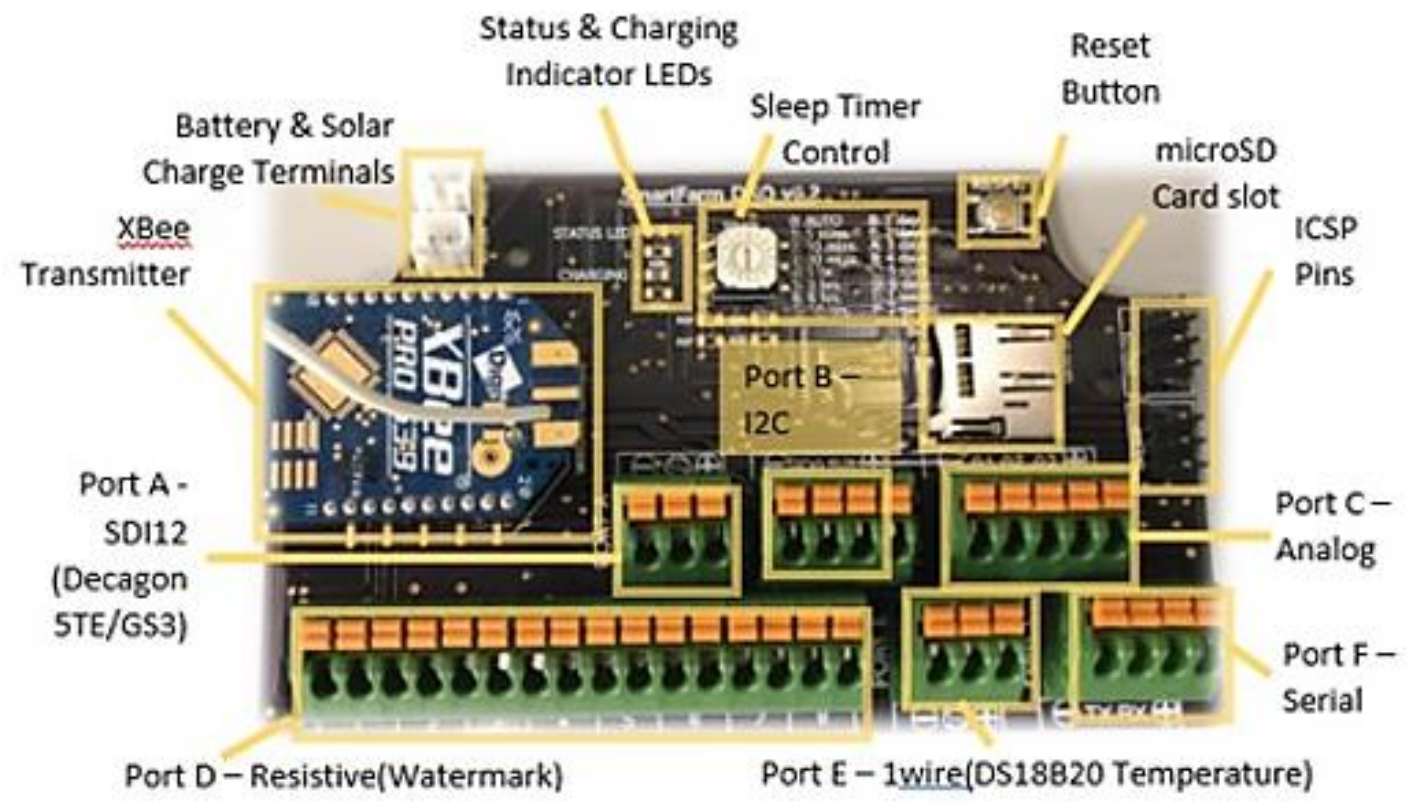

Figure 0-2. SmartFarm DAQ v6.2 node

\section{Design Objective 1 - Cloud data for remote SmartFarm DAQ nodes}

The gateway was designed to post data from remote SmartFarm DAQ nodes to the cloud. The gateway accomplishes this by utilizing ThingSpeak ${ }^{\mathrm{TM}}$ (https://thingspeak.com/). ThingSpeak ${ }^{\mathrm{TM}}$ is a trademark of MathWorks $®$, the makers of MATLAB® and Simulink ${ }^{\circledR}$, and give access to using MATLAB® style code for analyzing data. The free service of ThingSpeak ${ }^{\mathrm{TM}}$ allows approximately 8,200 messages per day, less than 3 million messages per year and allows 
posting data every 15 seconds. A message is a write of data to a single channel. A single message can be written to 8 fields in a given channel and can't exceed 3,000 bytes. An account was created to use ThingSpeak ${ }^{\mathrm{TM}}$ and expires April 3, 2019. Data is collected via a 'Channel' which can be private or public, provides 8 fields for data, includes write and read API keys, and allows for importing or exporting data. The ThingSpeak ${ }^{\mathrm{TM}}$ service does not limit the number of channels per use. A python script called ThingSpeakCode.py, Figure 0-3, was written to post data from a remote DAQ node. It utilizes ThingSpeak ${ }^{\mathrm{TM}}$ write API key and channel ID.

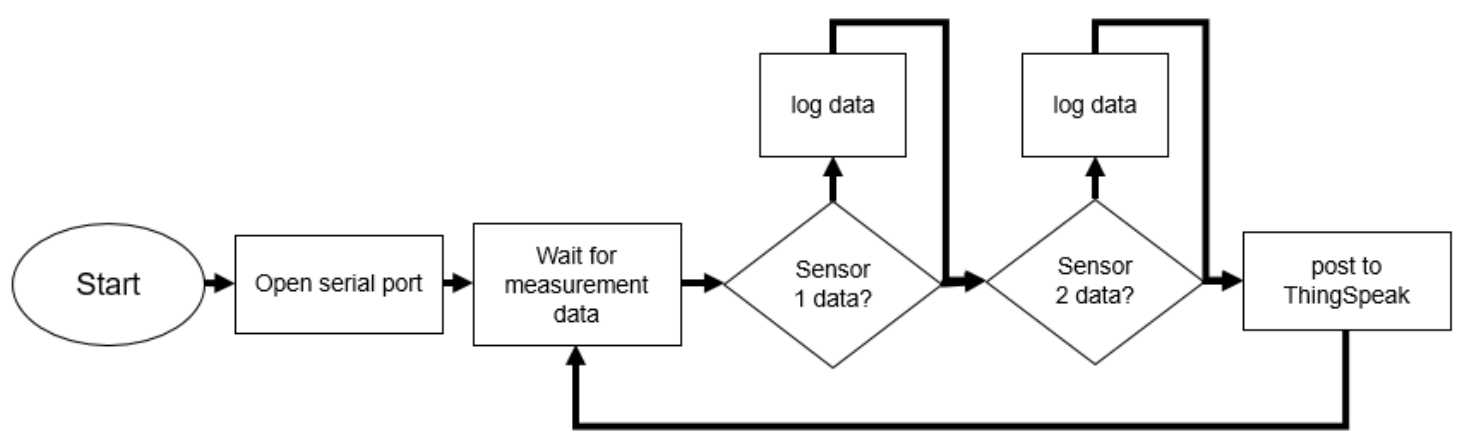

Figure 0-3. ThingSpeakCode.py flowchart

To test posting data from a remote SmartFarm DAQ node, a private channel was created and used to post data from a SmartFarm DAQ v6.2 node. The nodes analog ports A0-A4 were recorded to emulate watermark sensor data, with a fan blowing over the node to produce a somewhat consistent environment. Each analog port was given a ThingSpeak ${ }^{\mathrm{TM}}$ channel field. 
The gateway can record its own central processing unit, i.e. CPU, usage and CPU temperature, which can be used as onboard sensors. The Gateway CPU temperature, field 1, and CPU usage, field 2, were posted to ThingSpeak ${ }^{\mathrm{TM}}$ on a separate channel named Gateway Status. This channel made use of MATLAB® Visualizations to display the data.

\section{Design Objective 2 - Local storage from remote SmartFarm DAQ nodes}

The gateway was used in 2 field sites, Fresno and San Luis Obispo, both testing for local storage. In the first study, the gateway collected data from 2 remote nodes. This field study was in an almond orchard in Fresno, CA with the gateway installed inside a tin shed on site near Fresno State $\left(36^{\circ} 49^{\prime} 32.5^{\prime \prime} \mathrm{N}\right.$ $\left.119^{\circ} 44^{\prime} 59.5 \mathrm{~W} \mathrm{~W}\right)$, Figure $0-4$. The gateway was connected to an Intel® NUC programmed by UCSB to collect the gateway data and post it to an external site managed by UCSB. The Intel® NUC was connected to the internet via a virtual private network, i.e. VPN, set up by Fresno State. The gateway radio used a high-gain $11.1 \mathrm{~dB}$ Yagi antenna, (Digi International, Minnetonka, MN) to connect to the remote DAQ nodes. The field study was designed to test the gateway in field conditions, collecting data from remote nodes and passing the data to the NUC. Each remote node was set up with 3 Irrometer® Watermark sensors (Watermark 200SS; Irrometer, Riverside, CA) and 3 temperature sensors each (DS18B20; Maxim Integrated, San Jose, CA) at 108.31ft from the tin shed. The sensors were installed by first drilling 7/8" holes with a soil auger, at depths of 1 foot, 2 feet, and 3 feet. The wiring between the DAQ nodes and the sensors was spliced together within a junction box. PVC and drip irrigation line were used to 
protect the wires, Figure 0-5 through Figure 0-8. The script utilized is daq2rpi.py, Figure 0-9.

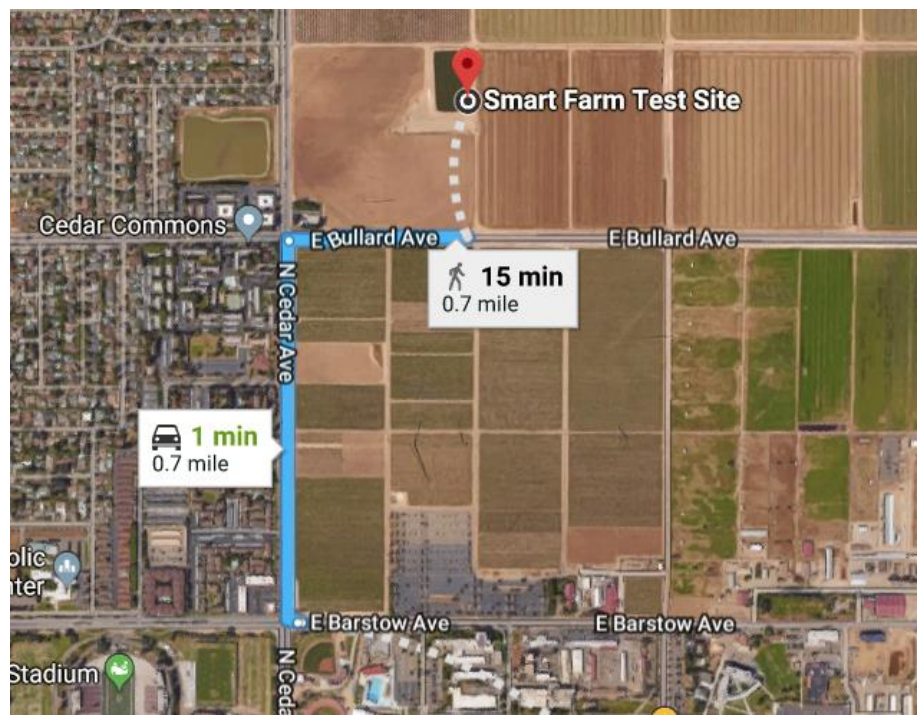

Figure 0-4. SmartFarm Field Test Fresno Almond Orchard, (36²49'32.5"N $119^{\circ} 44^{\prime} 59.5$ "W) Image credit: Google Maps

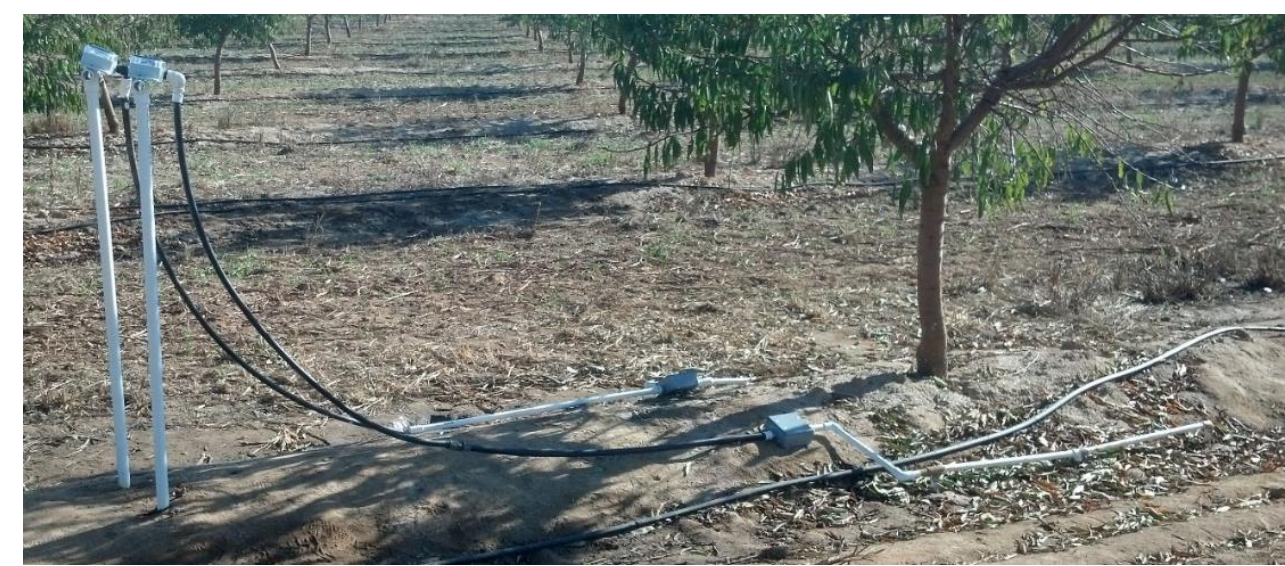

Figure 0-5. SmartFarm Fresno Initial Field Deployment side view 


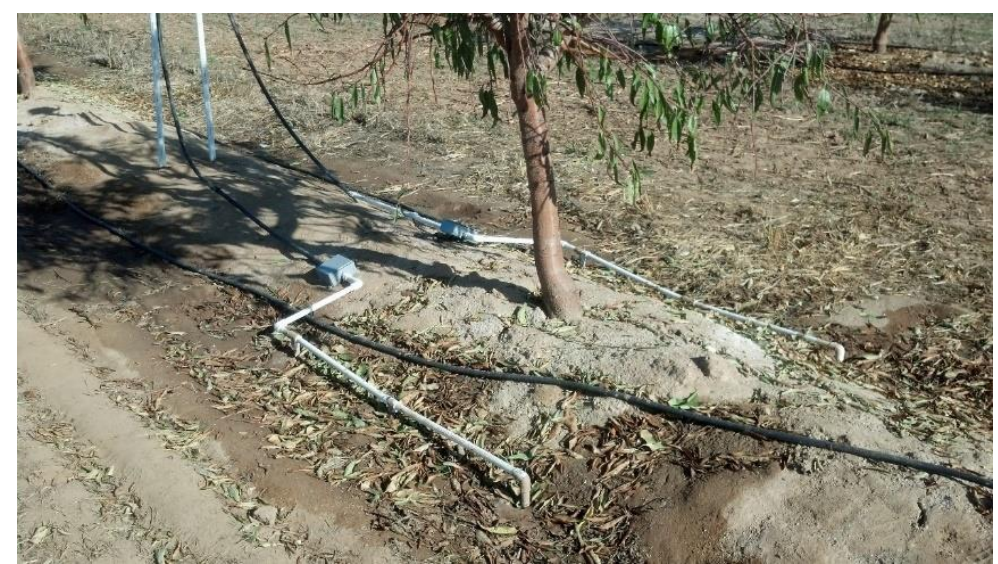

Figure 0-6. SmartFarm Fresno Initial Field Deployment sensor view

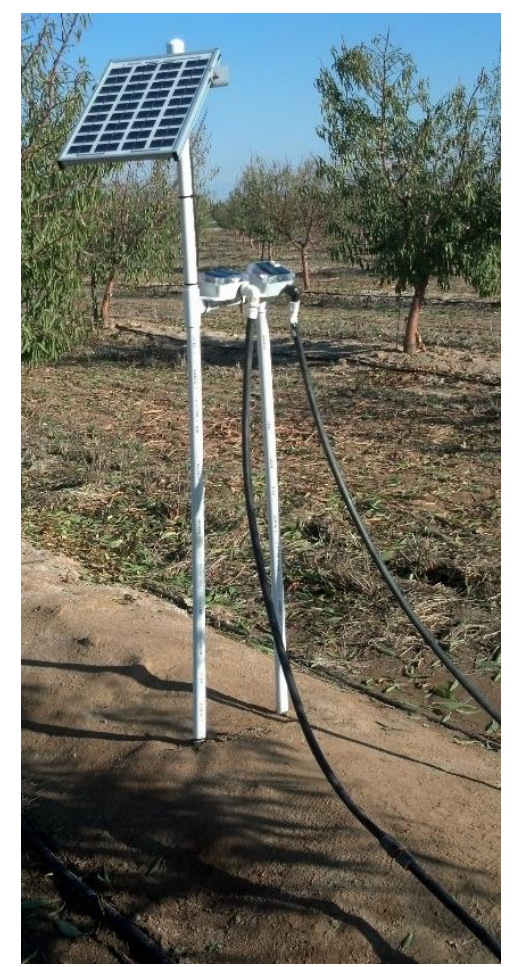

Figure 0-7. SmartFarm Fresno Initial Field Deployment solar panel view 


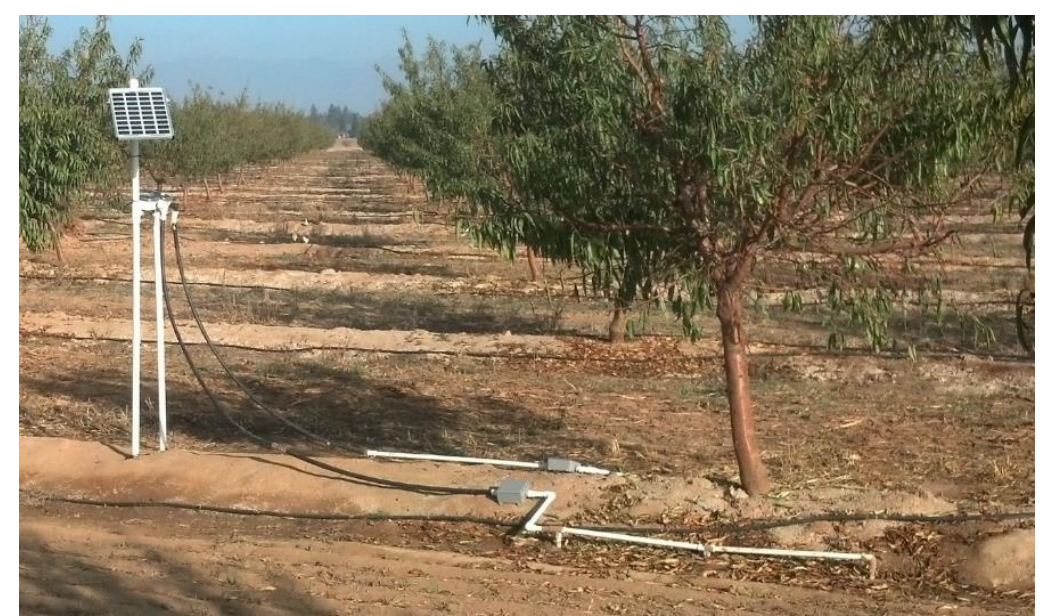

Figure 0-8. SmartFarm Fresno Initial Field Deployment side view 2

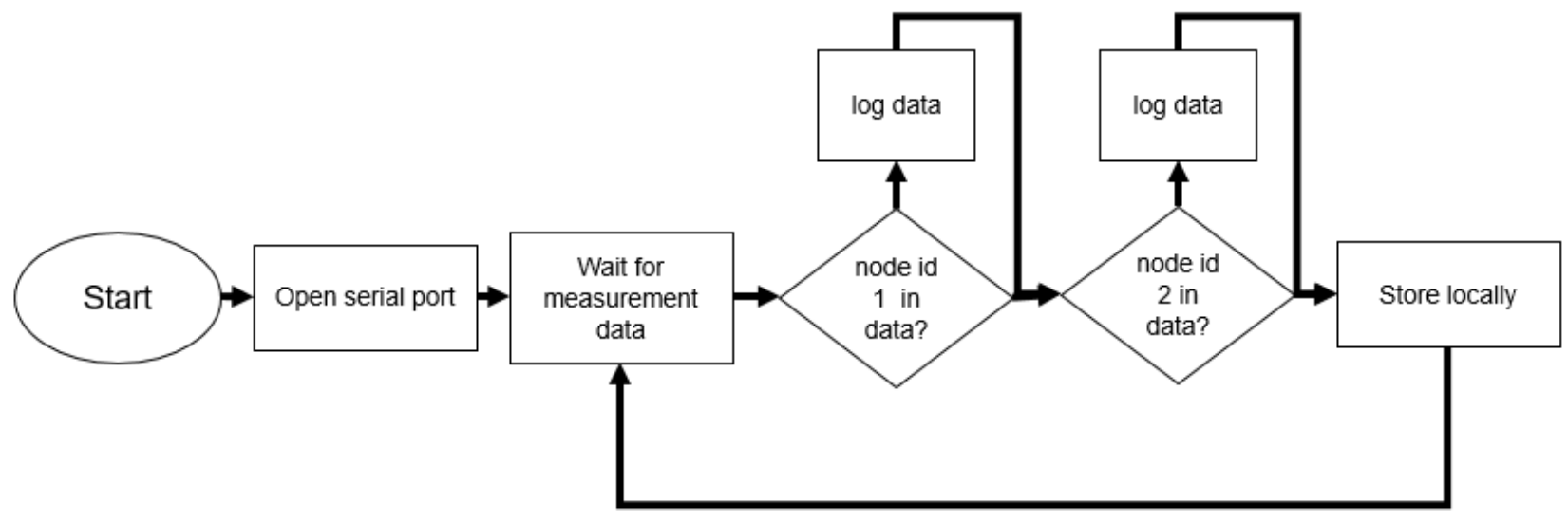

Figure 0-9. Flow chart for daq2rpi.py local storage script

The Student Experiment Farm (SEF, 35¹8'36.6"N 12040'24.7"W), Figure 0-10, was used as another field testing site. The gateway was installed inside a weatherproof enclosure inside a greenhouse with the cable adaptor exposed for some airflow, Figure $0-11$. The gateway was powered with a backup battery, which was powered by the greenhouse main solar power. The gateway software was set up to store data locally in a file, named according to the node identifier received from the node. For example, node 3 data were stored in node_N3.txt. 
The gateway stores a log file, which records the name of the script that is currently running, the name of the function being called, and the node id that data was written from. The gateway served for a single DAQ v6.2 node with 6 watermark and 6 temperature sensors, with the DAQ node installed $280 \mathrm{ft}$ from the gateway. The watermark and temperature sensors were installed on the east and west side of a tree at 3-feet, 2-feet, and 1-foot depths, Figure $0-12$. The gateway radio was configured in normal mode, while the $D A Q$ radio was configured in asynchronous pin sleep mode. The DAQ node was setup for sleeping at 10-minute intervals.

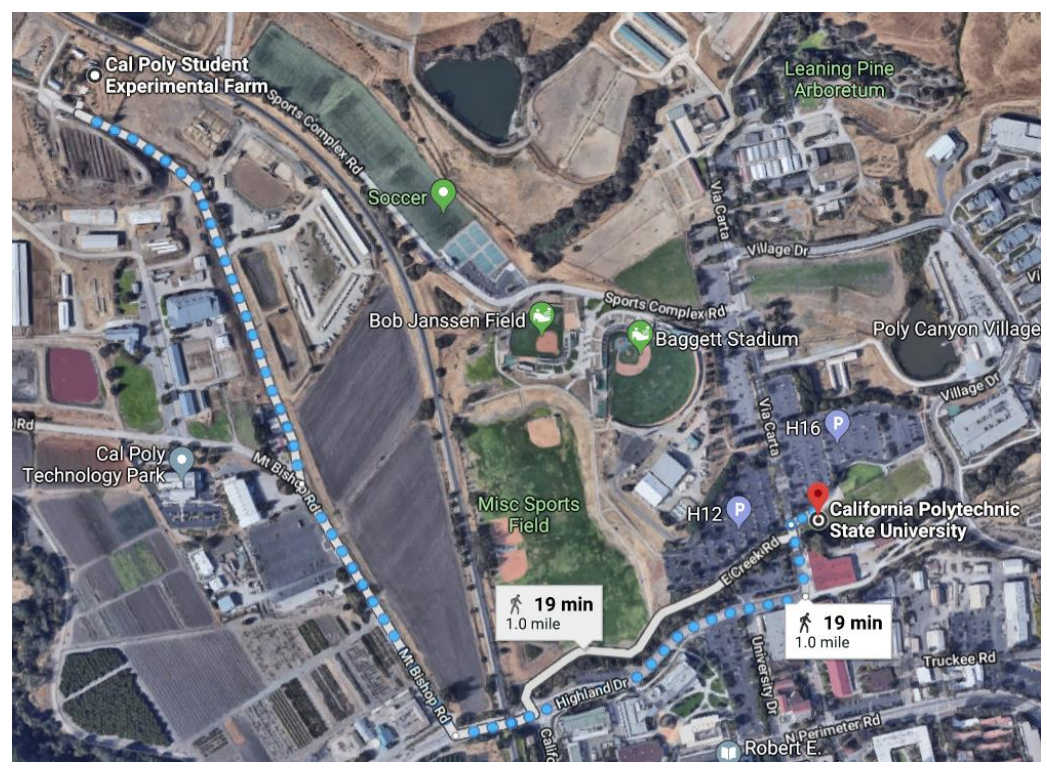

Figure 0-10. Greenhouse Student Experiment Farm, Cal Poly, San Luis Obispo, CA, (35॰18'36.6"N 12040'24.7"W). Image credit: Google Maps 


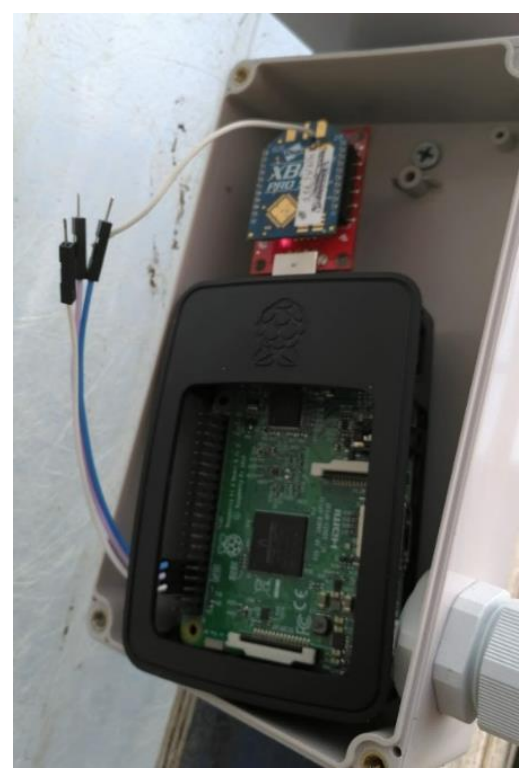

Figure 0-11. SEF Gateway Install with serial wires and coordinator radio

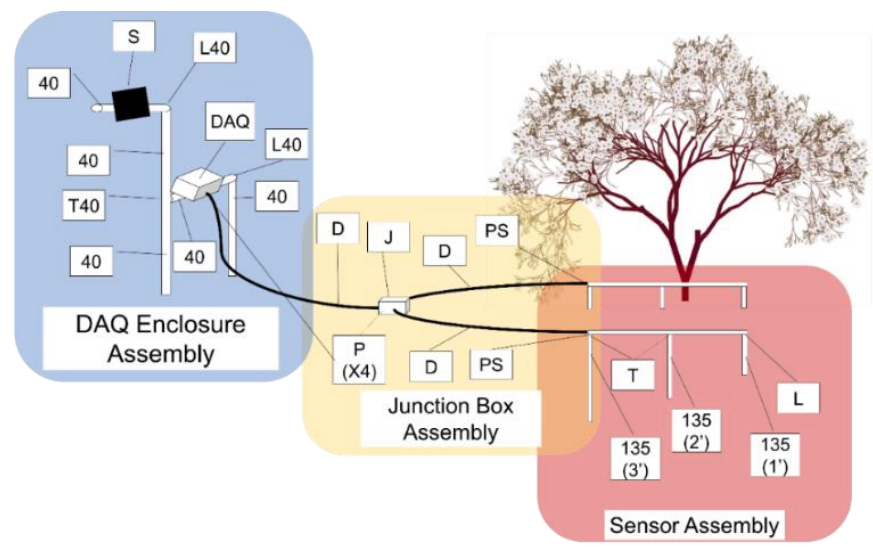

\begin{tabular}{|c|c|c|c|c|c|c|c|c|}
\hline \multicolumn{3}{|c|}{ DAQ Enclosure Assembly } & \multirow{2}{*}{\multicolumn{3}{|c|}{ Junction Box Assembly }} & \multirow{2}{*}{\multicolumn{3}{|c|}{ Sensor Assembly }} \\
\hline Part & Label & Quantity & & & & & & \\
\hline \multirow{2}{*}{$\begin{array}{l}\text { 1" PVC Sch } 40 \\
\text { pipe }\end{array}$} & 40 & 5 & Part & Label & Quantity & Part & Label & Quantity \\
\hline & & & $1 / 2$ " Drip Irrigation Line & D & 3 & \multirow{2}{*}{$\begin{array}{l}1 / 2 " \text { PVC SDR } \\
13.5\end{array}$} & \multirow{2}{*}{135} & \multirow{2}{*}{3} \\
\hline 1" PVC Sch 40 ' $T$ ' & $\mathrm{T} 40$ & 1 & 1/2" MPT Perma-Loc & $\mathrm{P}$ & 4 & & & \\
\hline 1" PVC Sch 40 'L' & L40 & 2 & 1/2" Perma-Loc Slip Fit & PS & 2 & $1 / 2$ " PVC 'T' & $\mathrm{T}$ & 2 \\
\hline 5V Solar Panel & $S$ & 1 & \multirow{2}{*}{$\begin{array}{c}\text { Weatherproof } \\
\text { Junction Box 3-way }\end{array}$} & \multirow[t]{2}{*}{$J$} & \multirow[t]{2}{*}{1} & \multirow[t]{2}{*}{$1 / 2 "$ PVC 'L' } & \multirow[t]{2}{*}{$\mathrm{L}$} & \multirow[t]{2}{*}{1} \\
\hline DAQ Enclosure & DAQ & 1 & & & & & & \\
\hline
\end{tabular}

Figure 0-12. SEF field deployment diagram for a single DAQ node with 6 watermark and 6 temperature sensors 
Design Objective 3-Capability of wirelessly programming remote SmartFarm

\section{$\underline{D A Q}$ nodes}

The gateway utilizes PlatformIO compiler to reprogram remote nodes wirelessly. PlatformIO is an open source cross-platform IDE. A script called UPLOAD_CurrentDAQ.py was developed to upload a program to a remote DAQ node on the next wake cycle of that node using a keyword from the data, Figure $0-13$. The gateway radio was configured with its destination low, i.e. DL, address to that of the remote radio, and the remote DAQ node radio was configured with its $\mathrm{DL}$ radio to that of the gateway radio.

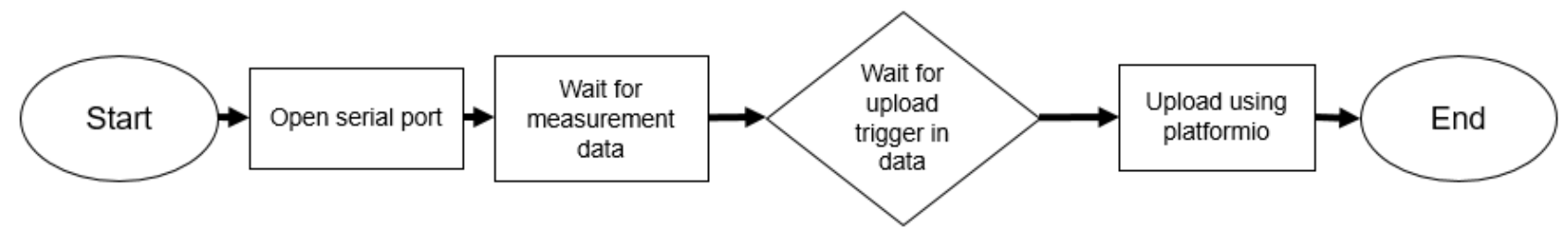

Figure 0-13. Flowchart for uploading on next wake cycle with PlatformIO

Design Objective 4-Capability of providing data analysis and insight from remote SmartFarm $D A Q$ nodes

The ThingSpeak ${ }^{\mathrm{TM}}$ platform service can be setup to analyze incoming data or pre-existing data from the gateway utilizing apps. The apps include MATLAB® Analysis, MATLAB® Visualizations, Plugins from HTML, CSS, and JavaScript, alerts and remote control from Tweets, controls at specific times, reaction commands if certain conditions are met, remote queue commands, and HTTP requests. 


\section{Evaluation Objective 1- Data rate}

Posting data from remote nodes to the cloud depends on the gateway internet speed. This was tested using an open source speed test called speedtest-cli,

Figure 0-14.

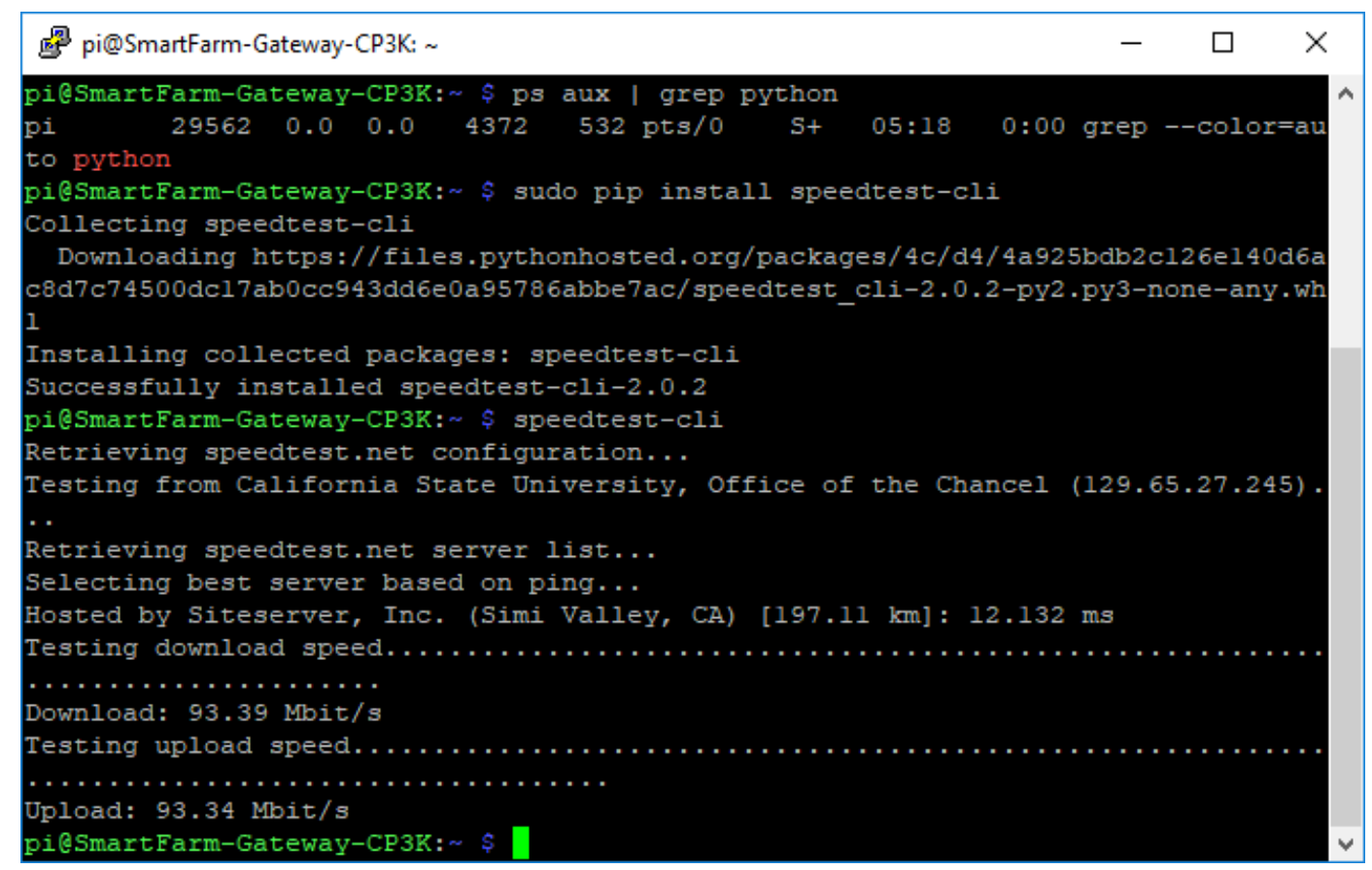

Figure 0-14. Speed testing the SmartFarm Gateway internet connection

\section{Evaluation Objective 2-Data amount}

The XBee radios and DAQ node are configured for 57600 baud. The DAQ node data amount varies depending on the amount of sensors and the sensor types.

The data amount is measured based on what the DAQ is configured to send. For a DAQ with 6 watermark, 6 temperature and 1 Decagon sensor the message was measured with Microsoft Word, word count, which displays the number of characters. Each character is a byte long, or 8 bits. 


\section{Evaluation Objective 3-Power consumption}

The power consumption of the gateway was measured using a Kill A Watt meter (P3 International Corporation, New York, NY) with the gateway powered by a switching power adapter (DSA-13PFC-05 FCA; Stontronics, RG2 OAH, UK).

\section{Evaluation Objective 4-Software efficiency}

The gateway CPU usage percent was recorded while idle and while running daq2rpi.py script. This compares the gateways resources while the script is running to when it is idle.

\section{Evaluation Objective 5-Measurement efficiency}

The gateway measurement efficiency is the ThingSpeak ${ }^{\mathrm{TM}}$ limit of posting. This is an indication of how efficiently measurement data is posted to the cloud with the ThingSpeak ${ }^{\mathrm{TM}}$ free service.

\section{Evaluation Objective 6-Ease of use}

The gateway was evaluated for its ease of use based on the number of steps to set up. The procedure for setup was recorded in steps.

1. Clone the SmartFarm Gateway repo

2. Setup crontab for running the script at reboot

3. Plug in radio to USB port

4. Start the script or reboot the gateway 


\section{Evaluation Objective 7-Availability of resources and support}

The gateway was developed from a Raspberry Pi single board computer (Raspberry Pi 3 Model B v1.2; Raspberry Pi Foundation, UK) which has a supportive community. Raspberry $\mathrm{Pi}$ is a trademark of the Raspberry $\mathrm{Pi}$ Foundation. Many questions were found answered in the development process in the Raspberry Pi forums, Stack Overflow, and various hobbyist websites for working with the Raspberry Pi. References for support can be found in the Appendix.

\section{Evaluation Objective 8-Maintenance required}

Maintenance is required if the gateway hardware becomes physically damaged due to environmental conditions, such as rain. Very little to no maintenance is required otherwise. The gateway is equipped with starting the data collection script after a reboot, so if power goes out, the next time the gateway comes on, it will immediately listen for remote DAQ nodes.

\section{Evaluation Objective 9-Installation time}

The gateway installation at a test site or for deployment is simple. Plug in the USB dongle with the coordinator radio into an available USB port and power on the gateway. The node data collection script will start immediately; no monitor, keyboard, or mouse are required. The installation time for the SEF deployment was used for a typical installation time. 


\section{Evaluation Objective 10-Adaptability}

The gateway can be utilized with other wireless protocols, including Bluetooth and $\mathrm{Wi}-\mathrm{Fi}$, which are onboard the Raspberry Pi used to develop the gateway.

\section{Evaluation Objective 11 - Software portability}

The gateway can be ported to other systems due to its open source nature.

Software can be written or likely already exists to port into other systems.

\section{Evaluation Objective 12 - Comparison of gateways}

The SmartFarm gateway was compared with other open source gateways for cost, node limit, range, open source software and hardware, wireless technologies, nodes, enclosure, and power consumption.

\section{Results}

\section{Design Objective 1 - Cloud data for remote SmartFarm DAQ nodes}

Initial testing posted 380 entries to ThingSpeak ${ }^{\mathrm{TM}}$ using ThingSpeakCode.py, Figure $0-15$. The data shows a steady decline from 49 to 34 kiloPascals, i.e. $\mathrm{kPa}$, and then a final peak to $59 \mathrm{kPa}$. This data represents a complete datapath from a remote node through the gateway and posted to the ThingSpeak ${ }^{\mathrm{TM}}$ cloud service. 


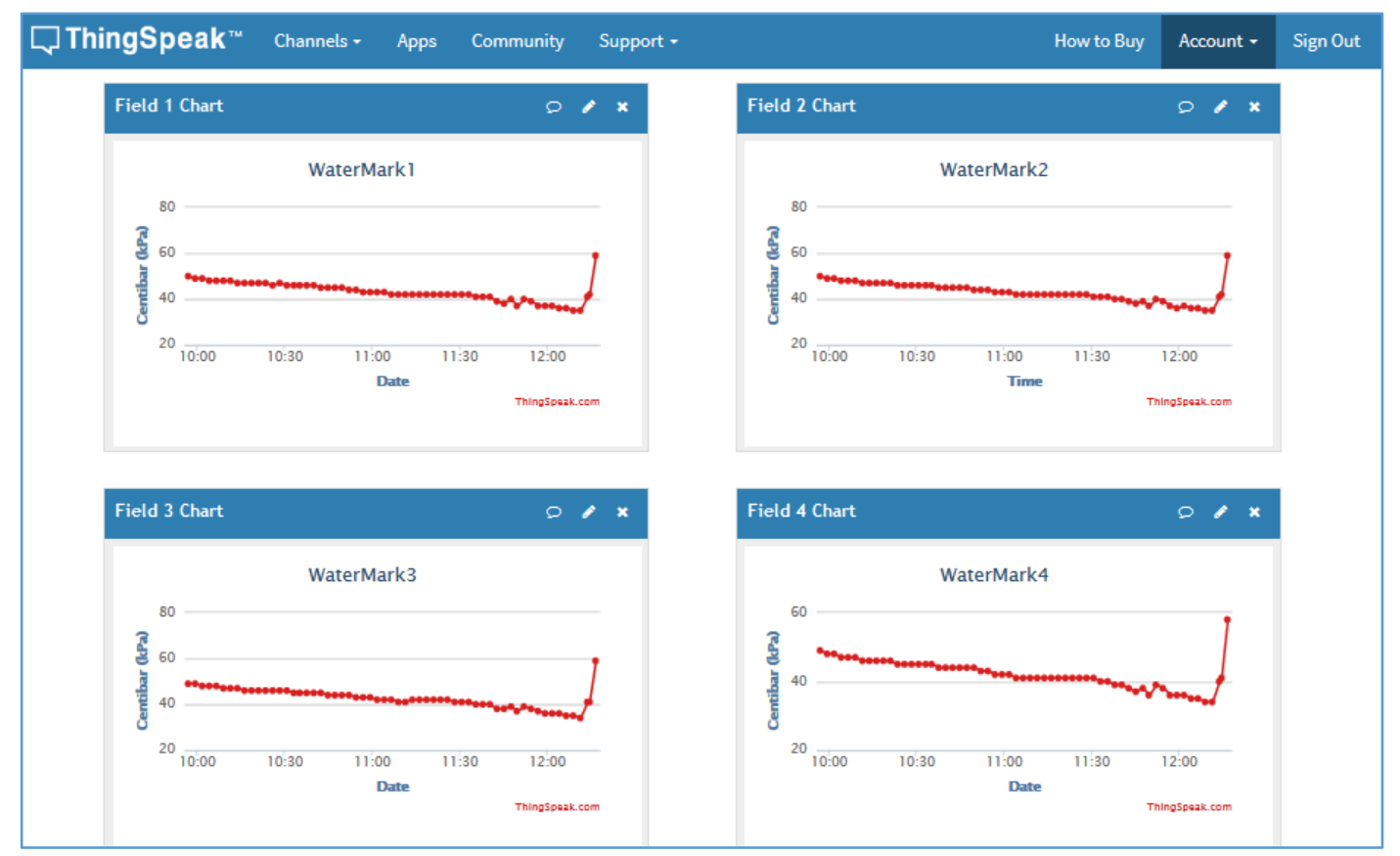

Figure 0-15. Sample SmartFarm DAQ v6.2 data posted to ThingSpeak ${ }^{\mathrm{TM}}$. Image credit: ThingSpeak.com

Gateway status posting CPU usage is relatively steady at about $0.3 \%$ to about $2.0 \%$. Peaks of $5.9 \%$ occur from 2-23-18 $11 \mathrm{pm}$ to $2-24-1811 \mathrm{pm}$, Figure $0-16$. This is the idle state of the gateway. During the idle state the temperature is recorded around $40{ }^{\circ} \mathrm{C}$ from 2-24-18, 1 am to $2-24-18,9$ am and around $42{ }^{\circ} \mathrm{C}$ from 2-24-18, 11:40am to 2-24-18, 10:50pm, Figure 0-16. The gateway then performs processes from 2-24-18 $11 \mathrm{pm}$ to $2-25-18$ at $12: 50 \mathrm{pm}$ which cause the CPU usage to rise to around $25 \%$ and the temperature to rise to around $54{ }^{\circ} \mathrm{C}$. This relation can be used to determine status of the gateway, whether processes are running or not, and how much of an impact a process has on the gateway. This is useful for determining a possible cause of failure in the gateway. 


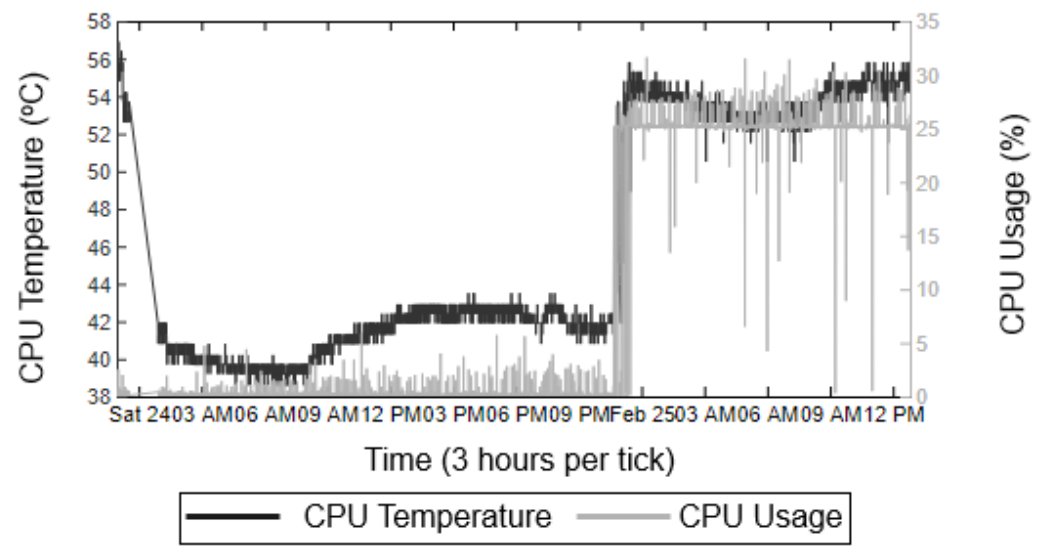

Figure 0-16. Gateway CPU temperature and usage from ThingSpeak ${ }^{\mathrm{TM}}$ MATLAB® Visualization App,

The DAQ script includes a limit of 99,000 ohms for dry watermark sensors. When the limit is reached or exceeded, the DAQ will print 'NA' to indicate that the sensor is not available. ThingSpeak ${ }^{\mathrm{TM}}$ doesn't record this, Figure $0-17$, but Microsoft Excel does as a '0', Figure 0-18. The gateway was running the posting script for just over 30,000 entries to ThingSpeak ${ }^{\mathrm{TM}}$, which was 26 days of continuous posting.

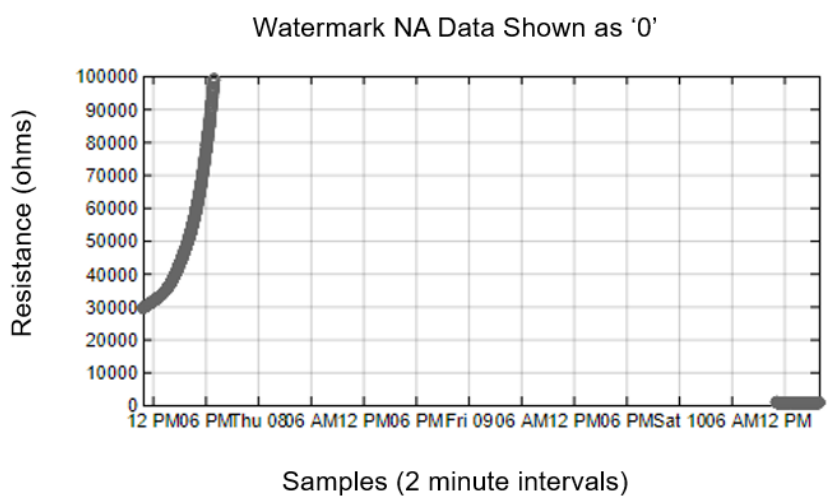

Figure 0-17. An 'NA' value from the DAQ is not shown in ThingSpeak ${ }^{\mathrm{TM}}$ using $M A T L A B \otimes$ visualization, continuous posting 26 days 
Watermark NA Data Shown as '0'

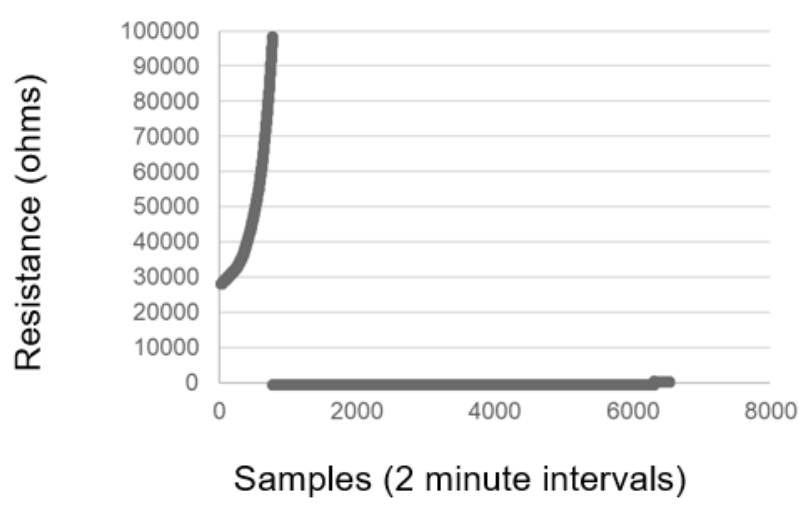

Figure 0-18. An 'NA' value from the DAQ is shown as ' 0 ' in Microsoft Excel, continuous posting 26 days

\section{Design Objective 2 - Local storage from remote SmartFarm DAQ nodes}

The Fresno initial field deployment of 2 nodes, with 3 watermark and 3 soil temperature sensors each, was extracted from UCSB's NUC over the VPN service. The gateway recorded data for 168 days from December to May, and is still collecting data.

The single board v6.2 with 6 watermark and 6 temperature sensors at the SEF demonstrates an active DAQ and wireless data collection at the gateway. The 1foot watermark and temperature sensors on the east and west side of the trees follow a similar trend, with the east temperature sensor reaching a cooler temperature, Figure 0-19. They read beginning at 5,000 ohms and drying to about 15,000 ohms. The 1 -foot sensors experience faster changes to soil moisture. 


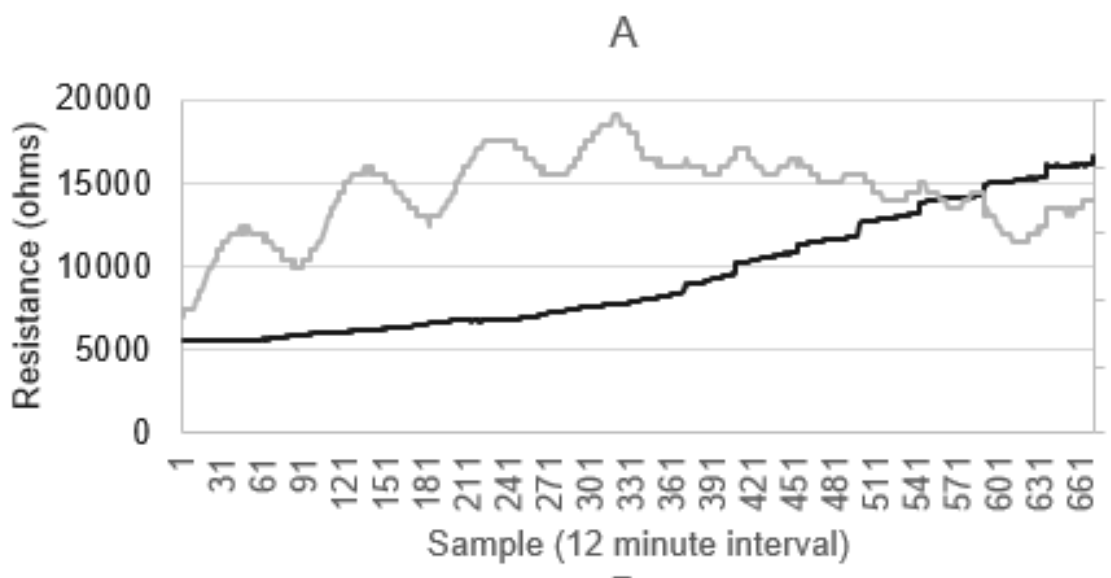

B

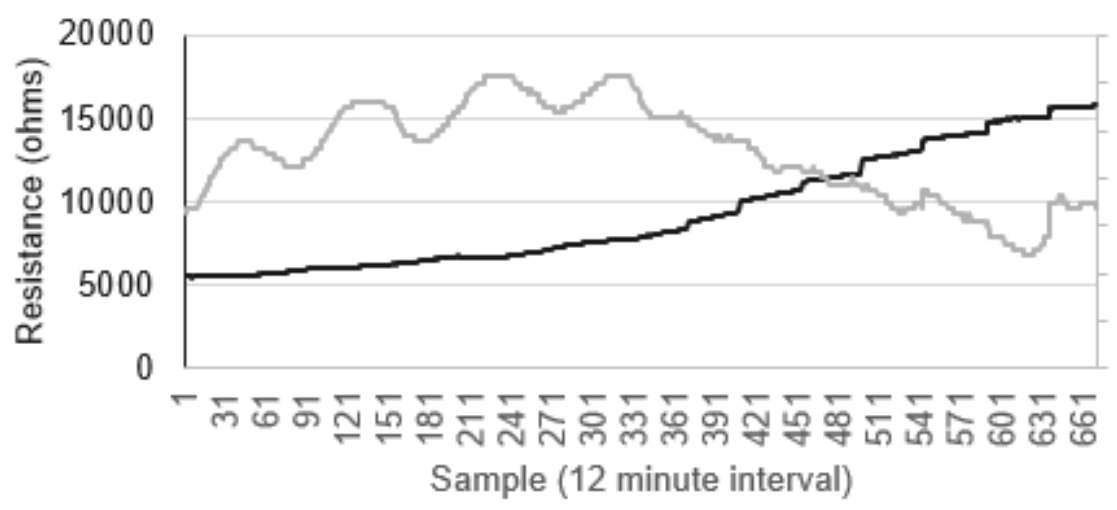

17.5

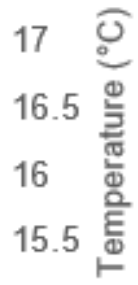

15

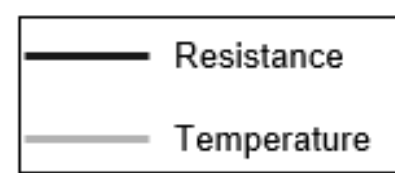

18

$17.5 \widehat{0}$

$17 \stackrel{\circ}{2}$

16.5

16

15.5

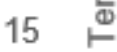

14.5

Figure 0-19. 1-foot depth sensors (A) Watermark and Soil Temperature West, (B) Watermark and Soil Temperature East

The 2-foot sensors were similar, Figure 0-20, comparing east and west. They read moister than the 1 -foot sensors with a reading of $4,000 \mathrm{ohms}$. These sensors were drying slower than the 1 -foot sensors, with a reading of about 11,500 ohms. The temperature for the west side reaches a peak of $17^{\circ} \mathrm{C}$ and remains a relatively constant $16.9^{\circ} \mathrm{C}$ while the east side reaches a peak of 17.2 ${ }^{\circ} \mathrm{C}$ and decreases to $16.8^{\circ} \mathrm{C}$. 
A

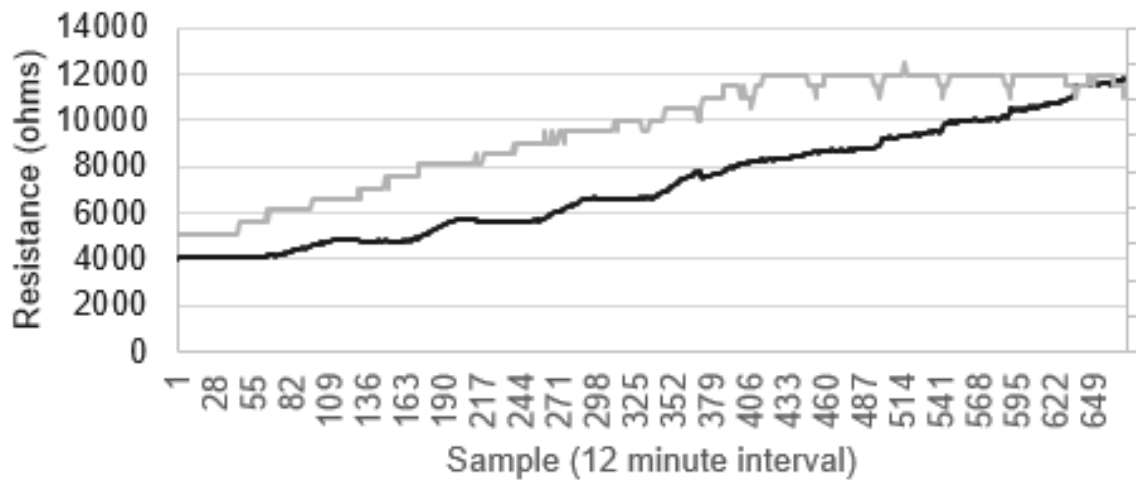

B

17.2

17 o

16.6

16.4

16.2

16

15.8

$15.6 \vdash$

15.4

Sample (12 minute interval)

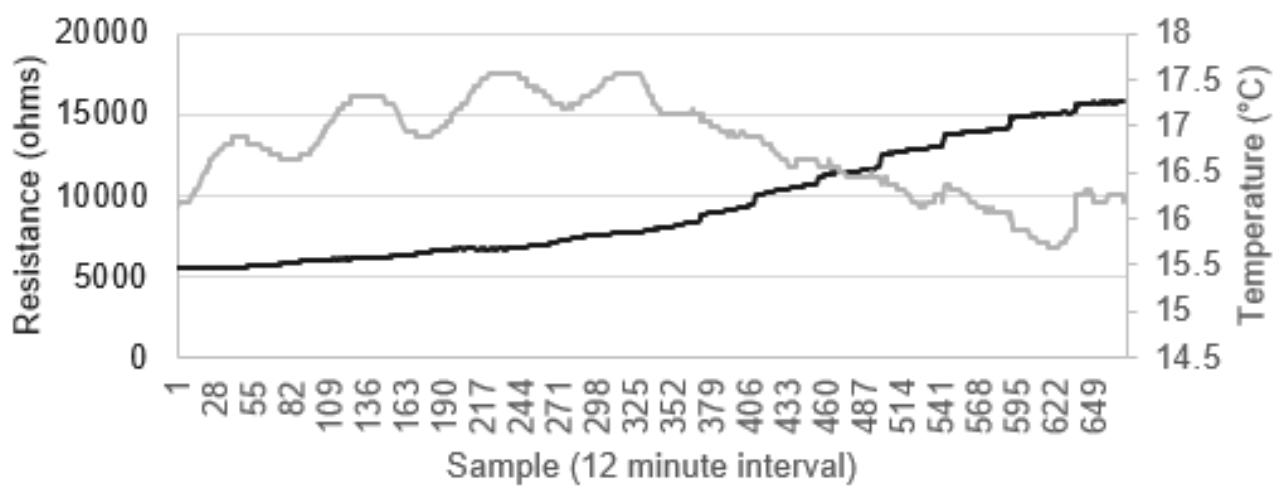

Figure 0-20. 2-foot depth sensors (A) Watermark and Soil Temperature West, (B) Watermark and Soil Temperature East

The west and east side 3-foot sensors are like the 2-foot sensors, Figure 0-21.

They are moister than the 2-foot and 1-foot sensors with readings of 2,000 ohms.

These sensors are drying slower than the 1-foot and 2-foot, with a reading of about 4,300 ohms. 
A

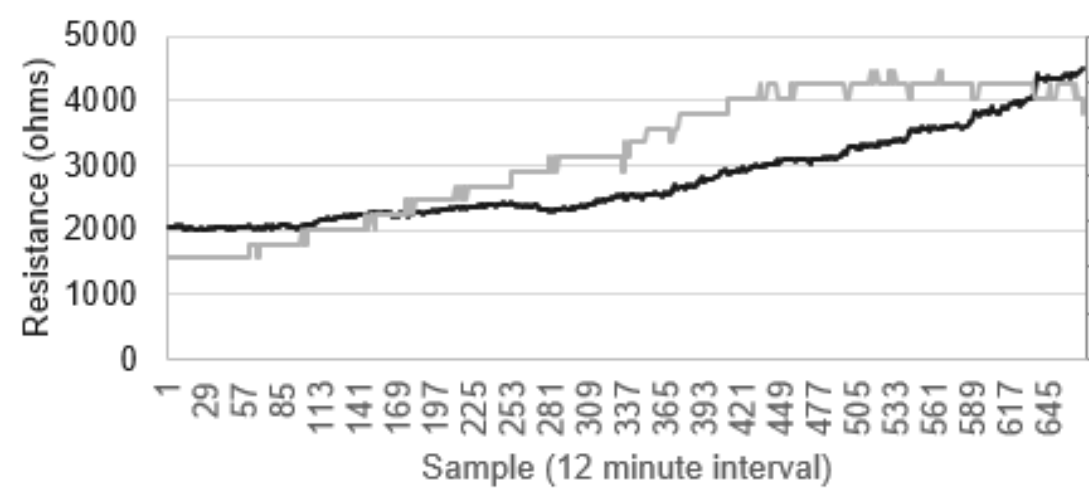

B

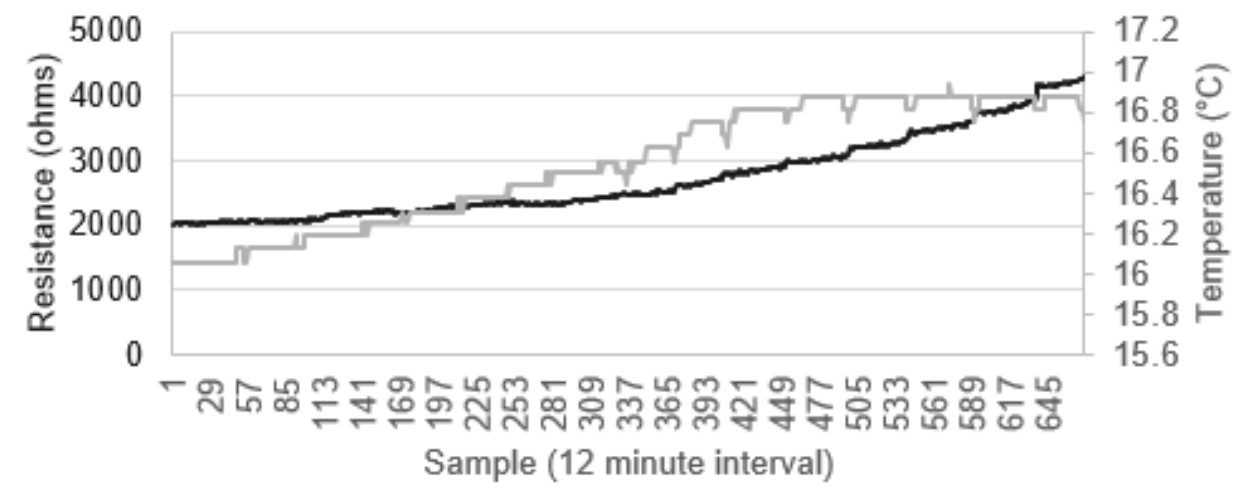

Figure 0-21. 3-foot depth sensors (A) Watermark and Soil Temperature West, (B) Watermark and Soil Temperature East

The battery voltage of the node starts high at 3.7 volts and drops down over time to 3.3 volts, which is the lowest the node will measure and remain powered to protect the battery from undervoltage, Figure 0-22. It does have a steep decline at around 300 samples, which is about where the solar voltage becomes constant. The reason for the solar voltage becoming constant is that the board is only available to sense data when the board receives solar power, as the battery needs to be charged. 


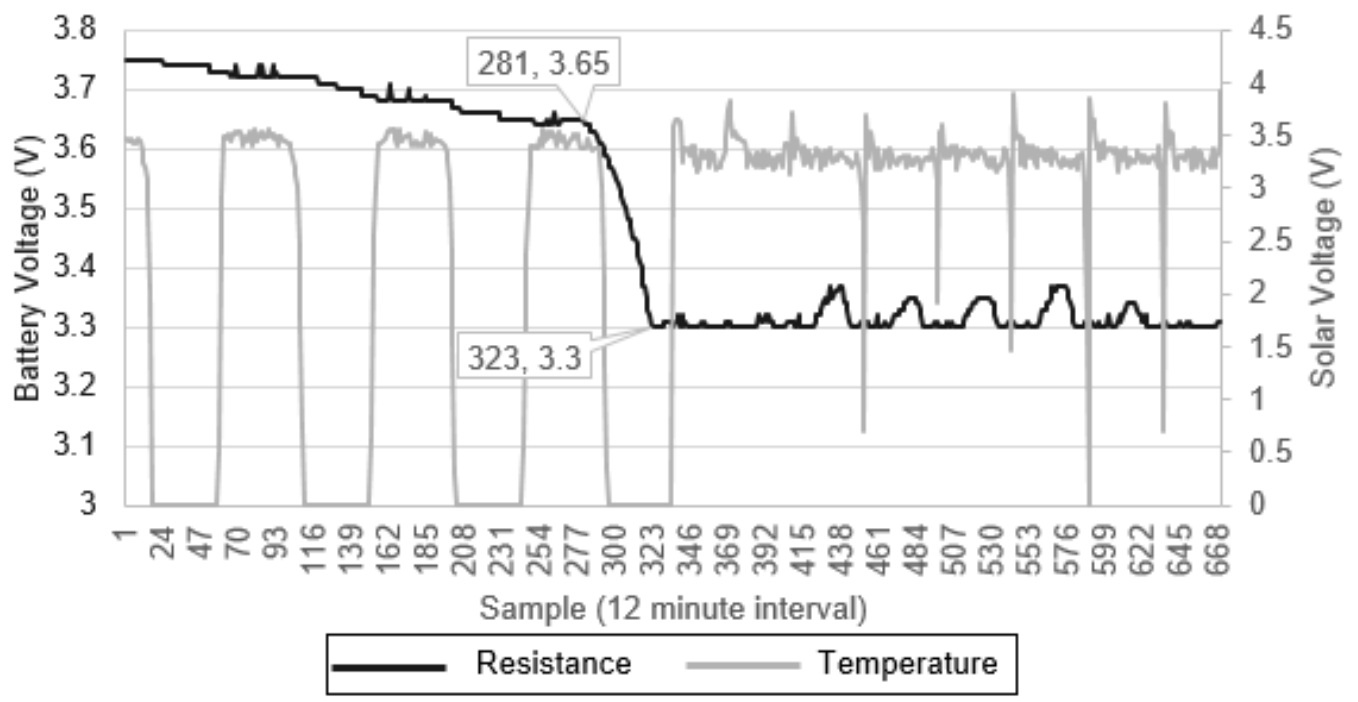

Figure 0-22. Node Battery and Solar Panel Voltage

Design Objective 3-Capability of wirelessly programming remote SmartFarm $\underline{D A Q}$ nodes

Wireless programming is successful. PlatformIO was called from the script which compiled the code, and then uploaded it when the serial trigger was read from the remote node. The node was reprogrammed successfully from the gateway and responded with running the new program during the measurement mode.

Design Objective 4-Capability of providing data analysis and insight from remote SmartFarm $D A Q$ nodes

ThingSpeak ${ }^{\mathrm{TM}}$ MATLAB ${ }^{\circledR}$ analysis can be used to analyze SmartFarm DAQ or gateway data. ThingSpeak ${ }^{\mathrm{TM}}$ provides examples and documentation for analyzing channels and data, Figure 0-23. 


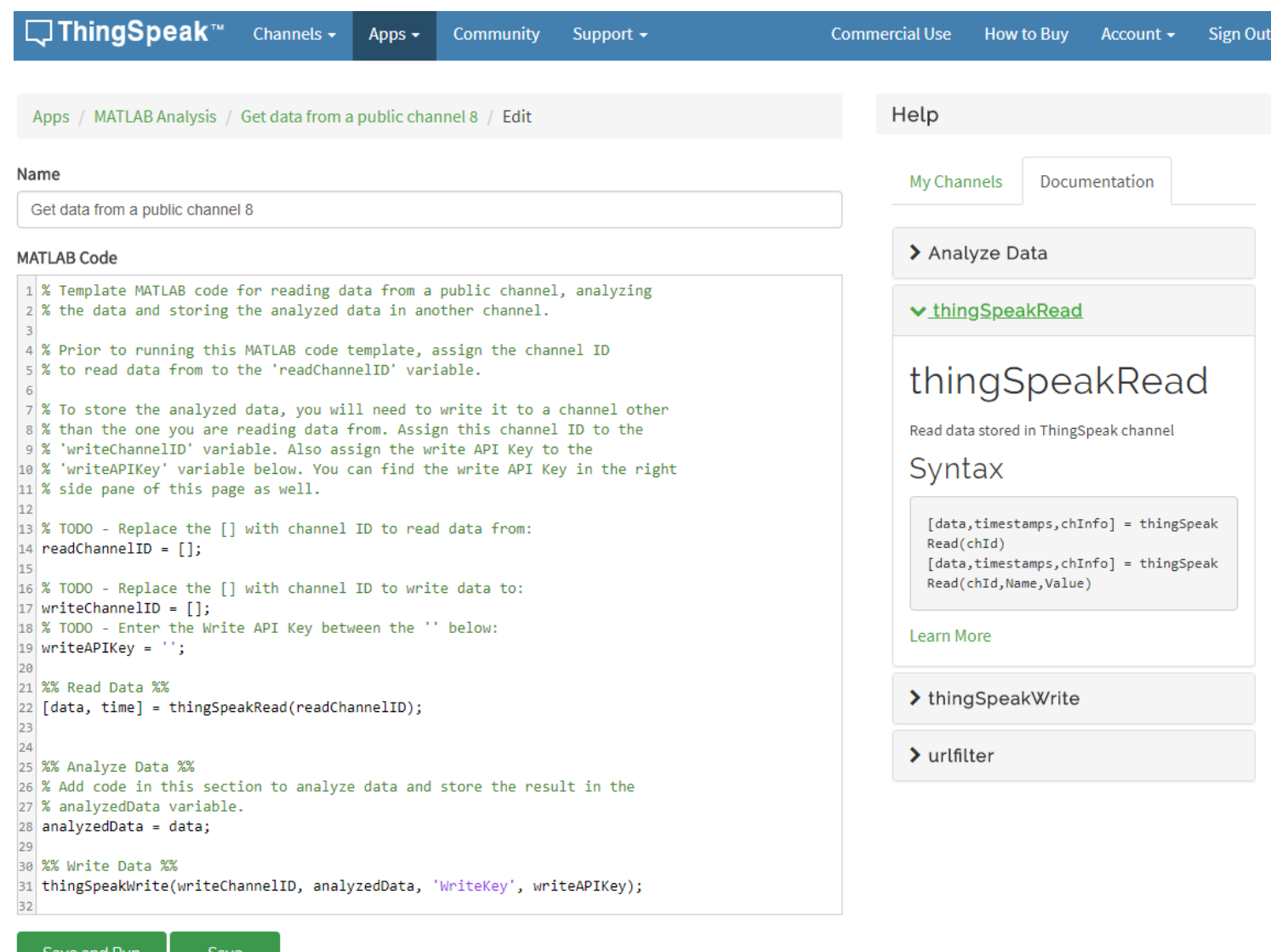

\section{Save and Run $\quad$ Save}

Figure 0-23. ThingSpeak ${ }^{\mathrm{TM}}$ MATLAB® Analysis, Image Credit ThingSpeak.com

\section{Evaluation Objectives 1 through 11}

The evaluation objectives have been recorded and summarized in Table $0-1$. The upload speed is fast enough to not limit the ThingSpeak ${ }^{\text {TM }}$ message posting limit of 200 bytes per second, (or 3,000 bytes per 15 seconds). The data amount does not impact the posting limit as it is less than the 3,000 bytes. The power consumption of the gateway is negligible. The software used to collect data could be more efficient. The resources and support are given as links which were used in the development of the gateway. There was no maintenance required with any 
of the field tests. The install time included the 4-step process and installing the gateway inside the weatherproof enclosure. The gateway is adaptable with the ability to use multiple wireless technologies as well as its planned open source software. The software is portable to other systems as it is planned to be open source.

Table 0-1. Gateway Evaluations 1 through 11
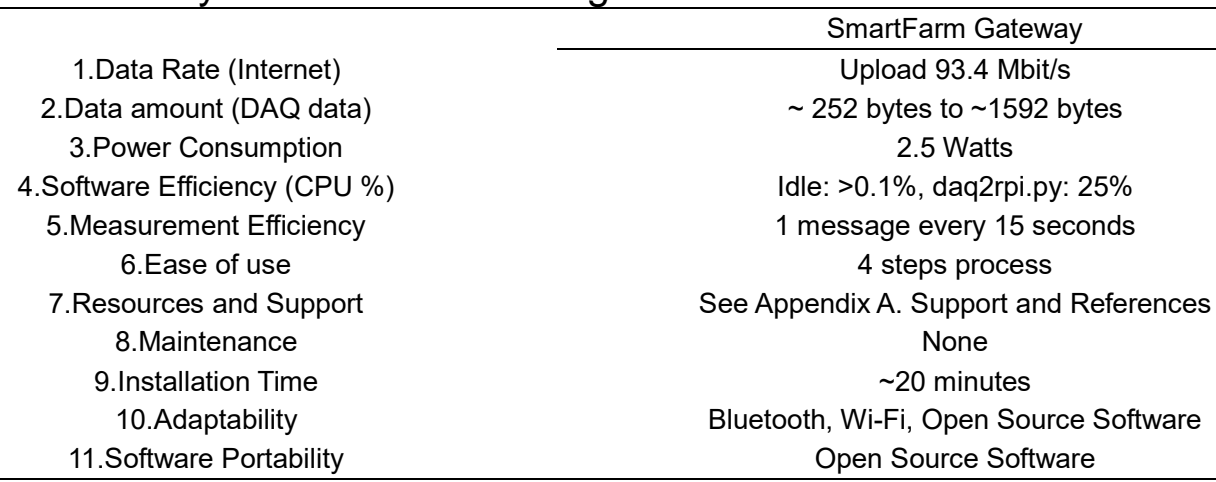

Bluetooth, Wi-Fi, Open Source Software Open Source Software

\section{Evaluation Objective 12 - Comparison of Gateways}

The SmartFarm gateway is comparable amongst other open source gateways,

Table 0-2. It is not the least expensive, though the least expensive gateway, Vinduino printed circuit board, i.e. PCB, Gateway, Figure $0-24 \mathrm{C}$ is priced as only a bare PCB, with none of the components. The range varies between gateways and wireless technologies. Libelium ${ }^{\mathrm{TM}}$, Figure $0-24 \mathrm{~B}$, is the only gateway that comes with a weatherproof enclosure while the others can get one separately. The SmartFarm and Libelium ${ }^{\mathrm{TM}}$ gateways are adaptable to various wireless technologies, though the adaptability comes at a higher cost with Libelium ${ }^{\mathrm{TM}}$. The Things Network gateway does include an enclosure, but it is not weatherproof. 

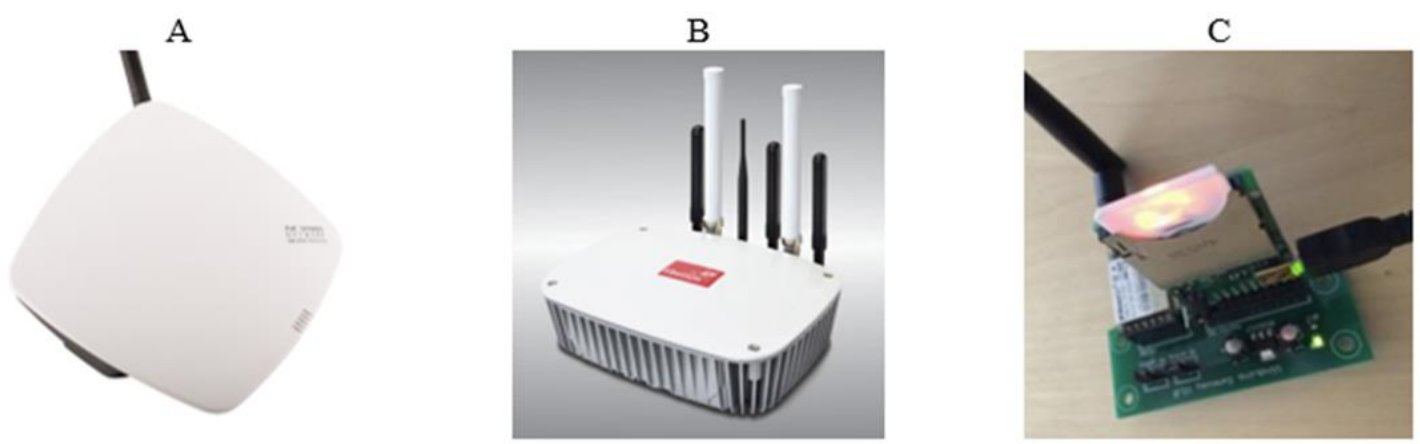

Figure 0-24. Open source gateways. (A) The Things Network Gateway image credit: The Things Network, (B) Libelium ${ }^{\mathrm{TM}}$ MeshLium $^{\mathrm{TM}}$ image credit: Libelium ${ }^{\mathrm{TM}}$ Comunicaciones Distribuidas S.L, (C) Vinduino PCB Gateway image credit: Vinduino LLC

Table 0-2. Comparison of Open Source Gateways. XBee radios tested successfully to 1.2 miles point to point. SmartFarm Gateway is planned for release as open source. Others may be used but have not been tested. Range is dependent on which wireless technology is used

\begin{tabular}{|c|c|c|c|c|}
\hline & SmartFarm Gateway & $\begin{array}{c}\text { The Things Network } \\
\text { Gateway }\end{array}$ & $\begin{array}{c}\text { Libelium }^{\mathrm{TM}} \text { MeshLium } \\
\text { Xtreme Gateway }\end{array}$ & Vinduino Gateway PCB \\
\hline Cost & $\$ 35$ & $\$ 325$ & $\$ 580$ & $\$ 5$ \\
\hline Node Limit & NA & $1000+$ & NA & 300 \\
\hline Range & LOS : 9 mi., 1.2 mi. $^{1}$ & 6 miles LOS & Varies $^{4}$ & 7 miles LOS \\
\hline $\begin{array}{c}\text { Open source software } \\
\text { and hardware }\end{array}$ & software only ${ }^{2}$ & both & IDE and Manager & both \\
\hline Wireless technologies & $\begin{array}{c}900 \mathrm{MHz}, 868 \mathrm{MHz}, \\
802.15 .4, \mathrm{Wi}-\mathrm{Fi}, \\
\text { Bluetooth, others }{ }^{3}\end{array}$ & LoRaWAN $^{\mathrm{TM}}$ & $\begin{array}{c}900 \mathrm{MHz}, 868 \mathrm{MHz} \\
802.15 .4, \mathrm{Wi}-\mathrm{Fi}, \\
\text { Cellular, ZigBee }\end{array}$ & LoRaß/LAN \\
\hline Nodes & $\begin{array}{c}\text { SmartFarm DAQ v5.4, } \\
\text { v6.1, v6.2 }\end{array}$ & $\begin{array}{l}\text { The Things UNO, The } \\
\text { Things Node, other } \\
\text { LoRaWAN }^{\mathrm{TM}} \text { devices }\end{array}$ & $\begin{array}{l}\text { WaspMote }{ }^{\mathrm{TM}} \text { Plug and } \\
\text { Sense! }\end{array}$ & $\begin{array}{c}\text { Vinduino Remote Sensor } \\
\text { Station Board }\end{array}$ \\
\hline Enclosure & Separate & Not weatherproof & Aluminum IP65 & Separate \\
\hline
\end{tabular}

Gateway Conclusion

In conclusion, the SmartFarm gateway was designed to post data to a cloud service from remote SmartFarm DAQ nodes, store SmartFarm DAQ data locally, have the ability to wirelessly program a remote SmartFarm DAQ node, can provide data analysis for remote SmartFarm DAQ nodes, and is evaluated by metrics such as data rate, data amount, power consumption, software efficiency, measurement efficiency, ease of use, availability of resources, required maintenance, installation time, adaptability, and portability. The objectives were 
met in developing and evaluating a gateway for the SmartFarm Decision Support System. Future recommendations include improving the gateway with more developing and testing of onboard gateway status and serving as an analytics tool for remote nodes. The open source nature of SmartFarm provides the users with the ability to customize and develop the system to meet their needs. 
DEVELOPMENT AND EVALUATION OF USING A MOBILE APPLICATION AS A DEMONSTRATION TOOL FOR OUTREACH TO INFORM AND

\section{EDUCATE FARMERS, ACADEMIA, AND THE COMMUNITY OF \\ AGRICULTURAL STEWARDSHIP USING THE SMARTFARM DECISION SUPPORT SYSTEM}

Introduction

Population growth around the world affects the way we eat, and more so, the way we will eat. Our current farming practices are not enough to produce food for our growing population, and we need sustainable farming methods (Foley et al., 2011). Current methods may be underutilizing systems and tools, such as a decision support system (DSS), that can support farmers in producing sustainable food. Commercial and available systems are privately owned, complicated to use, limited in functionality, geographically unavailable, and expensive (Krintz et al., 2016). An open source DSS solves these issues, by giving farmers ownership to their data, simple data collection and analysis, insights from their data, and improved farming practices and methods. Farmers should know these benefits, as they contribute to sustainable agriculture. However, this responsibility does not fall to farmers alone. Educating farmers, academia, and community members about open source DSS contributes to the general knowledge base of ag stewardship. As smartphones are widely available, they can serve as effective educational tools (Thornton \& Houser, 2005). By developing a mobile app, we can educate farmers, academia, and community members about sustainable farming. 
The objectives of this research are to develop, evaluate, and demonstrate a mobile app for the SmartFarm decision support system. The design objective of the mobile application tool is to teach farmers, academia, and community members on ag stewardship. The mobile app will be evaluated by 1) adaptation of DSS usage, 2) frequency of use, 3) usage, 4) assessment of ag stewardship, and 5) teaching effectiveness.

\section{Materials and Methods}

The mobile app functions as a demonstration tool for teaching sustainable farming practices, and how a Decision Support System, i.e. DSS, can improve existing farming practices. The app was developed using Flutter, "Google mobile app SDK" (https://flutter.io/). Flutter allows the app to be written in one language and deployed on a variety of devices, including Android and iOS phones. The language used was Dart, made by Google (https://www.dartlang.org/). Android Studio editor was used to write the dart code to make the app.

To develop the app, the Flutter.io 'Get Started' guide was used. This guide walks through installing and setting up the Flutter SDK and console, Figure 0-1, setting up a development environment, working with an emulator, testing the first Flutter app, hot reloading, and writing a demo app. The Flutter and Dart plugins were installed in Android Studio. Android Studio was setup to emulate a Nexus 5X API 24. 


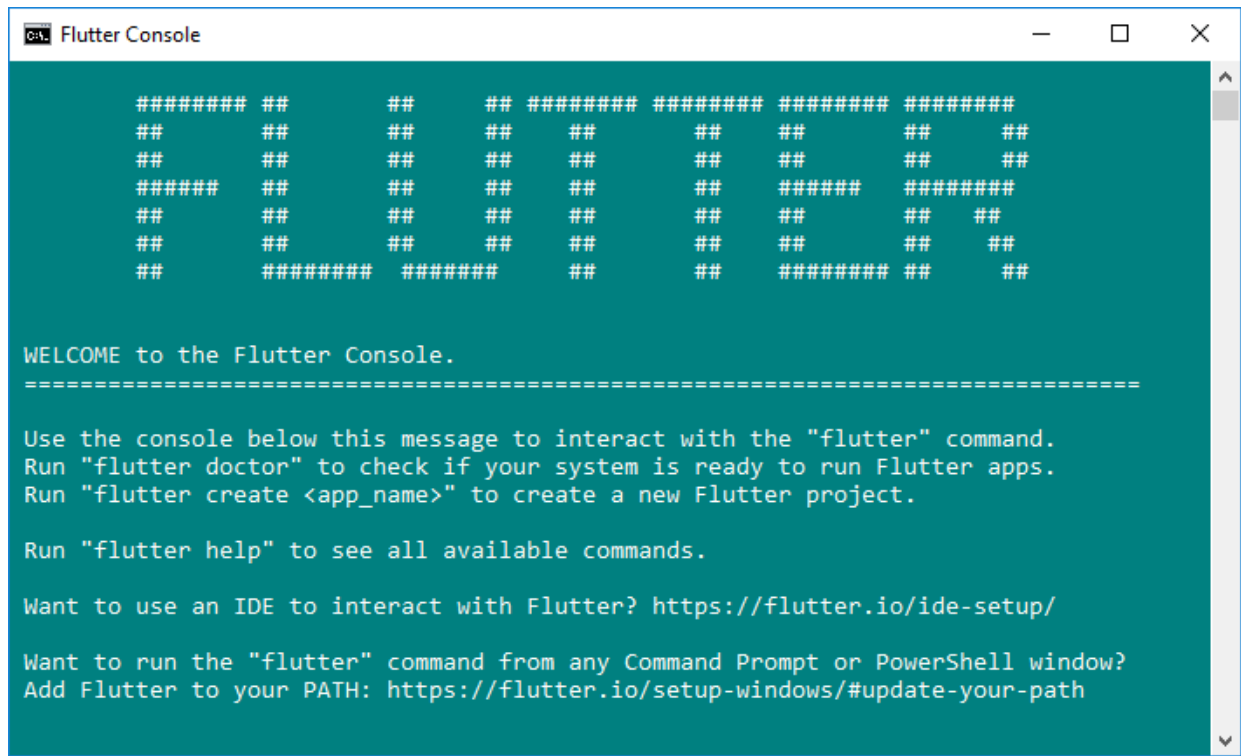

Figure 0-1. Flutter Console

Design Objective - Used to teach academia, farmers, and community members on sustainable farming and stewardship practices

The design of the app is an educational walkthrough followed by a quiz and survey. The walkthrough includes educational slides, buttons, and link for the quiz and survey.

\section{Evaluation Objective 1-Adaptation}

Adaptation is defined as the percent of farmers who do not use a DSS but responded that it would be beneficial. This evaluates the app for who would likely adapt to using a DSS. 


\section{Evaluation Objective 2 - Frequency of use}

Frequency of use is a calculation for how often the app was used. This was determined to be the number of respondents divided by the survey collection time.

\section{Evaluation Objective 3- Usage}

Usage is the percentage of people surveyed in each category. The categories are farmers, academia, and community members.

\section{Evaluation Objective 4-Assessment of ag stewardship}

Assessment of ag stewardship is a respondent passing the quiz with $100 \%$, which indicates the app demonstrates ag stewardship.

\section{Evaluation Objective 5-Teaching effectiveness}

Teaching effectiveness is a measurement of the individual quiz question scores. If more than or equal to $80 \%$ of the respondents answer a question correctly, then the material is adequately covered in the app. If the question is answered incorrectly with more than $20 \%$ respondents, then the app needs improvement for teaching effectiveness. 
Results

Design Objective 1 - Used to teach academia, farmers, and community

members on sustainable farming and stewardship practices such as using

SmartFarm DSS

The mobile app was designed with a homepage, Figure 0-2, instructional slides

on the goal of this thesis, Figure $0-3$, a description of the mobile app, Figure $0-4$, definition for agricultural stewardship and environmental conservation, Figure

0-5, description of how SmartFarm DSS works, Figure 0-6, decision support

system function, Figure 0-7 through Figure 0-13, soil water tension charts, Figure

0-14 through Figure 0-16, and field results for the soil water tension charts,

Figure 0-17. The sequence of the app takes the demonstrator through the

educational module in the following order, with the ability to navigate back and forth, and to the homepage:

1. Homepage

2. Thesis Project Goal

3. Mobile App Description

4. Definition of Ag Stewardship \& Environmental Conservation

5. Graphics of How SmartFarm DSS Works

6. Describing a DSS part 1

7. Describing a DSS part 2

8. Describing a DSS part 3

9. Describing a DSS part 4

10. Describing a DSS part 5

11. Describing a DSS part 6

12. Describing a DSS part 7

13. Sample Irrigation Trend Field 1

14. Sample Irrigation Trend Field 2

15. Sample Irrigation Trend Field 3

16. Sample Irrigation Trend Field Results

17. Quiz and Survey Link 
The homepage was created with a picture from a royalty free site called pixabay, a button to begin the educational module, and two text boxes, one with the title and another with an inspirational quote by Antoine de Saint-Exupery, Figure 0-2. The thesis project goal screen in Figure $0-3$ gives context to the mobile application and was created with a graphic of the SmartFarm gateway and of this mobile app. On the right-hand side of the app there are buttons for navigation. The HOME button navigates to the homepage and the NEXT button navigates to a description of the mobile app.

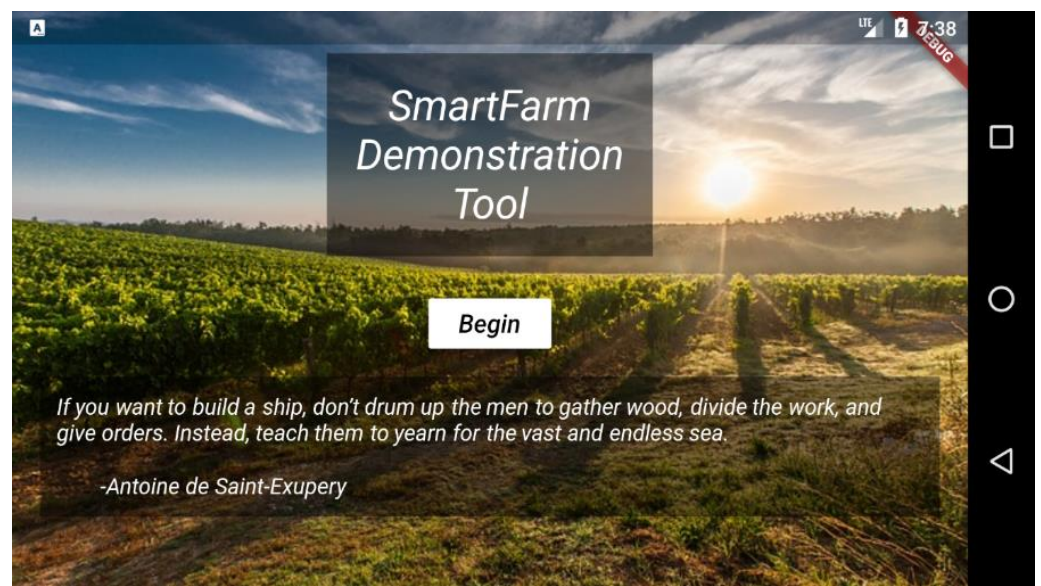

Figure 0-2. The Mobile app homepage Titled SmartFarm Demonstration Tool. Image credit: https://pixabay.com/, Quote credit: BrainyQuote.com 


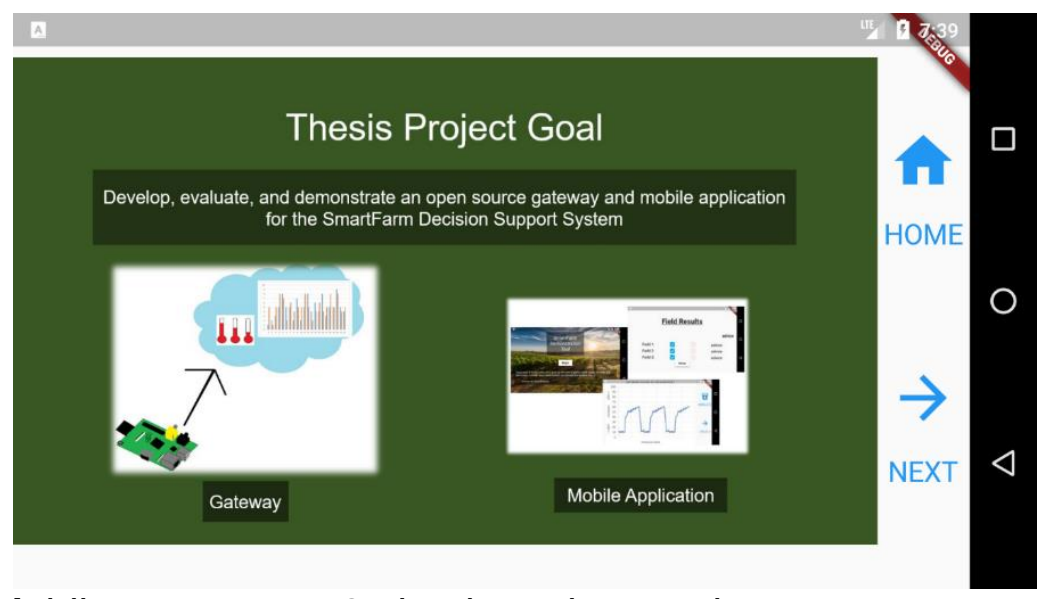

Figure 0-3. Mobile app screen 2, thesis project goal

The mobile app screen in Figure $0-4$ is a description of this mobile app with a similar layout and navigation buttons as the thesis project goal screen, HOME and NEXT. The NEXT navigates to Definition of Ag Stewardship \& Environmental Conservation, Figure 0-5, which then navigates to How SmartFarm DSS works, Figure 0-6. This page is used to show the SmartFarm Data Acquisition nodes, i.e. DAQ, how they communicate with the SmartFarm gateway, and post data to the cloud.

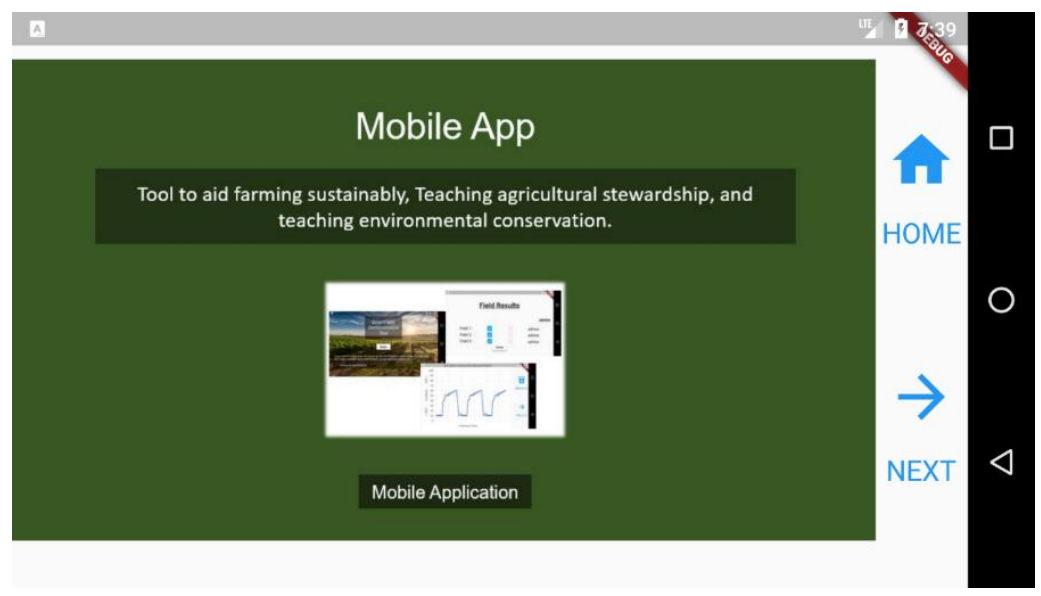

Figure 0-4. Mobile app screen 3 description of the mobile app 


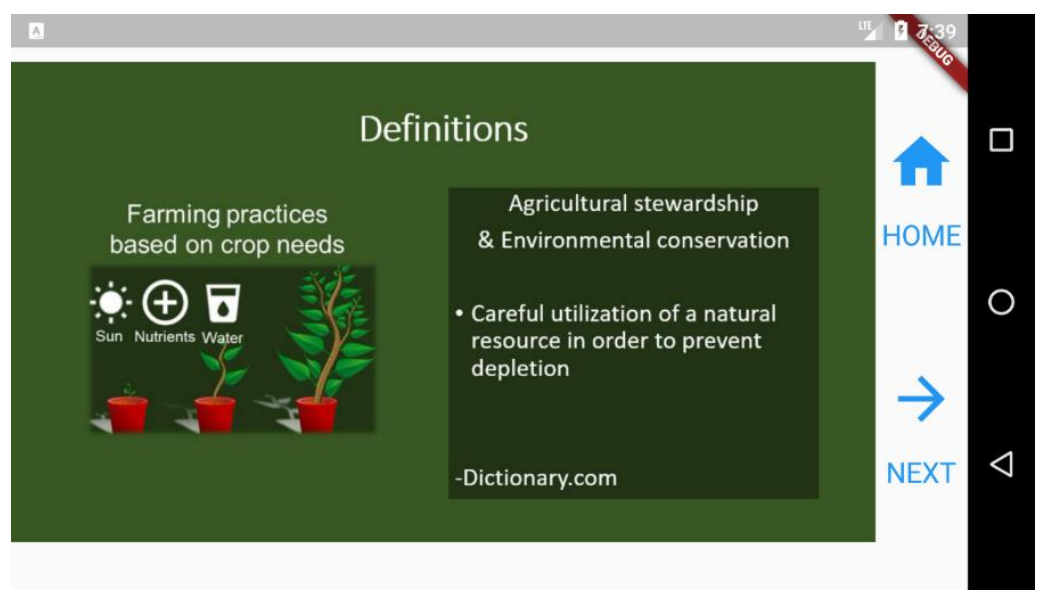

Figure 0-5. Mobile app screen 4 Definition for ag stewardship and environmental conservation

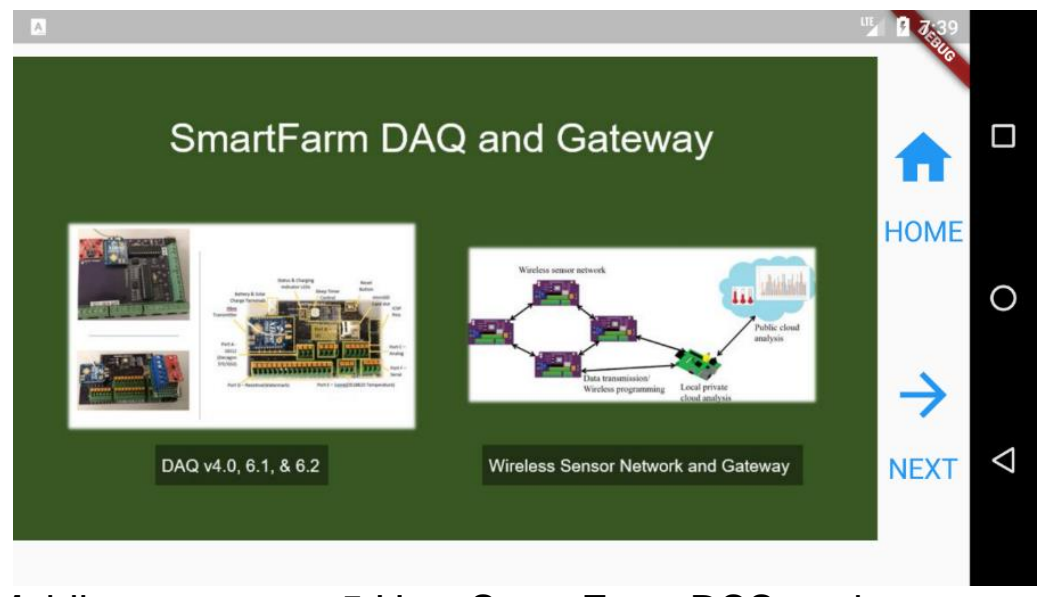

Figure 0-6. Mobile app screen 5 How SmartFarm DSS works

The NEXT button navigates to the description of a DSS, which is distributed

across 7 screens. The DSS is described with a flowchart, starting and ending at food production. Food production relies on farming practices, Figure 0-7. These farming practices are based on what crops need, i.e. sunlight, water, and nutrients, Figure 0-8. If we can monitor these crop needs and these inputs, we can gather data that allows us to develop insights, Figure 0-9 and Figure 0-10. These insights allow us to improve on our farming practices and crop inputs, Figure 0-11, which improves our food production, Figure 0-12. This is the function of the DSS, Figure 0-13. The DSS flowchart includes a BACK button to 
go back and forth between the parts of the DSS, and the NEXT button progresses through the description and on to the sample irrigation trend data, Figure 0-14.

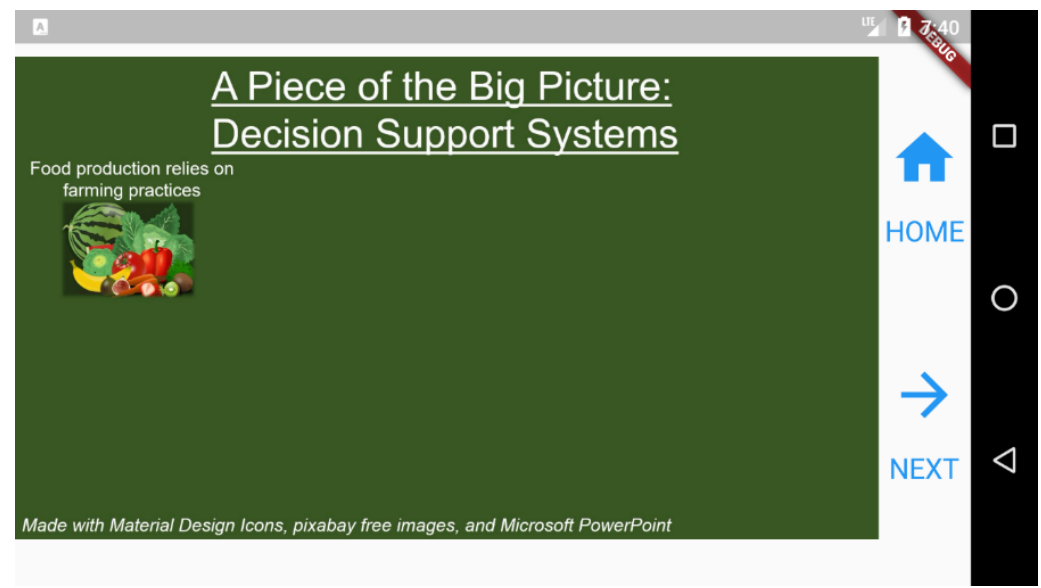

Figure 0-7. Mobile app screen 7, Describing a DSS

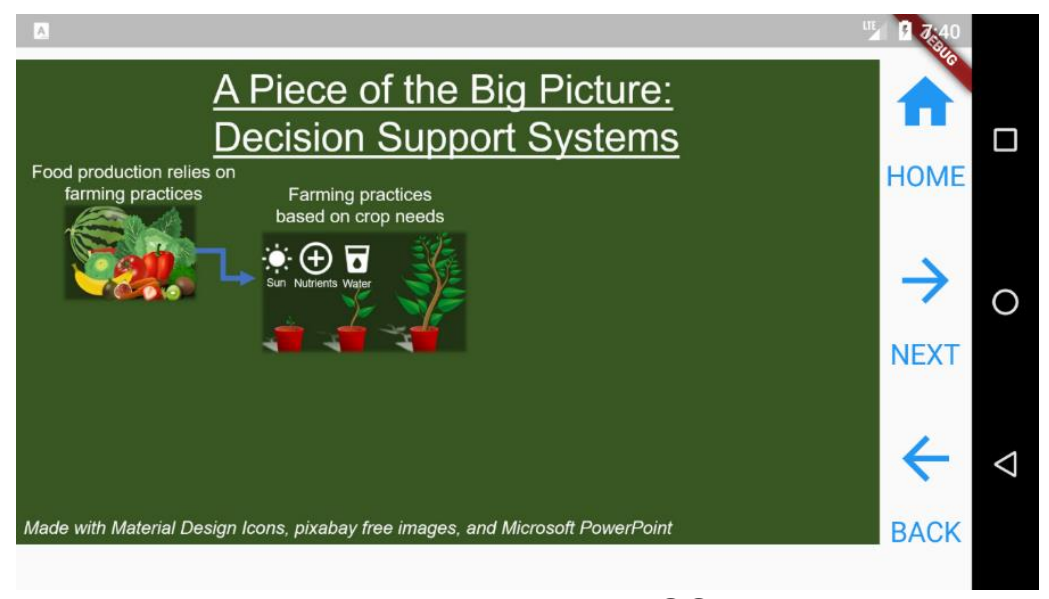

Figure 0-8. Mobile app screen 8, Describing a DSS part 2 


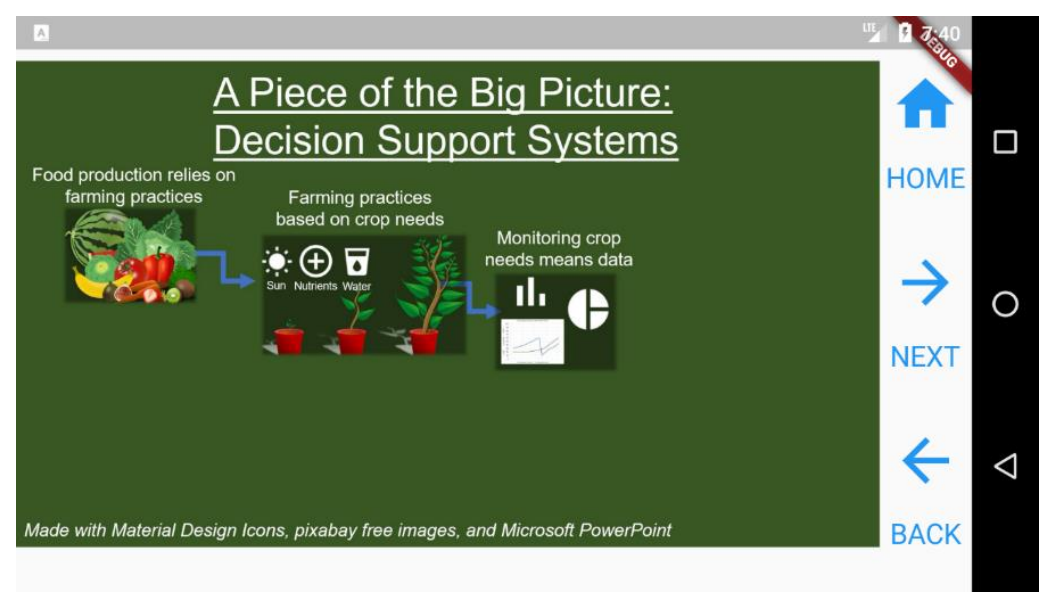

Figure 0-9. Mobile app screen 9, Describing a DSS part 3

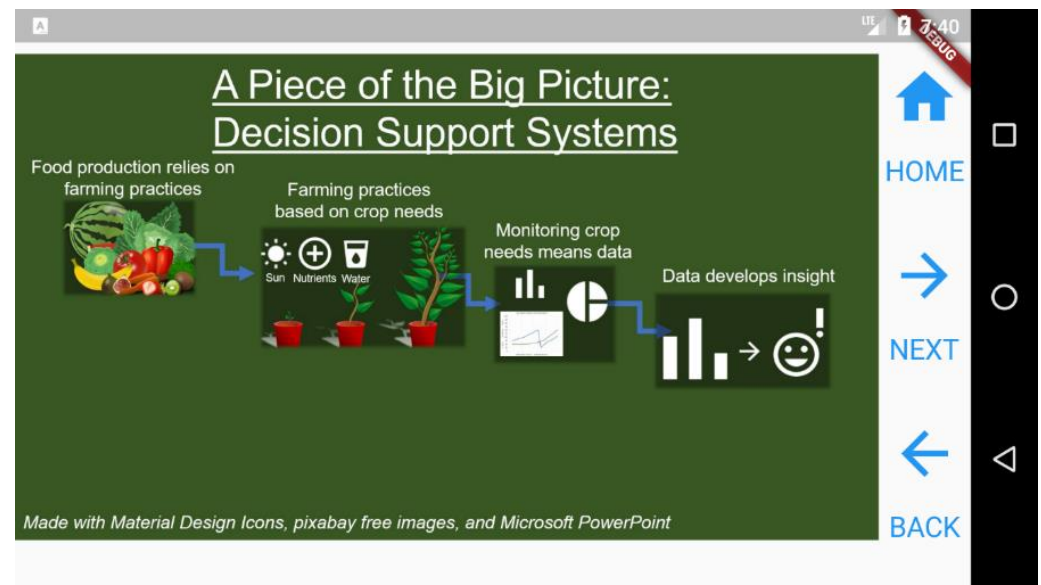

Figure 0-10. Mobile app screen 10, Describing a DSS part 4

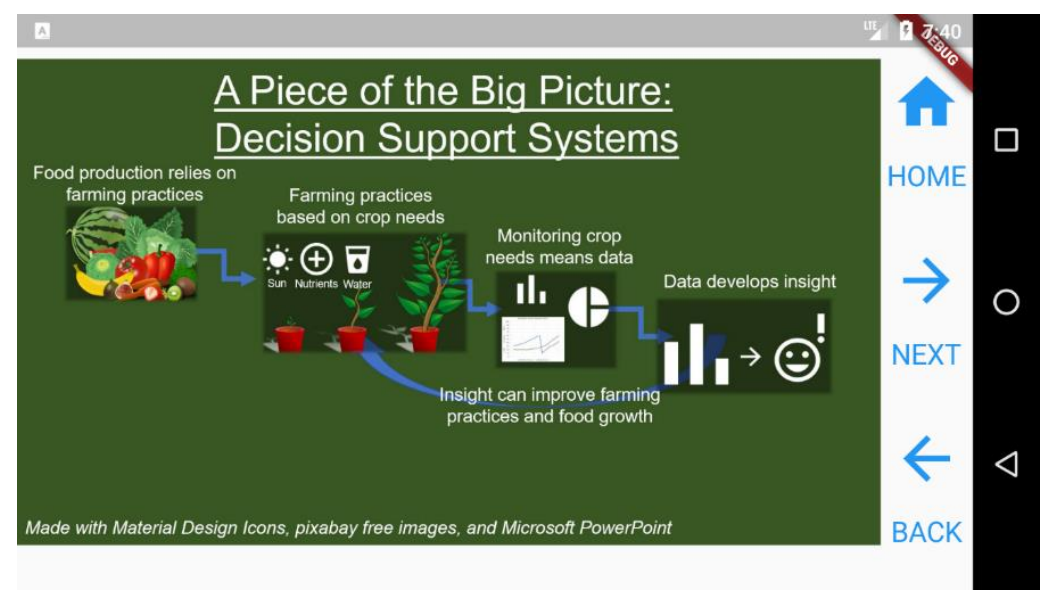

Figure 0-11. Mobile app screen 11, Describing a DSS part 5 


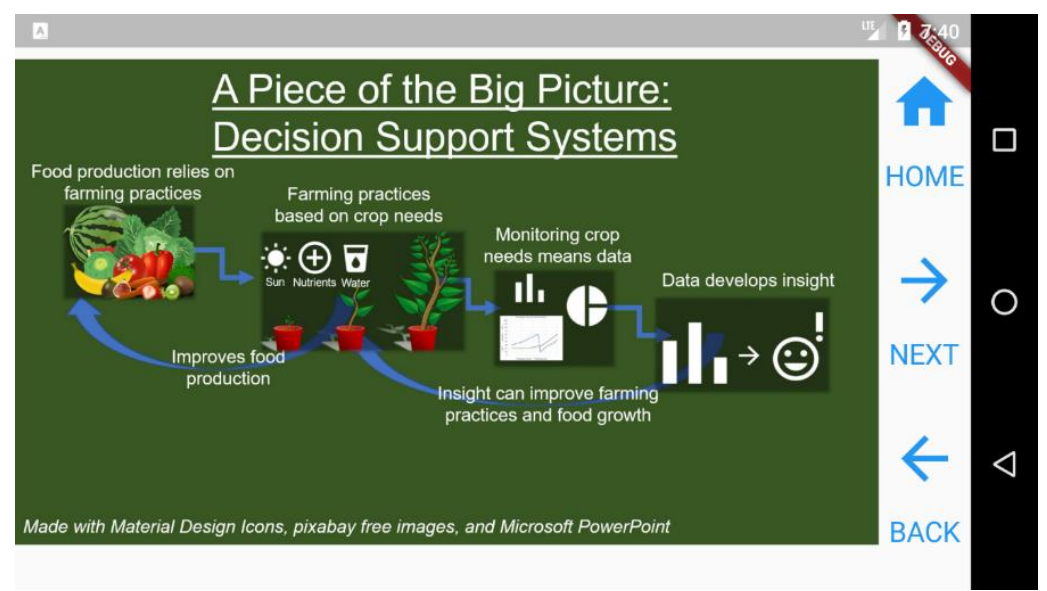

Figure 0-12. Mobile app screen 12, Describing a DSS part 6

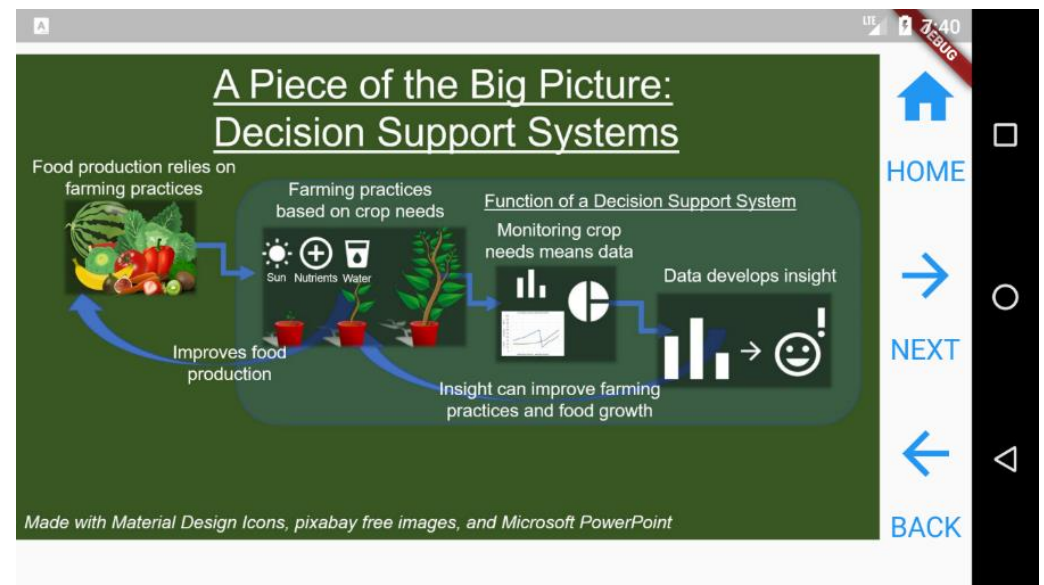

Figure 0-13. Mobile app screen 13, Describing a DSS part 7

The sample irrigation trend data, shown in Figure 0-14, is a simple representation of what to expect from irrigation data. The left-hand side is the units of moisture in centibars which shows wet and dry labels. The trend shows a wet-dry irrigation cycle and ends at a 'dry' point. The demonstrator will ask the participant whether they should irrigate. If so, then the demonstrator will click the IRRIGATE button and the NEXT button onto the next 'field'. Field 2 is like field 1, other than adding a navigation button back to field 1, Figure 0-15. 


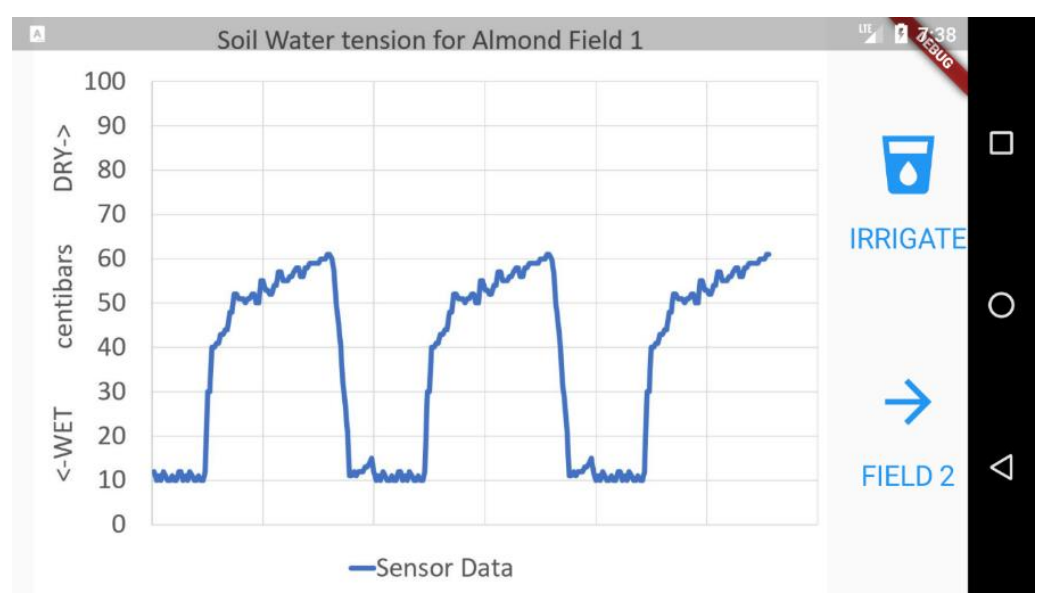

Figure 0 -14. Mobile app screen 14 , sample irrigation trend data field 1

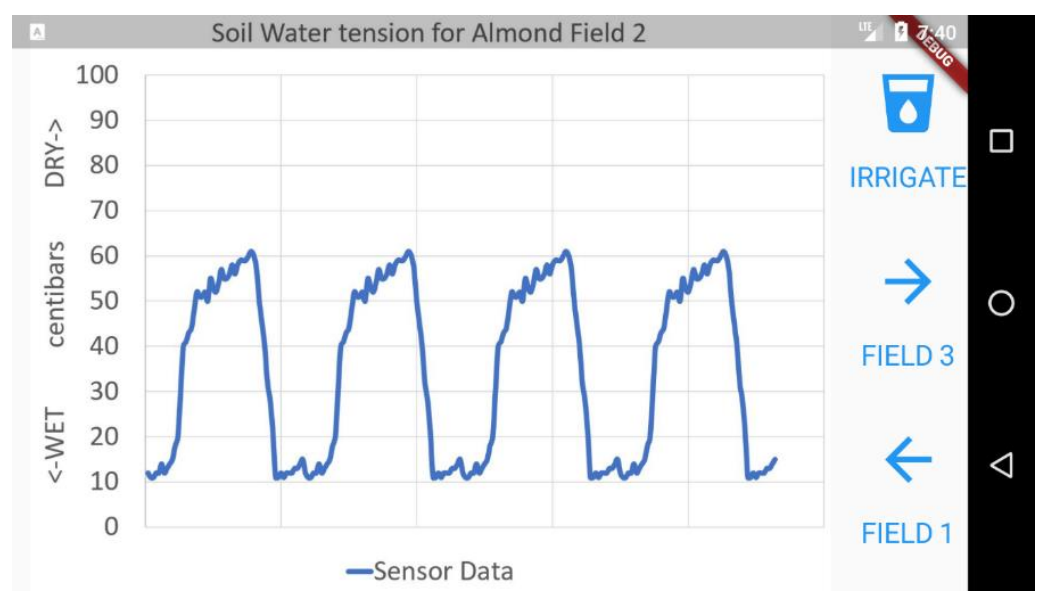

Figure 0-15. Mobile app screen 15, sample irrigation trend data field 2

The last sample 'field' includes two sensors, one shallow and one deep, Figure

$0-16$. It shows that the shallow sensor dries slower over time than the deep sensor. The participant is asked whether to irrigate or not. If so, the IRRIGATE button is pressed. The NEXT button navigates to the field results, which gives advice on what should have been done, whether to water or not in each respective field, Figure $0-17$. The field results screen includes a button that navigates to a link to take the quiz and survey. 


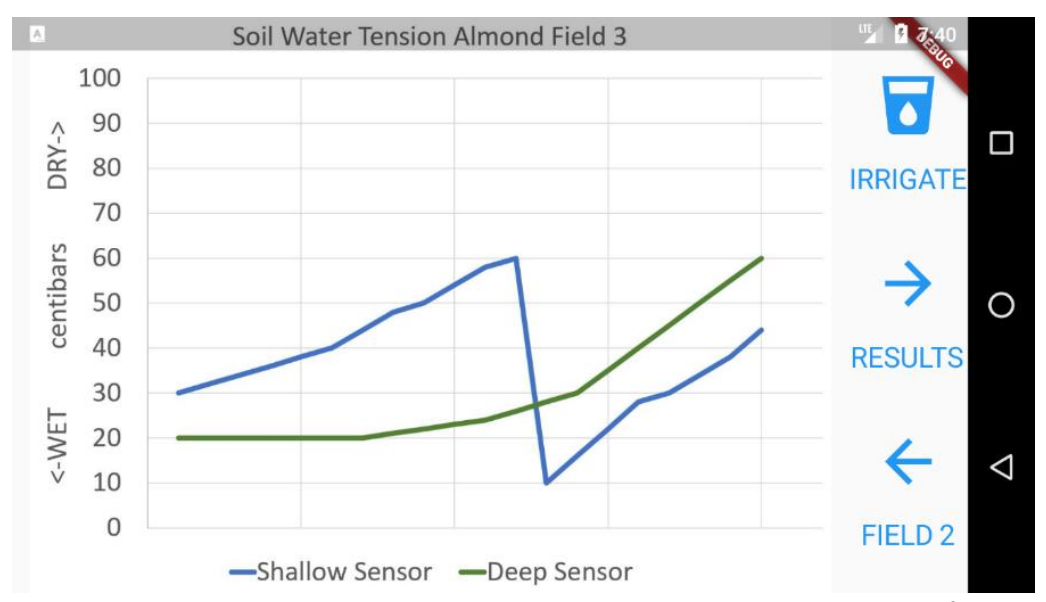

Figure 0-16. Mobile app screen 16, sample Irrigation trend data field 3

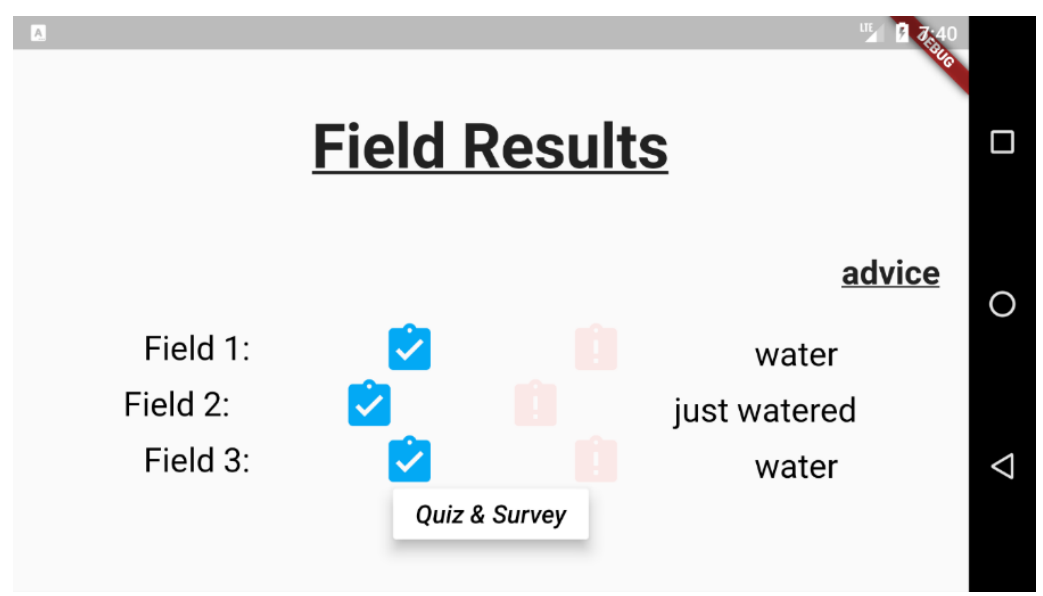

Figure 0-17. Mobile app screen 17, sample Irrigation trend field results

These slides were presented to farmers, academia, and members of the community with the app in one on one conversations and group settings at Downtown Farmers Market San Luis Obispo, CA, 35¹6'45.5"N 120³9'47.6"W, Figure $0-18$, as well as on Cal Poly campus with faculty and students. The presentation included participating in the educational module as well as taking a quiz and survey made with Google Forms (https://www.google.com/forms/about/) as a link referenced in the app. 

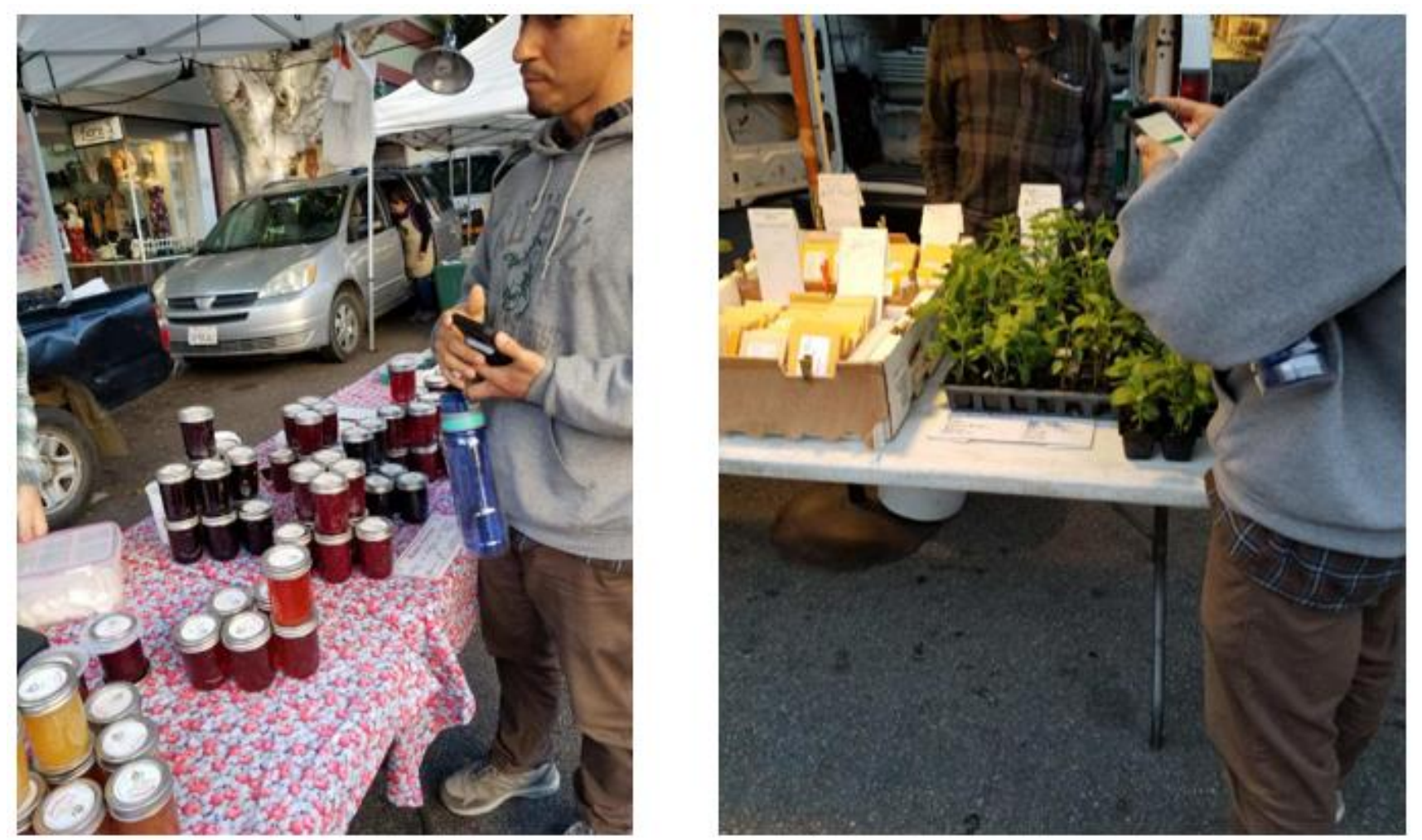

Figure 0-18. Using the Mobile app at Downtown San Luis Obispo Farmers Market

The demonstration survey resulted in 37 samples, of which 14 are farmers. Not one of the survey participants use a decision support system. A majority responded that they believed a DSS like SmartFarm would be beneficial, Figure 0-19. 


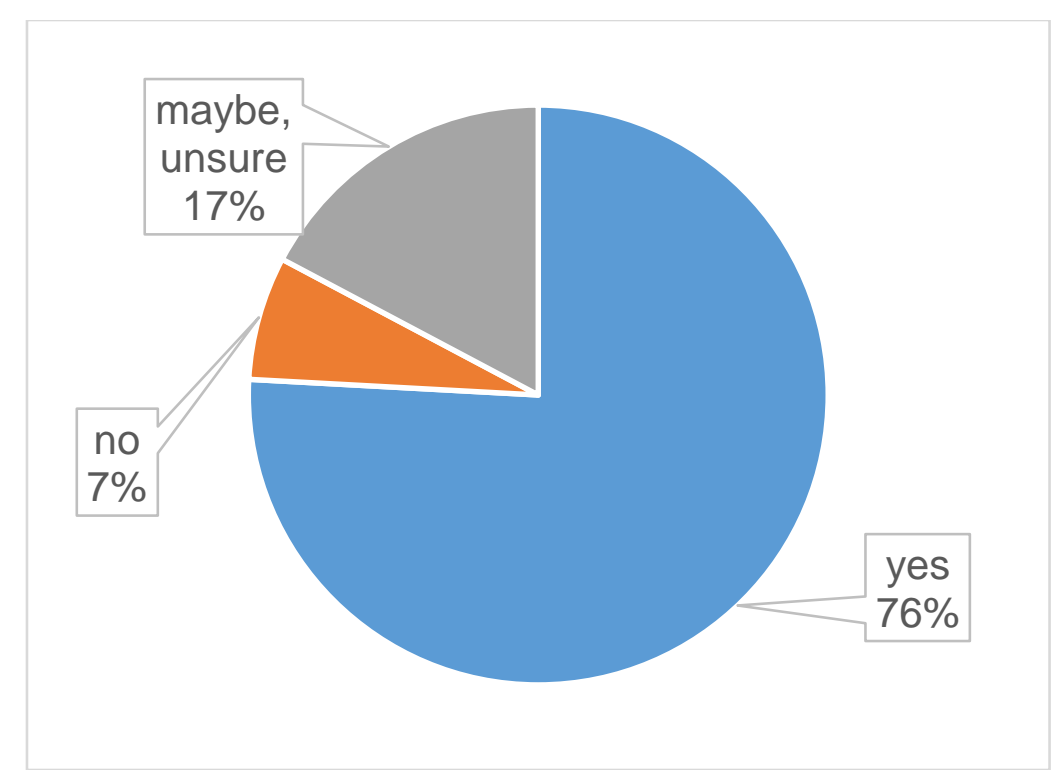

Figure 0-19. Survey question: Would using a DSS like SmartFarm be beneficial? $\mathrm{N}=35$

Quiz results indicated that the term decision support system was learned and taught effectively. The mobile app, DAQ node, and gateway questions resulted in poor retention or education, Figure $0-20$, which means that the mobile app would need either more emphasis or clarity, or that the presentation method should be improved. 


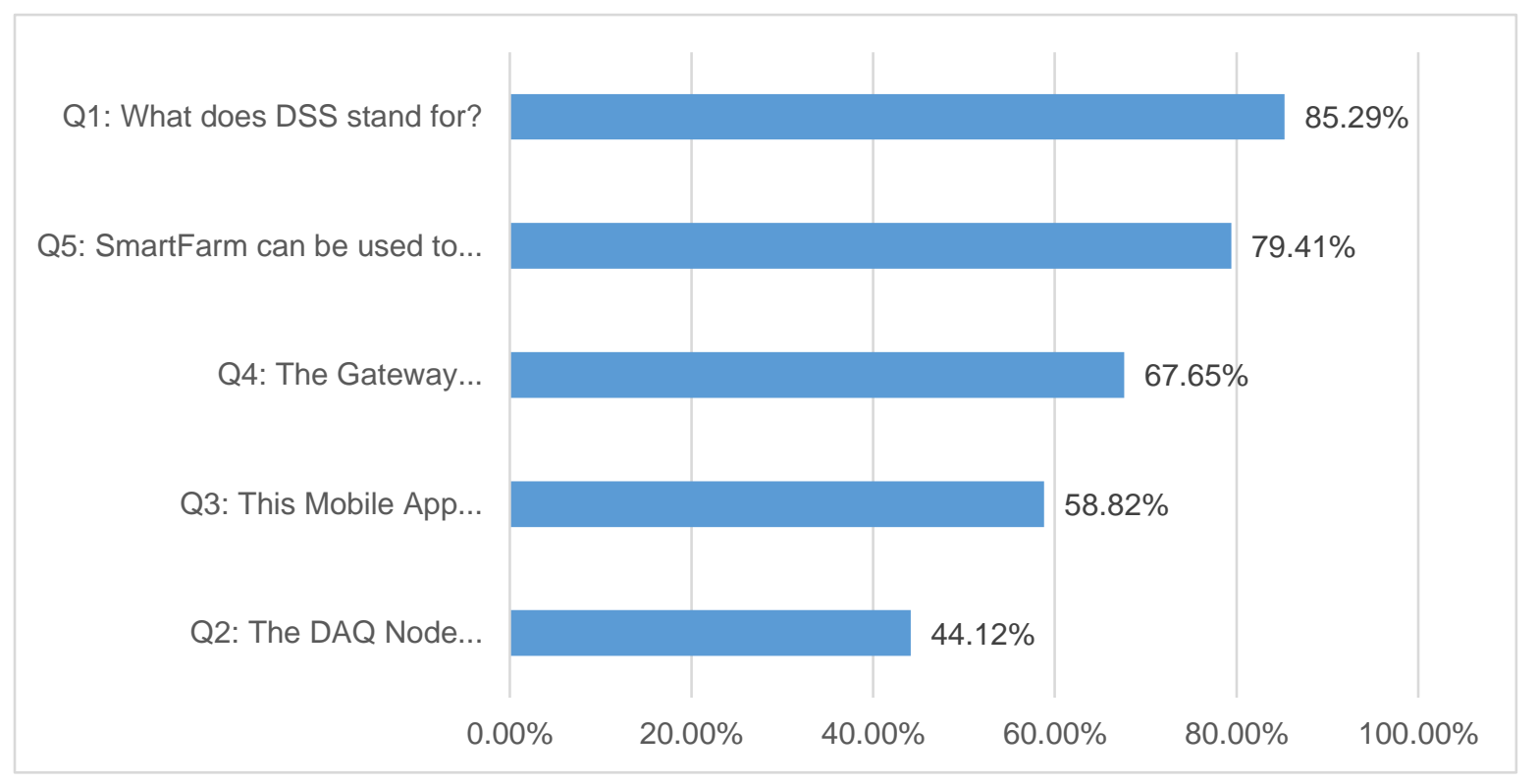

Figure 0-20. Percentage of respondents that answered questions correctly. Example: Question 1 What does DSS stand for? $85.29 \%$ of respondents answered correctly. Questions above Threshold of Effective Teaching percentage are well presented and taught. Questions below the threshold need more development to teach effectively with the app.

\section{Evaluation Objectives}

Table 0-1 summarizes the 5 evaluation objectives for the mobile app. The adaptation of a DSS resulted in more than half respondents. The frequency of use indicated that using the app was slow. The respondents included farmers, academia, and community members.

Table 0-1. Frequency of use was determined by total responses/length of demonstration period outing. Assessment of Ag stewardship is a count of 'yes' responses for beneficial DSS. App effectiveness calculated as percentage of correct answers. $\mathrm{N}=37$

\begin{tabular}{cc} 
1. Adaptation & SmartFarm Demonstration Tool \\
\cline { 2 - 2 } 2. Frequency of use (respondents / minute) & $85.71 \%$ \\
3. Usage & 0.12 \\
4. Assessment of Ag stewardship & 14 farmers, 18 academia, 5 neither \\
5. Teaching effectiveness & 22 \\
\end{tabular}




\section{Demonstration Mobile App Tool Conclusion}

In conclusion, the SmartFarm Demonstration Tool was designed to teach farmers, academia, and community members on sustainable farming, and was evaluated for adaptation, frequency of use, usage, assessment of ag stewardship, and teaching effectiveness. The objectives were met in developing and evaluating a mobile application for teaching farmers, academia, and community members about agricultural stewardship and farming sustainably. The mobile application can be further developed to provide the SmartFarm system with a tool for insight on remote nodes and making decisions on the fly. The open source nature of SmartFarm allows the users to be able to customize and develop the system to how they want and to meet their needs, as well as retain control and ownership of their data. The SmartFarm system can be a viable option for sustainable food production and should be put to good use for the betterment of mankind. 


\section{BIBLIOGRAPHY}

Anisi, M. H., Abdul-Salaam, G., \& Abdullah, A. H. (2015). A survey of wireless sensor network approaches and their energy consumption for monitoring farm fields in precision agriculture. Precision Agriculture, 16(2), 216-238.

doi:10.1007/s11119-014-9371-8

Aqeel ur, R., Abbasi, A. Z., Islam, N., \& Shaikh, Z. A. (2014). A review of wireless sensors and networks' applications in agriculture. Computer Standards \& Interfaces, 36(2), 263-270. doi:10.1016/j.csi.2011.03.004

Bonney, R., Cooper, C. B., Dickinson, J., Kelling, S., Phillips, T., Rosenberg, K. V., \& Shirk, J. (2009). Citizen Science: A Developing Tool for Expanding Science Knowledge and Scientific Literacy. Bioscience, 59(11), 977-984.

doi:10.1525/bio.2009.59.11.9

Brittain, C., Williams, N., Kremen, C., \& Klein, A. M. (2013). Synergistic effects of non-Apis bees and honey bees for pollination services. Proceedings of the Royal Society B-Biological Sciences, 280(1754), 7. doi:10.1098/rspb.2012.2767।

CDFA. (2017). California Agricultural Statistics Review, 2015-2016. Retrieved from https://www.cdfa.ca.gov/statistics/PDFs/2016Report.pdf

Clarke, N., Bizimana, J. C., Dile, Y., Worqlul, A., Osorio, J., Herbst, B., . . Jeong, J. (2017). Evaluation of new farming technologies in Ethiopia using the Integrated Decision Support System (IDSS). Agricultural Water Management, 180, 267-279. doi:10.1016/j.agwat.2016.07.023

Dargie, W. (2012). Dynamic Power Management in Wireless Sensor Networks: State-of-the-Art. leee Sensors Journal, 12(5), 1518-1528. doi:10.1109/jsen.2011.2174149

Dehnen-Schmutz, K., Foster, G. L., Owen, L., \& Persello, S. (2016). Exploring the role of smartphone technology for citizen science in agriculture. Agronomy for Sustainable Development, 36(2), 8. doi:10.1007/s13593-016-0359-9 
Delgado, J. A., Kowalski, K., \& Tebbe, C. (2013). The first Nitrogen Index app for mobile devices: Using portable technology for smart agricultural management. Computers and Electronics in Agriculture, 91, 121-123. doi:10.1016/j.compag.2012.12.008

Fisher, R., Ledwaba, L., Hancke, G., \& Kruger, C. (2015). Open Hardware: A Role to Play in Wireless Sensor Networks? Sensors, 15(3), 6818-6844. doi:10.3390/s150306818

Foley, J. A., Ramankutty, N., Brauman, K. A., Cassidy, E. S., Gerber, J. S., Johnston, M., ... Zaks, D. P. M. (2011). Solutions for a cultivated planet. Nature, 478(7369), 337-342. doi:10.1038/nature10452

Goldhamer, D. A., \& Fereres, E. (2017). Establishing an almond water production function for California using long-term yield response to variable irrigation. Irrigation Science, 35(3), 169-179. doi:10.1007/s00271-016-0528-2

Goldhamer, D. A., Viveros, M., \& Salinas, M. (2006). Regulated deficit irrigation in almonds: effects of variations in applied water and stress timing on yield and yield components. Irrigation Science, 24(2), 101-114. doi:10.1007/s00271-0050014-8

IRROMETER. (2016, May 17). IRROMETER's SOLAR POWERED -WirelessDAT LOGGING SYSTEM Flyer. Riverside, CA, U.S.A.

Kennedy, G. E., Judd, T. S., Churchward, A., Gray, K., \& Krause, K. L. (2008). First year students' experiences with technology: Are they really digital natives? Australasian Journal of Educational Technology, 24(1), 108-122.

Krintz, C., Wolski, R., Golubovic, N., Lampel, B., Kulkarni, V., Sethuramasamyraja, B., Roberts, B., and Liu, B., (2016). SmartFarm: Improving Agricultural Sustainability Using Modern Information Technology (PDF). KDD 2016 Workshop on Data Science for Food, Energy, and Water.

Lobell, D. B., Field, C. B., Cahill, K. N., \& Bonfils, C. (2006). Impacts of future climate change on California perennial crop yields: Model projections with climate 
and crop uncertainties. Agricultural and Forest Meteorology, 141(2-4), 208-218. doi:10.1016/j.agrformet.2006.10.006

Mesas-Carrascosa, F. J., Santano, D. V., Merono, J. E., de la Orden, M. S., \& Garcia-Ferrer, A. (2015). Open source hardware to monitor environmental parameters in precision agriculture. Biosystems Engineering, 137, 73-83. doi:10.1016/j.biosystemseng.2015.07.005

O'Malley, R., Marsh, A. S., \& Negra, C. (2009). Closing the Environmental Data Gap. Issues in Science and Technology, 25(3), 69-74.

Phogat, V., Skewes, M. A., Mahadevan, M., \& Cox, J. W. (2013). Evaluation of soil plant system response to pulsed drip irrigation of an almond tree under sustained stress conditions. Agricultural Water Management, 118, 1-11. doi:10.1016/j.agwat.2012.11.015

Rose, D. C., Sutherland, W. J., Parker, C., Lobley, M., Winter, M., Morris, C., . . . Dicks, L. V. (2016). Decision support tools for agriculture: Towards effective design and delivery. Agricultural Systems, 149, 165-174.

doi:10.1016/j.agsy.2016.09.009

Shirk, J. L., Ballard, H. L., Wilderman, C. C., Phillips, T., Wiggins, A., Jordan, R., ... Bonney, R. (2012). Public Participation in Scientific Research: a Framework for Deliberate Design. Ecology and Society, 17(2), 20. doi:10.5751/es-04705170229

Silvertown, J. (2009). A new dawn for citizen science. Trends in Ecology \& Evolution, 24(9), 467-471. doi:10.1016/j.tree.2009.03.017

Sullivan, B. L., Wood, C. L., lliff, M. J., Bonney, R. E., Fink, D., \& Kelling, S. (2009). eBird: A citizen-based bird observation network in the biological sciences. Biological Conservation, 142(10), 2282-2292. doi:10.1016/j.biocon.2009.05.006

Thornton, P., \& Houser, C. (2005). Using mobile phones in English education in Japan. Journal of Computer Assisted Learning, 21(3), 217-228. doi:10.1111/j.1365-2729.2005.00129.x 
Zaks, D. P. M., \& Kucharik, C. J. (2011). Data and monitoring needs for a more ecological agriculture. Environmental Research Letters, 6(1). doi:10.1088/17489326/6/1/014017

\section{Publication Plans}

I plan on publishing my thesis via Digital Commons Cal Poly as well as at the ASABE International Meeting in Detroit, MI. 


\section{APPENDIX A. SUPPORT AND REFERENCES}

\begin{tabular}{|l|l|}
\hline Reference Link & Why it may be useful \\
\hline$\underline{\text { https://stackexchange.com/ }}$ & Getting second opinions and answers \\
on how code should be written \\
\hline$\underline{\text { https://raspberrypi.stackexchange.com/ }}$ & Getting second opinions and answers \\
& on specific Raspberry Pi questions \\
\hline$\underline{\text { https://www.raspberrypi.org/ }}$ & Great resource for getting into \\
& Raspberry Pi \\
\hline
\end{tabular}




\section{APPENDIX B. THINGSPEAKCODE.PY POSTS DATA TO}

THINGSPEAK.COM

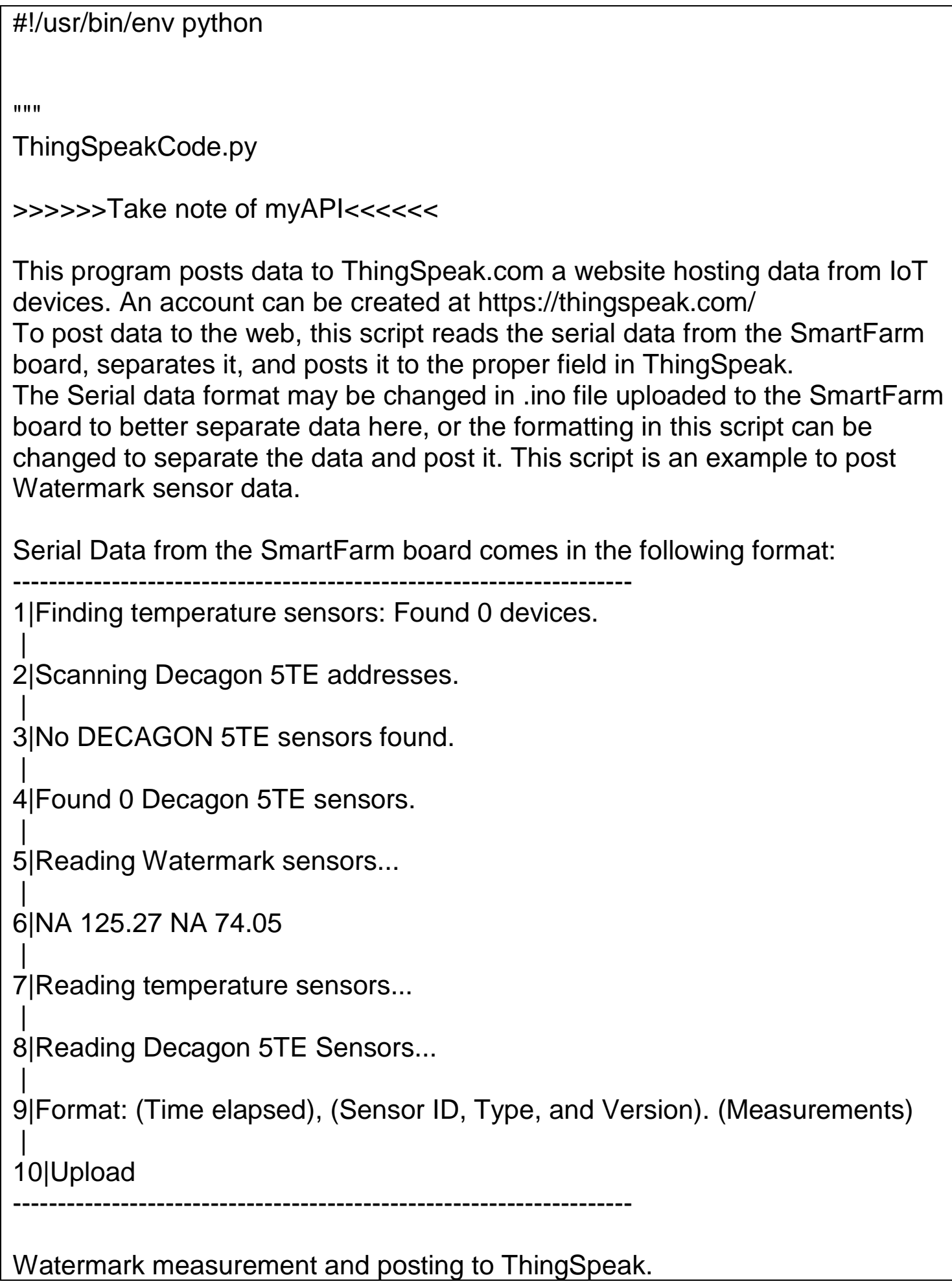

Watermark measurement and posting to ThingSpeak. 


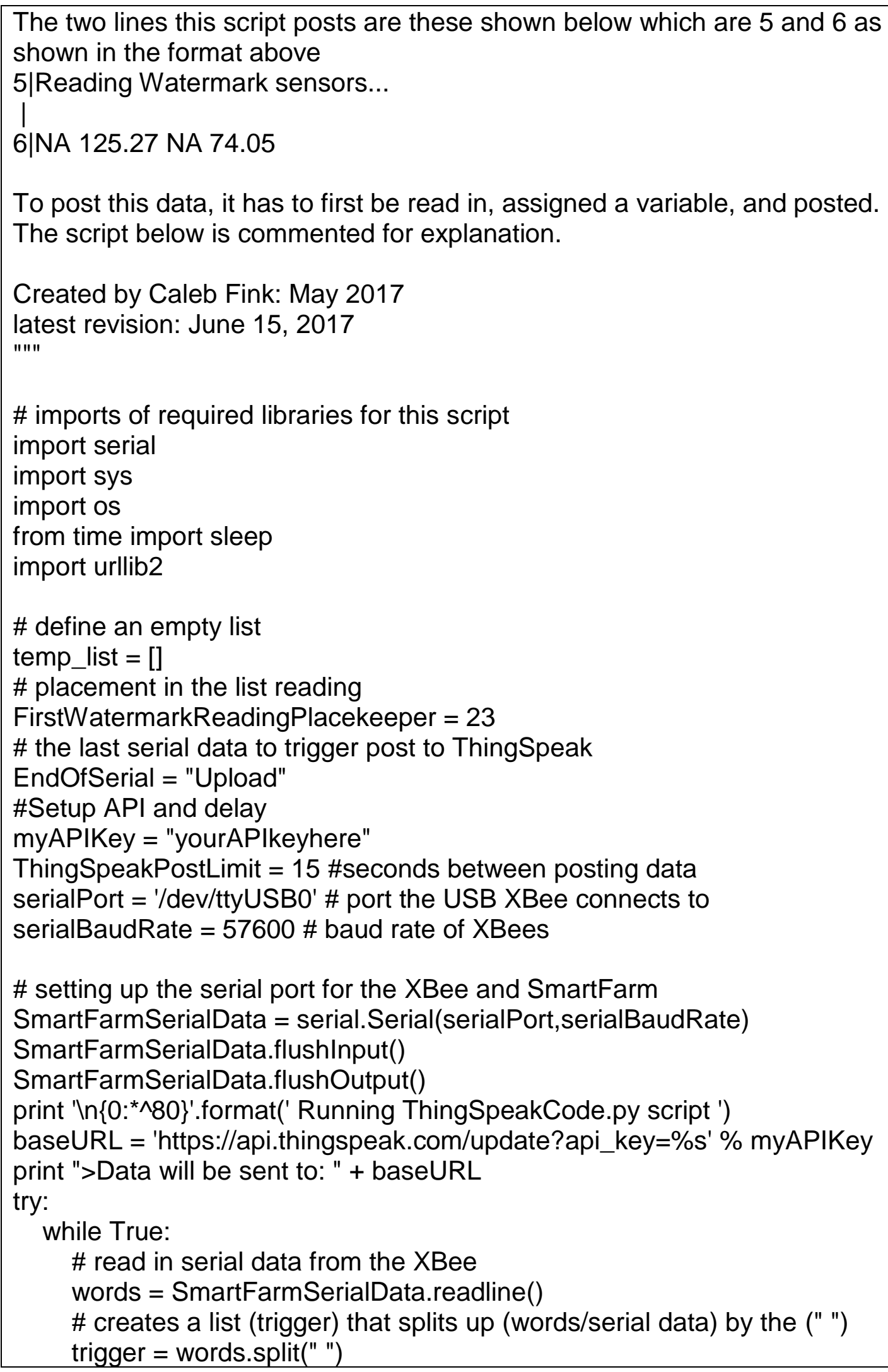




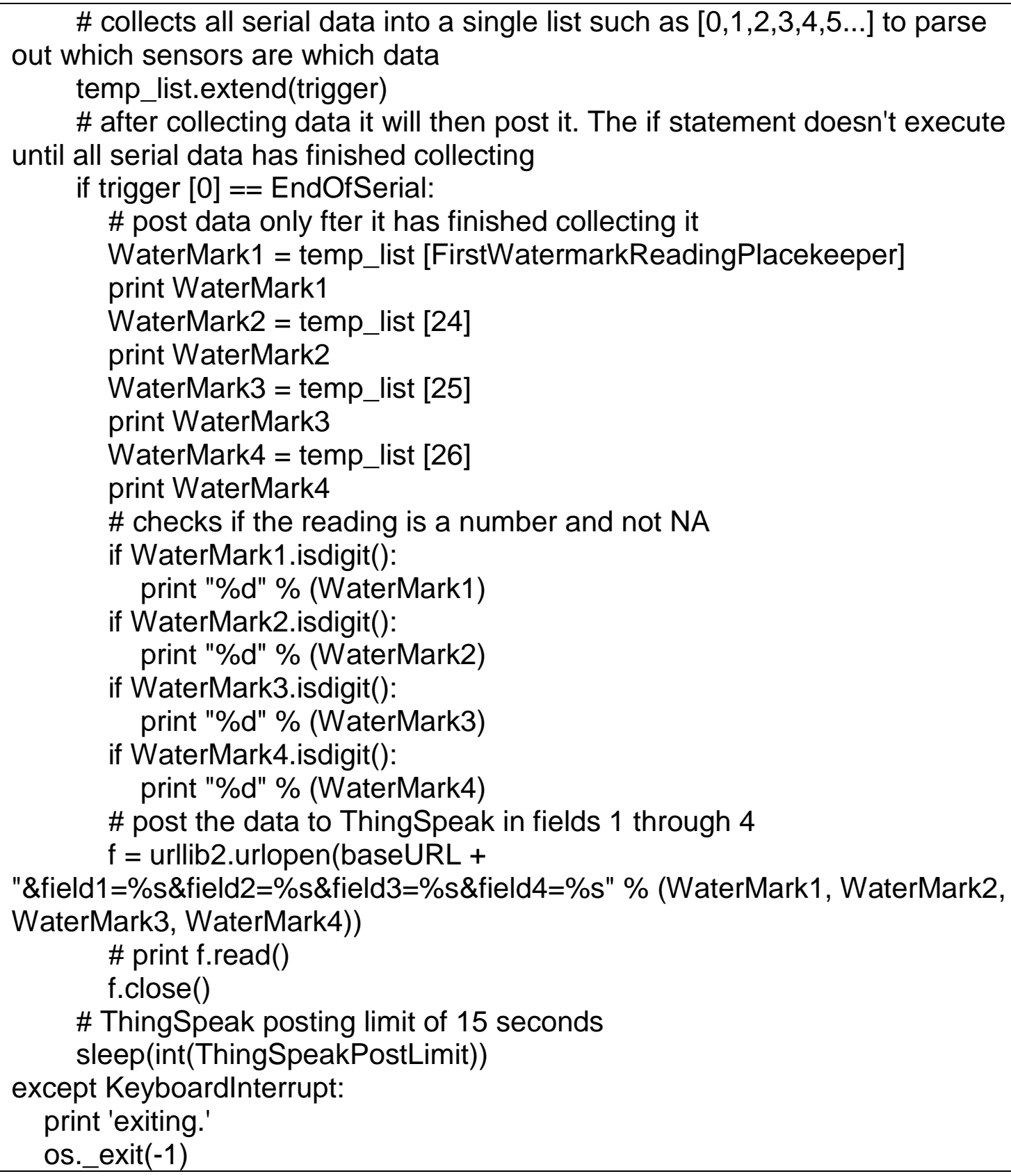




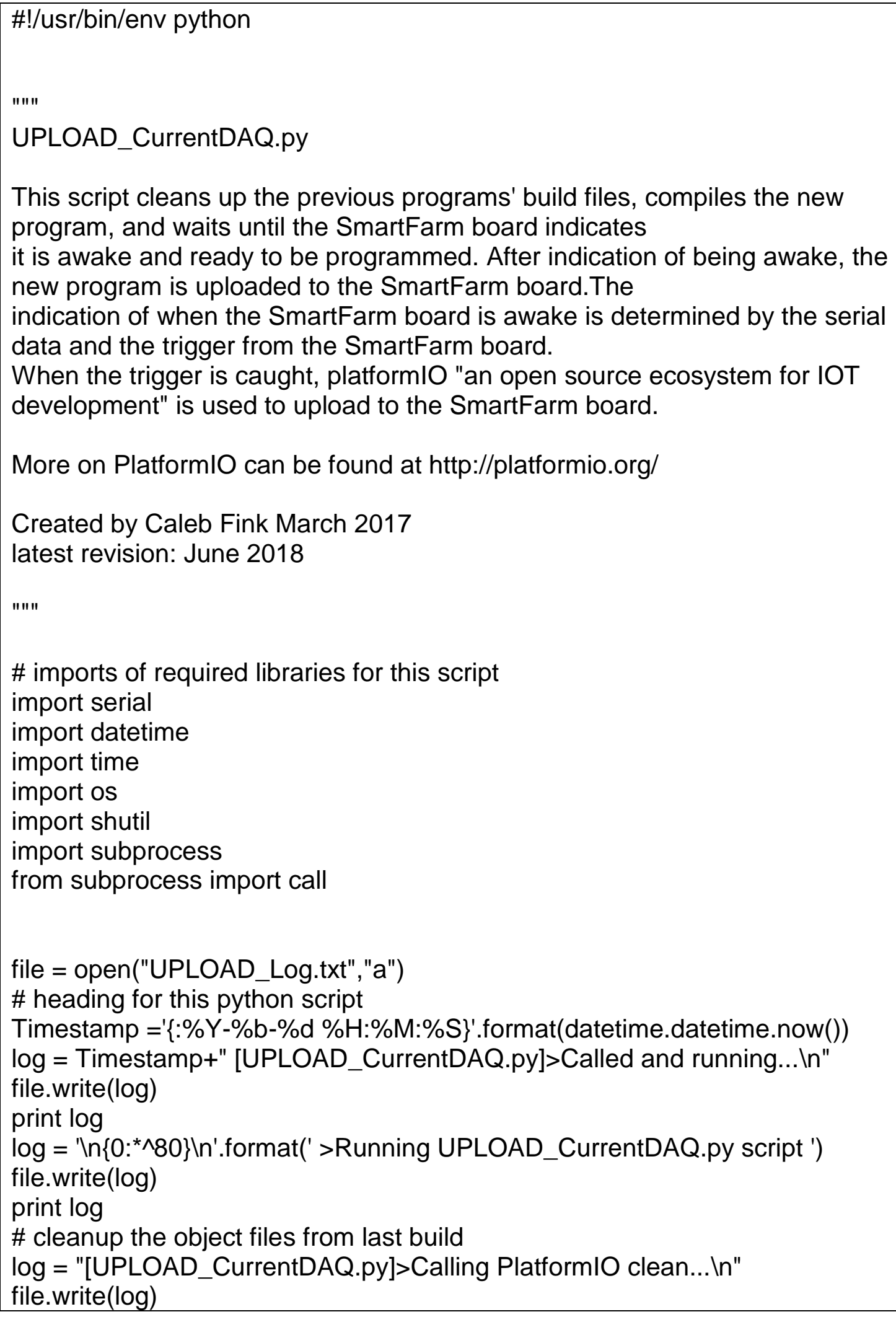




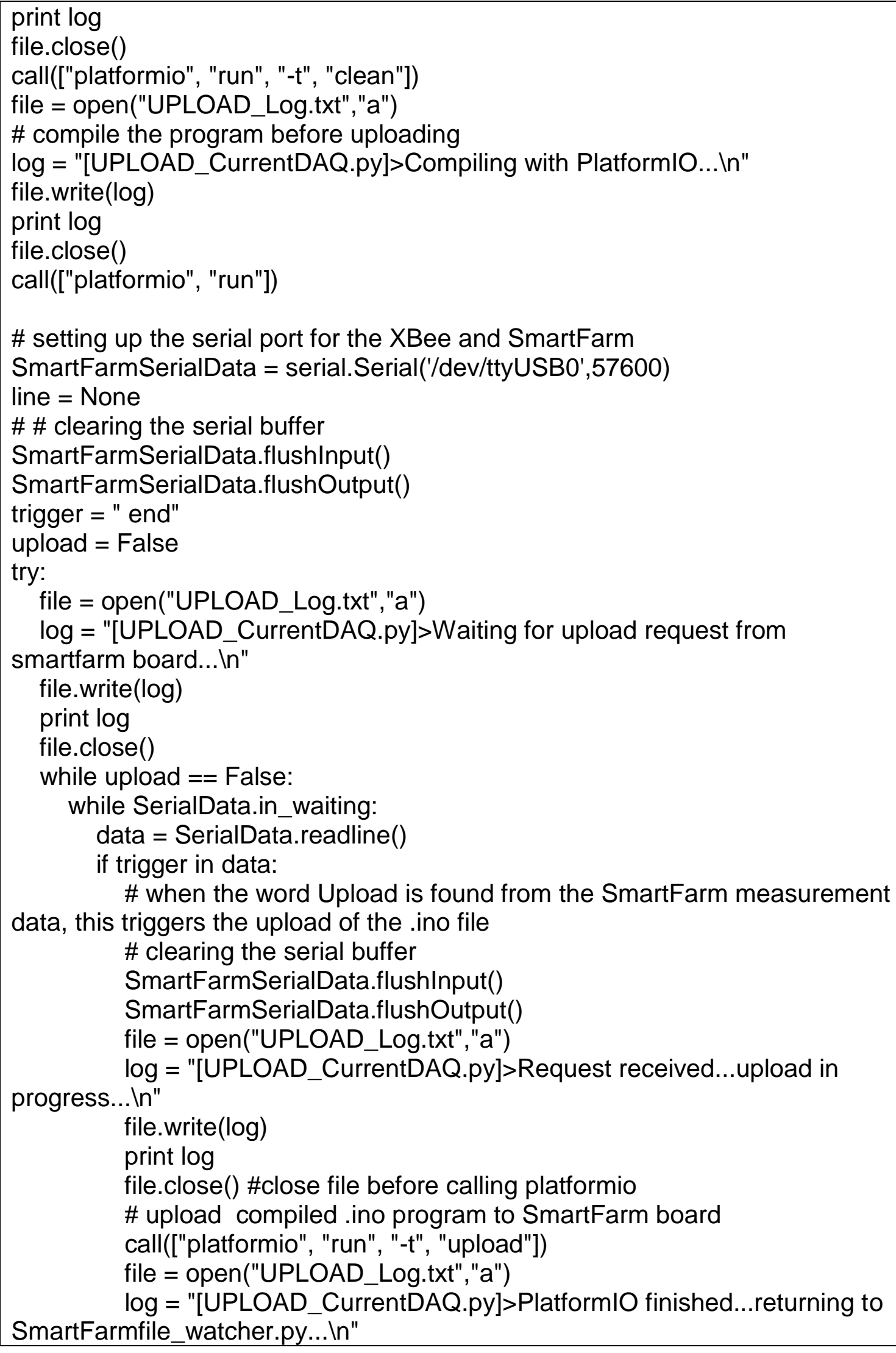




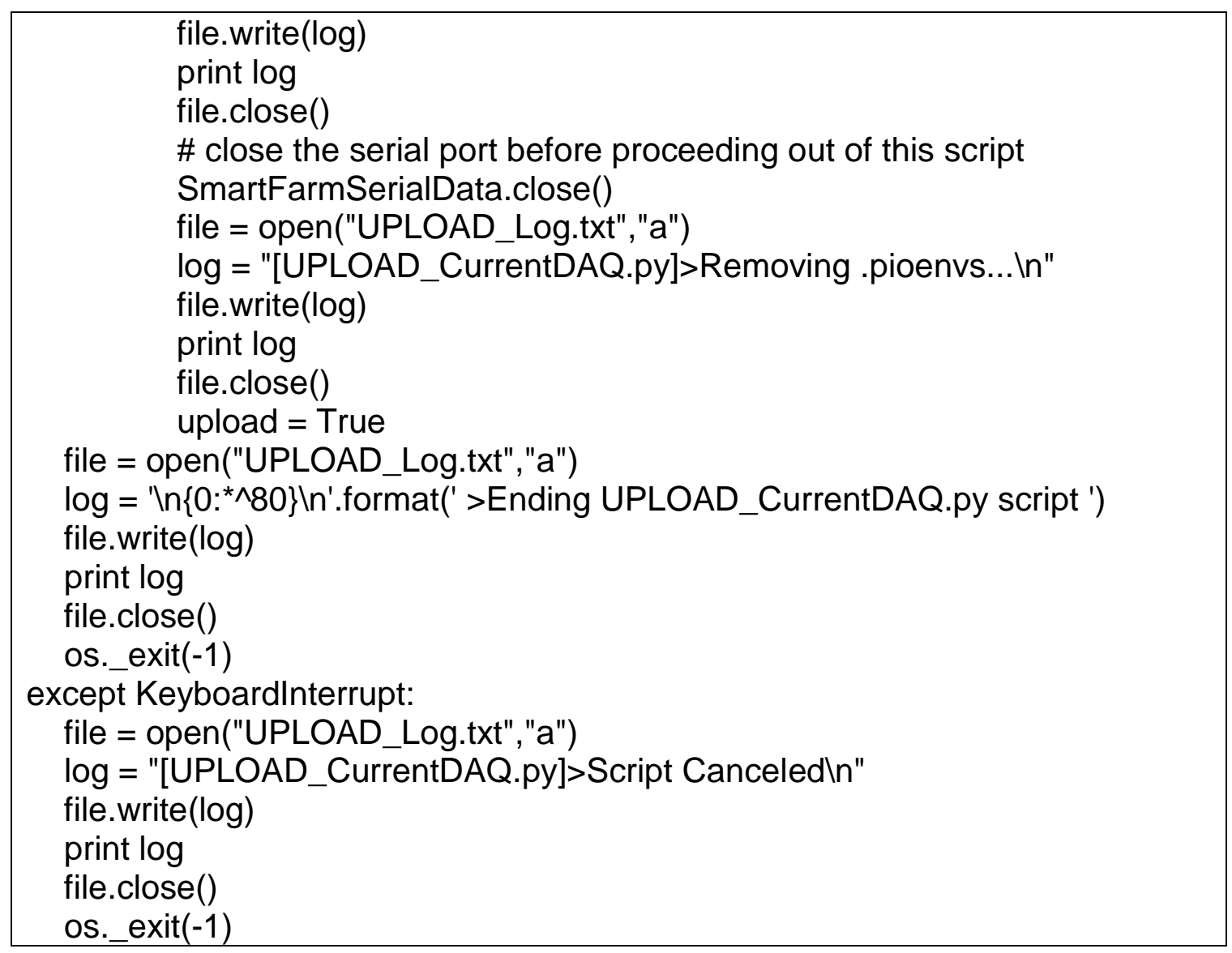

